\title{
The extrinsic apoptotic pathway in aged skeletal muscle: Roles of tumor necrosis factor-alpha and interleukin-15
}

\author{
Emidio E. Pistilli \\ West Virginia University
}

Follow this and additional works at: https://researchrepository.wvu.edu/etd

\section{Recommended Citation}

Pistilli, Emidio E., "The extrinsic apoptotic pathway in aged skeletal muscle: Roles of tumor necrosis factor-alpha and interleukin-15" (2006). Graduate Theses, Dissertations, and Problem Reports. 2511. https://researchrepository.wvu.edu/etd/2511

This Dissertation is protected by copyright and/or related rights. It has been brought to you by the The Research Repository @ WVU with permission from the rights-holder(s). You are free to use this Dissertation in any way that is permitted by the copyright and related rights legislation that applies to your use. For other uses you must obtain permission from the rights-holder(s) directly, unless additional rights are indicated by a Creative Commons license in the record and/ or on the work itself. This Dissertation has been accepted for inclusion in WVU Graduate Theses, Dissertations, and Problem Reports collection by an authorized administrator of The Research Repository @ WVU. For more information, please contact researchrepository@mail.wvu.edu. 
The Extrinsic Apoptotic Pathway in Aged Skeletal Muscle: Roles of Tumor Necrosis Factor- $\alpha$ and Interleukin-15

Emidio E. Pistilli, BS, MS

\author{
Dissertation submitted to the \\ School of Medicine at West Virginia University \\ in partial fulfillment of the requirements \\ for the degree of \\ Doctor of Philosophy \\ in \\ Exercise Physiology
}

Stephen E. Alway, Ph.D., Chair

Randall W. Bryner, Ph.D.

Christopher Cuff, Ph.D.

Paul M. Gordon, Ph.D.

William T. Stauber, Ph.D.

Morgantown, West Virginia

2006

Keywords: sarcopenia, cytokines, apoptosis 


\section{Abstract \\ The Extrinsic Apoptotic Pathway in Aged Skeletal Muscle: Roles of TNF- $\alpha$ and IL-15 \\ Emidio E. Pistilli}

Apoptosis is implicated in the loss of skeletal muscle mass following periods of reduced activity (i.e.-disuse) as well as during the normal aging process (i.e.-sarcopenia). Aging is also characterized by elevations in circulating cytokines, specifically TNF- $\alpha$, which has been associated with the sarcopenic process. The specific signaling components that participate in the pro-apoptotic pathway downstream of the type I TNF receptor (i.e.extrinsic apoptotic pathway) within skeletal muscle have not been clarified.

Additionally, few studies have been performed with the aim of disrupting this apoptotic pathway, and thereby sparing muscle mass in the aged. Therefore, the purposes of this dissertation were to characterize the extrinsic apoptotic pathway within aged skeletal muscles and to test the effectiveness of another cytokine, IL-15, at disrupting this apoptotic pathway. Apoptotic signaling markers involved in the extrinsic pathway, including tumor necrosis factor-alpha (TNF- $\alpha$ ), TNF receptor (TNFR), fas-associated death domain protein (FADD), TNFR-associated death domain protein (TRADD), caspase-8, caspase-3, BCL-3 interacting domain protein (Bid), and FLICE-inhibiting protein (FLIP), as well as the cytokine interleukin-15 (IL-15), were accessed in skeletal muscles from aged rodents and compared to muscles from young adult rodents. Muscles from aged animals were smaller and the incidence of apoptosis was greater when compared to muscles from young adult rodents. Additionally, aged muscles expressed greater mRNA and protein contents for the apoptotic markers involved in the extrinsic 
pathway, thereby suggesting the extrinsic pathway is active in skeletal muscles.

Furthermore, IL-15 mRNA concentrations were, in general, greater in aged muscles and following periods of muscle unloading. However, over-expression of IL-15 was unable to disrupt this apoptotic pathway in either aged rodents or in myoblast cultures stimulated with TNF- $\alpha$. These data suggest that while the extrinsic apoptotic pathway is active within aged skeletal muscles, and that TNF- $\alpha$ is able to promote these apoptotic changes in myoblast cultures, IL-15 is not an effective agent at disrupting this pathway and preserving muscle mass. 


\section{Dedications}

This dissertation is dedicated to my family, and especially to my wife Stacy, who has supported me in this pursuit from day one. 


\section{Acknowledgements}

I would first like to acknowledge my dissertation chair and mentor, Dr. Stephen Alway. In addition to excellent guidance and support in and out of the laboratory, he gave me the freedom to explore an independent idea as it pertained to muscle physiology. This freedom allowed me to stay passionate about my research. I truly feel I had the best training experience possible in my time at WVU.

I would also like to thank each of my dissertation committee members: Dr. Christopher Cuff, Dr. Randall Bryner, Dr. Paul Gordon, and Dr. William Stauber for advice and support leading to the completion of this dissertation. An added note of thanks to Dr. Paul Gordon for allowing me to work on the FAMuSS Study, which helped pave the way to my Post-Doc position, and for all the statistical advice. 


\section{Table of Contents}

Abstract..............................................................

Dedications.............................................................

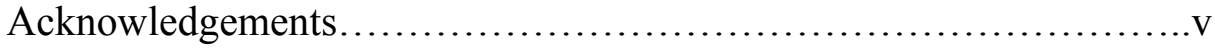

Table of Contents.................................................

List of Figures.................................................. vii

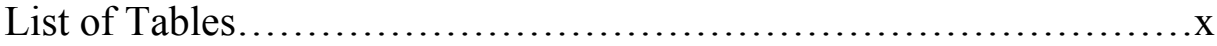

Specific Aims.........................................................

Background and Significance...................................... 4

References....................................................14

Chapter 1: Molecular regulation of apoptosis in fast plantaris muscles of aged rats

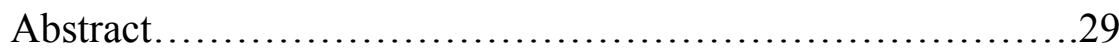

Introduction ................................................ 30

Methods........................................................32

Results......................................................

Discussion...................................................40

References.............................................. 48

Chapter 2: Death receptor-associated pro-apoptotic signaling in aged skeletal muscle

Abstract....................................................65

Introduction................................................ 67

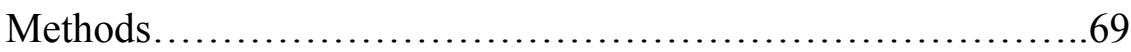


Results.............................................74

Discussion............................................... 77

References............................................87

Chapter 3: Interleukin-15 responses to aging and unloading-induced skeletal muscle atrophy

Abstract................................................ 106

Introduction................................................. 108

Methods..................................................110

Results.................................................113

Discussion..............................................116

References.............................................. 122

Chapter 4: Recombinant IL-15 does not attenuate TNF- $\alpha$ and/or aging induced pro-apoptotic signaling in skeletal muscles

Abstract.....................................................139

Introduction...........................................141

Methods.................................................. 143

Results...............................................149

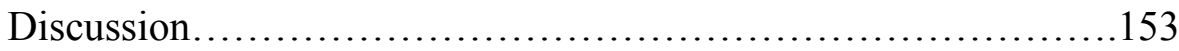

References...............................................156

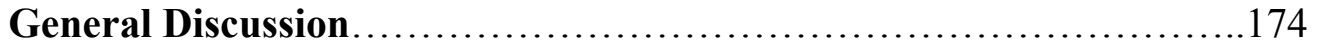

References................................................183 


\section{List of Figures}

\section{Background and Significance}

Figure 1: The intrinsic-mitochondrial apoptotic pathway............27

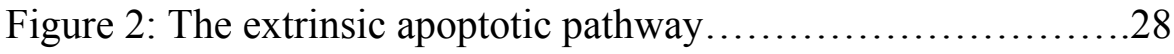

Chapter 1: Molecular regulation of apoptosis in fast plantaris muscles of aged rats

Figure 1: Plantaris muscle characteristics.........................53

Figure 2: Incidence of apoptosis................................55

Figure 3: Bax and Bcl-2 mRNA and protein content..................57

Figure 4: Bax protein localization................................59

Figure 5: mRNA expression of selected apoptotic markers............60

Figure 6: Correlational analyses................................662

Chapter 2: Death receptor-associated pro-apoptotic signaling in aged skeletal muscle

Figure 1: Rodent and skeletal muscle characteristics.................96

Figure 2: RT-PCR Analysis of Muscle mRNA.......................98

Figure 3: Western-immunoblot analyses..........................99

Figure 4: Caspase enzymatic analyses.............................101

Figure 5: Correlational analyses in plantaris and soleus muscles........102

Figure 6: Cross-talk between apoptotic pathways.....................104

Chapter 3: Interleukin-15 responses to aging and unloading-induced skeletal muscle atrophy

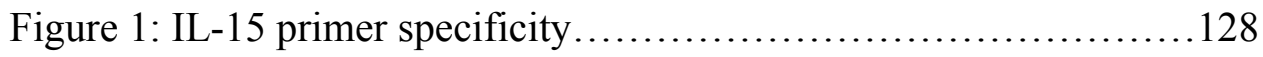

Figure 2: IL-15 transcriptional changes following HS.................130 
Figure 3: IL-15 transcriptional changes in response to wing overload and subsequent unloading................................... 132

Figure 4: Unique IL-15R $\alpha$ Sequence in Rattus Skeletal Muscle..........134

Figure 5: mRNA Expression of the Trimeric IL-15R in Skeletal

Muscle..............................................136

\section{Chapter 4: Recombinant IL-15 does not attenuate TNF- $\alpha$ and/or aging induced pro-apoptotic signaling in aged skeletal muscles}

Figure 1: Flow cytometric analysis of cell viability using 7AAD .......163

Figure 2: Flow cytometric analysis of mitochondrial integrity using

MitoTracker...........................................165

Figure 3: Verification of systemic elevation of human IL-15...........167

Figure 4: Incidence of apoptosis assessed by DNA fragmentation........168 


\section{List of Tables}

Chapter 1: Molecular regulation of apoptosis in fast plantaris muscles of aged rats

Table 1: Primers used for PCR amplifications of cDNA..................64

Chapter 2: Death receptor-associated pro-apoptotic signaling in aged skeletal muscle

Table 1: Primers used for semi-quantitative RT-PCR amplification of cDNA ................................................... 105

Chapter 3: Interleukin-15 responses to aging and unloading-induced skeletal muscle atrophy

Table 1: PCR primer information.....................................137

Table 2: Rodent muscle characteristics...............................138

Chapter 4: Recombinant IL-15 does not attenuate TNF- $\alpha$ and/or aging induced pro-apoptotic signaling in aged skeletal muscles

Table 1: Analysis of mitochondrial integrity in myoblast cultures.........170

Table 2: Bodyweight changes during 14d IL-15 intervention..............171

Table 3: Organ and skeletal muscle weights from experimental rodents...172 


\section{Specific Aims}

A natural and unavoidable consequence of advanced age is a reduction in skeletal muscle mass and strength, known as sarcopenia. Although the causes of sarcopenia are multifactorial, the systemic elevation of circulating cytokines is one of the recognized risk factors for sarcopenia. Epidemiological studies have consistently reported associations between signs of sarcopenia and elevated concentrations of cytokines, such as tumor necrosis factor-alpha (TNF- $\alpha$ ) and interleukin-6 (IL-6). Mechanistic studies have also revealed that TNF- $\alpha$ can initiate not only increases in protein degradation though the ubiquitin-dependent proteolytic pathway, but also DNA fragmentation within skeletal muscle, which is a characteristic indicator of apoptosis. Given that aging results in elevated circulating concentrations of TNF- $\alpha$ and in characteristic signs of apoptosis within skeletal muscle, the objective of this dissertation is to determine if the extrinsic pathway of apoptosis, initiated by binding of TNF- $\alpha$ to the type-I TNF receptor (TNFR) and subsequent activation of downstream caspases, is an active process within aged skeletal muscle. In addition, experiments will be performed to determine if the basal expression of IL-15 within skeletal muscles is altered during periods of muscle unloading and as a result of aging. Lastly, experiments will be performed to determine if the extrinsic apoptotic pathway can be suppressed by the systemic elevation of IL-15 in aged rodents in vivo, and in myoblast cultures stimulated with TNF- $\alpha$ in vitro.

\section{Central Hypothesis}

Increased circulating concentrations of TNF- $\alpha$ will initiate a pro-apoptotic signaling pathway involving: its binding to the type-I TNFR, formation of a death 
inducing signaling complex (DISC) at the TNFR composed of Fas-associated death domain containing protein (FADD) and procaspase- 8 , and cleavage and activation of downstream caspases. Elevation of IL-15 protein, both in vitro and in vivo, will attenuate this pro-apoptotic signaling downstream of the type-I TNFR.

Specific Aim 1: To characterize the signaling pathway from the type-I TNFR through caspase-3 activation, leading to nuclear apoptosis in aged skeletal muscle.

- Method: Compare fast plantaris and slow soleus muscles from young adult and aged Fischer ${ }_{344}$ x Brown Norway (FBN) rats (in vivo).

- Hypothesis 1.1: Young adult skeletal muscles will not have marked elevations in the components of this signaling pathway.

- Hypothesis 1.2: Aged skeletal muscles will have marked elevations in the components of this signaling pathway, specifically TNFR, FADD, caspase-8, and caspase-3.

- Hypothesis 1.3: Aged skeletal muscle will express higher protein levels of pro-apoptotic Bid, which connects the pro-apoptotic signal from caspase- 8 to the mitochondrial-associated apoptotic pathway.

Specific Aim 2: To determine if increases in IL-15 levels can attenuate TNF- $\alpha$ associated apoptotic signaling in vitro.

- $\quad$ Method 1: Stimulate $\mathrm{C}_{2} \mathrm{C}_{12}$ myoblasts with rTNF- $\alpha$.

- Method 2: Stimulate $\mathrm{C}_{2} \mathrm{C}_{12}$ myoblasts with rTNF- $\alpha$ and rIL-15.

- Hypothesis 2.1: Stimulation of $\mathrm{C}_{2} \mathrm{C}_{12}$ myoblasts with $\mathrm{rTNF}-\alpha$ will promote apoptosis. 
- Hypothesis 2.2: Stimulation of $\mathrm{C}_{2} \mathrm{C}_{12}$ myoblasts with rIL-15 alone will not promote apoptosis.

- Hypothesis 2.3: Recombinant IL-15 will attenuate the rTNF- $\alpha$ induced proapoptotic signaling in $\mathrm{C}_{2} \mathrm{C}_{12}$ myoblast cultures.

Specific Aim 3: To determine if systemic elevation of IL-15 protein in vivo can attenuate TNF- $\alpha$-associated apoptosis within aged skeletal muscle.

- Method: Osmotic mini-pumps containing rIL-15 protein will be implanted into young adult and aged FBN rats for a period of 14-days.

- Hypothesis 3.1: The systemic elevation of IL-15 protein within aged rodents will reduce signs of apoptosis within skeletal muscle and specifically attenuate the pro-apoptotic TNF- $\alpha$ signaling pathway.

- Hypothesis 3.2: The systemic elevation of IL-15 protein within young adult FBN rats will provide an anabolic stimulus resulting in increases in muscle mass of plantar flexor muscles. 


\section{Background and Significance}

The aging associated loss of muscle mass and strength, known as sarcopenia, is a normal consequence of advanced age. Reductions in muscle strength are directly correlated with decreases in muscle mass $(3 ; 24 ; 54)$. In a recent review, Doherty (27) reported that muscle strength declined an average of $20-40 \%$ in healthy men and women by the seventh and eighth decades of life. Muscle mass, determined by cross sectional area (CSA), is also reduced an average of $40 \%$ between the ages of 20 and 60 (27). Sarcopenia contributes to the loss of independence and frailty often observed in older adults (88). There are multiple contributing mechanisms leading to sarcopenia, including: denervation and reinnervation of myofibers, especially within skeletal muscles composed of a high degree of type II muscle fibers $(4 ; 28)$; an alteration in the hormonal environment in which anabolic hormone concentrations progressively decline $(84 ; 85)$; elevated concentrations of inflammatory mediators that are not only associated with disease states, but also occur in healthy older adults $(10-14 ; 68 ; 78 ; 86)$; and muscle nuclei and fiber loss through apoptotic mechanisms $(25 ; 56 ; 79-81)$.

Apoptotic signaling has previously been shown to be an active process in skeletal muscle during periods of reduced muscle activity (hindlimb suspension, denervation) as well as during aging (reviewed in $(26 ; 32 ; 55)$. The hindlimb suspension (HS) model has been used to investigate the mechanisms of muscle atrophy during periods of reduced activity, and is the preferred model to simulate the effects of microgravity on skeletal muscle (64). Allen et al. (2) utilized the HS model to investigate the role of apoptosis in muscle remodeling. The soleus muscles of HS rats atrophied beginning at 7-days of HS, with a further reduction in mass at 14-days. However, TdT-mediated dUTP nick end 
labeling (TUNEL) positive nuclei, indicative of apoptosis, were visualized beginning at 3-days of HS. The number of apoptotic nuclei was increased further at 7-days of HS and remained elevated at 14-days of HS. Thus, apoptosis appeared to be an early occurring event that can contribute to muscle atrophy at later time points. Data from Hikida et al. (50) supported these results. Myonuclear loss was evident in atrophic soleus muscles of space-flown rats, providing data to support the hypothesis that the nuclear domain is under strict control and myonuclear loss occurs in an attempt to maintain the myonuclear domain.

Apoptosis has been shown to be a contributing mechanism to muscle mass losses with aging. Dirks and Leeuwenburgh (25) first examined the effect of aging on the incidence of apoptosis in the gastrocnemius muscles of young and aged rats. Apoptosis, as measured by mono- and oligonucleosome fragmentation, was elevated $50 \%$ in aged muscles compared to young adult. The HS model was subsequently utilized to examine the effect of superimposing disuse in aged skeletal muscle $(56 ; 72 ; 80)$. A common finding is that aged skeletal muscle responds differently than young adult skeletal muscle during periods of HS. Increases in apoptotic nuclei, as well as in molecular markers of the intrinsic mitochondrial apoptotic pathway (Bax, Apaf-1, AIF, caspase-9, and caspase3) were evident in aged muscles (Figure 1), supporting the hypothesis that an intracellular environment exits in aged skeletal muscle that favors apoptosis. In addition, the changes in specific apoptotic markers were elevated and/or exacerbated in aged skeletal muscle following HS (AIF, EndoG, Bax). Thus, the apoptotic signaling pathways in aged skeletal muscle are distinct when compared to young adult muscle. 
The concentration of the pro-inflammatory cytokine, TNF- $\alpha$, increases in the circulation with age $(10-14 ; 68 ; 78 ; 86)$. This increased concentration has the potential to not only increase protein degradation through a ubiquitin-dependent pathway (40), but also to initiate an apoptotic pathway that can contribute to muscle mass reductions via loss of muscle nuclei $(20 ; 71)$. In defining a molecular marker of sarcopenia, Giresi et al. (44) reported that the forkhead box $3 \mathrm{~A}(\mathrm{FOXO} 3 \mathrm{~A})$ transcription factor is up-regulated in aged skeletal muscle compared to young muscle, as determined through microarray analysis. The FOXO3A gene product has been shown to promote apoptosis via the activation of proteins involved in the TNF-related apoptosis inducing ligand (TRAIL) pathway as well as by inhibiting expression of FLICE-inhibiting protein (FLIP), which serves to inhibit caspase- $8(42 ; 82)$. Thus, the changes in gene expression within aged skeletal muscle combined with the increase in circulating TNF- with aging, suggest that the apoptotic pathway initiated by this cytokine is active within aged muscle and can contribute to muscle mass reductions in aged animals and humans.

Effects of TNF- $\alpha$ in skeletal muscle. The circulating concentrations of specific cytokines have been shown to be elevated in the serum as a result of aging. Serum levels of TNF- $\alpha(11 ; 13 ; 78)$ and IL-6 $(10 ; 36 ; 68)$ are increased in healthy elderly compared to young adults. Serum concentrations of TNF- $\alpha$ have been proposed as a prognostic marker of all cause-mortality in centenarians (11). Additionally, in a cross-sectional study composed of 362 Danish elderly, Bruunsgaard et al. (13) implicated low-grade elevations of TNF- $\alpha$ and IL-6 with age-associated pathology and mortality in 80-year old adults. Studies have also drawn associations between the increases in circulating 
cytokines and the sarcopenic process $(68 ; 86)$. Specifically, elevated circulating levels of TNF- $\alpha$ are associated with lower appendicular skeletal muscle mass, as measured by dual-energy x-ray absorptiometry (DEXA), in healthy elderly adults (68). Additionally, elevated levels of TNF- $\alpha$ and IL-6 in aged humans have been associated with smaller muscle area, less appendicular skeletal muscle mass, and reduced knee extensor and grip strength (86). Thus, one potential mechanism contributing to the onset of sarcopenia may be the increase in circulating cytokines.

Increased protein degradation within skeletal muscle initiated by TNF- $\alpha$ has been previously demonstrated. Incubation of $\mathrm{C}_{2} \mathrm{C}_{12}$ myoblasts (57) and L6 myotubes (33) with recombinant TNF- $\alpha$ resulted in decreases in total protein content. Intravenous injection of rTNF- $\alpha$ also resulted in increased protein degradation in rat skeletal muscles that was associated with activity of the ubiquitin-dependent proteolytic pathway $(39 ; 41 ; 59-61)$. Protein degradation was increased in isolated rat soleus muscles incubated in the presence of TNF- $\alpha$ and this was associated with increased expression of components of the ubiquitin-dependent proteolytic pathway (58). In addition to the increases in protein degradation, elevated TNF- $\alpha$ concentrations can increase signs of apoptosis within skeletal muscle through the extrinsic apoptotic pathway (Figure 2). Cultured myoblasts incubated in rTNF- $\alpha$ had elevated levels of apoptosis, as determined by fragmented DNA, at $24 \mathrm{~h}$ and $48 \mathrm{~h}$ of culture $(37 ; 63)$. A reduction of procaspase- 8 was measured within $6 \mathrm{~h}$ of incubation with $\mathrm{rTNF}-\alpha$, indicating the cleavage and activation of this initiator caspase in these myoblast cultures (83). A systemic elevation of TNF- $\alpha$ in vivo induced an increase in the incidence of DNA fragmentation within rodent skeletal muscle (20). Muscle from aged rats also had elevations of molecular markers involved in the 
TNF- $\alpha$ associated apoptotic pathway, when compared to muscle from young adult rats

(71). These data demonstrate that elevations in TNF- $\alpha$ result in a catabolic state within skeletal muscle and may contribute to age-associated muscle loss via increases in apoptotic signaling.

The Pleiotropic Cytokine Interleukin-15. Interleukin-15 is a recently discovered cytokine $(19 ; 48)$ that belongs to the four $\alpha$-helix bundle family of cytokines, that also include IL-2, IL-3, IL-4, IL-5, IL-6, IL-7, and IL-9 (for in-depth reviews on IL15, see(34; 87). First identified as a T-lymphocyte growth factor, the roles of IL-15 within the immune system have been shown to also include the activation of natural killer (NK) cells (22), and proliferation of B cells (6). Redundancy in response between IL-15 and IL-2 is due to the similarity in the receptor composition for these two cytokines. The IL-15 and IL-2 receptors are trimeric structures composed of two identical chains, the IL$2 \mathrm{R}$ beta-chain and the common gamma $(\gamma \mathrm{c})$ chain, along with specific alpha-chains $(45$; 46). The IL-15R alpha chain exhibits a high affinity of binding for IL-15 protein, with a $\mathrm{K}_{\mathrm{d}}$ of $10 \mathrm{pM}$ (31). In addition to paracrine actions, IL-15 can be expressed in trans, in which the cytokine is either bound to cell surface IL-15R $\alpha$ or anchored to the cell membrane and presented to neighboring cells that express IL-2R $\beta$ and $\gamma c(15 ; 16)$. Although both IL-15 (66) and IL-15R $\alpha$ (47) mRNA is expressed in skeletal muscle, it is not known if the mRNA for a functional trimeric IL-15R is also expressed in skeletal muscle, which would allow for trans presentation of IL-15 by muscle cells. 
Despite similar effects of IL-15 and IL-2 within the immune system, the two cytokines share no sequence homology and the tissue distribution of these two cytokines differs dramatically (48). Interleukin-2 mRNA is expressed exclusively in activated Tlymphocytes, where it promotes proliferation. Interleukin-15 mRNA is widely distributed among tissue and cell types, including heart, brain, lung, liver, kidney, pancreas, and skeletal muscle (48). Among cytokine mRNAs expressed within skeletal muscle, IL-15 mRNA has been reported to be the highest $(65 ; 66)$. Despite this high concentration of IL-15 mRNA within skeletal muscle, there seems to be no effect of aerobic or anaerobic muscular contractions on its expression levels $(23 ; 65 ; 66)$.

In contrast to the wide expression of IL-15 mRNA, mature IL-15 protein has been difficult to measure (87). In a recent study, plasma IL-15 concentrations were determined by ELISA in response to an acute resistance training session and following a 10-week resistance training program (76). Interleukin-15 protein was elevated immediately following the acute exercise session, but was not significantly different as a result of the 10 -week training intervention. The IL-15 protein concentrations determined in the study by ELISA ranged from $1.65 \mathrm{pg}^{\cdot} \mathrm{ml}^{-1}$ to $1.75 \mathrm{pg}^{\cdot} \mathrm{ml}^{-1}$, displaying the extremely low concentration of this cytokine. The low concentration of mature IL-15 protein is due to multiple levels of regulation that include: the composition of the 5 , UTR; the unusually long signal peptide; and the C-terminus of the mature protein. First, the 5' UTR of human IL-15 is long and contains 12 AUGs upstream of the initiation AUG codon (7; 87). These multiple upstream AUGs may represent an attempt to reduce translation efficiency of proteins whose expression may be detrimental (7). Indeed, the ability of IL-15 to stimulate non-specific T-cell proliferation would necessitate a 
regulation of protein expression. Second, IL-15 protein contains an unusually long 48 amino acid signal peptide (53). This is in contrast to other proteins that demonstrate highly efficient translation. The effect of this signal peptide on protein translation was demonstrated by Bamford and co-workers (7), who replaced the peptide coding sequence of IL-15 with that of IL-2 and vise versa. When these chimeras were transfected into COS cells, the total amount of IL-15 protein generated was increased 17 - to 20 -fold. Additionally, the amount of IL-2 produced was reduced 40- to 50-fold. Third, the Cterminus region contains a structure that negatively regulates IL-15 protein production (7). In an effort to measure IL-15 protein, an epitope tag FLAG was added to the 3'end of the IL-15 protein. This modification increased IL-15 protein production alone by 5- to 10-fold. When these three negative elements noted above were eliminated and the resulting construct was transfected into COS cells, 250-fold more IL-15 protein was produced, demonstrating the extremely tight regulation of protein production (7). Initial experiments utilizing rIL-15 protein in vitro provided data suggesting IL-15 was an anabolic factor for skeletal muscle. The anabolic effects of rIL-15 were first demonstrated in differentiated myotubes in vitro $(38 ; 74)$. Myotubes incubated in rIL-15 protein $\left(10 \mathrm{ng}^{\cdot} \mathrm{ml}^{-1}\right)$ displayed a hypertrophic morphology as well as increased myosin heavy chain protein content in culture. These results were supported upon myotube infection with a retroviral expression vector expressing murine IL-15 (73). The anabolic effect of IL-15 in vivo has been demonstrated in diaphragm muscle from young mice (8 weeks), following systemic elevation of rIL-15 for 28 days through use of an osmotic mini-pump which controlled the rate of protein delivery $\left(0.125 \mu \mathrm{l}^{\cdot} \mathrm{h}^{-1}\right)(49)$. Muscle cross sectional area (CSA) and specific force $\left(\mathrm{Po} \cdot \mathrm{CSA}^{-1}\right)$ were elevated in the diaphragm 
muscles of $m d x$ mice treated with IL-15, compared to control $m d x$ mice. The controlled release of recombinant protein and/or duration of the treatment period may be critical factors for muscle hypertrophy, as rats provided once daily bolus injections of rIL-15 $\left(100 \mu \mathrm{g} \cdot \mathrm{kg} \mathrm{bw}^{-1}\right)$ for 7 -days showed no hypertrophy of gastrocnemius, soleus, or tibialis muscles $(21 ; 35)$.

Recent data have also shown effects of IL-15 within bone (67) and adipose tissue $(5 ; 75)$, illustrating tissue specific roles for this cytokine. The growth-promoting ability of IL-15 within skeletal muscle is in contrast to the proposed role of IL-15 in bone resorption (67). IL-15 concentrations are increased within joints in patients with rheumatoid arthritis, and studies have attempted to use IL-15 levels as a clinical marker of disease progression. In vitro studies have shown that IL-15 can stimulate the formation of multinucleated osteoclast-like cells in rat bone marrow cultures, as well as stimulate differentiation of osteoclast progenitors into preosteoclasts. The increase in osteoclasts, bone resorbing cells, can lead to bone loss within the affected joints. Increases in IL-15 can also promote lipogenesis (5) and adipokine secretion (75) from adipose cells, such as adiponectin. Additional research is required to decipher the multifaceted roles of IL-15 within individual tissues.

IL-15 and Apoptosis. Numerous cytokines have been implicated in attenuating apoptosis (reviewed in (62)). Manipulation of the IL-15/IL-15R system has been shown to inhibit apoptosis in numerous cell types, including T-lymphocytes $(1 ; 8 ; 29 ; 30 ; 70)$, neutrophils $(9 ; 43 ; 69)$, skeletal muscle fibers (35), keratinocytes (77), and fibroblasts (17). Multisystem apoptosis initiated in mice via treatment with an anti-Fas antibody was 
suppressed with injection of a long-lasting IL-15-IgG2b fusion protein (18). In addition, IL-15 transgenic (Tg) mice were resistant to a lethal dose of Escherichia coli (E. coli). Administration of $10 \mu \mathrm{g}$ of IL-15 intraperitonally (i.p.) into control mice also minimized the death rate from a lethal challenge of E. coli. These authors also demonstrated that IL15 administration into isolated peritoneal cells in vitro, prevented TNF- $\alpha$ induced apoptosis (51).

The well-characterized cell death pathway initiated by the binding of TNF- $\alpha$ to the type I TNFR is altered with increases in IL-15 protein $(17 ; 21)$. Specifically, in a rodent model of cancer, daily injections of IL-15 protein $\left(100 \mu \mathrm{g} \cdot \mathrm{bw}^{-1}\right)$ for 7 -days resulted in significant decreases in the gene expression of both the type I and type II TNFR (21). Although gene expression of TNF- $\alpha$ was not altered with IL-15 administration, the authors speculated that this signaling pathway could be affected by reducing the presence of TNR receptors. A more precise mechanism for this antiapoptotic effect was demonstrated in fibroblasts in vitro (17). When fibroblast cultures contained TNF- $\alpha$ protein in the media, significant apoptosis occurred. However, when IL-15 protein $\left(10 \mathrm{ng} \cdot \mathrm{ml}^{-1}\right)$ was included in the media with TNF- $\alpha\left(10 \mathrm{ng} \cdot \mathrm{ml}^{-1}\right)$, apoptosis was attenuated. Co-immunoprecipitation experiments revealed that upon IL-15 binding to the IL-15R $\alpha$, the cytoplasmic signaling molecule, TRAF2, was recruited to the cytoplasmic side of the IL-15R $\alpha$ and away from the TNFR. Interestingly, this recruitment of TRAF2 to IL-15R $\alpha$ was only observed when both TNF- $\alpha$ and IL-15 protein were present in the culture media. Thus, IL-15 seems to possess the ability to inhibit apoptosis by blocking the apoptotic signaling downstream of the TNFR. 
An association between IL-15 and the anti-apoptotic protein, Bcl-2, has also been demonstrated previously $(52 ; 70 ; 89)$. In IL-15R $\alpha-/-$ mice, a reduction in the percentage of CD8+ T cells has been reported. The reduced percentage of these cells was due in part to a reduction of Bcl-2 expression. Exogenous IL-15 up-regulated Bcl-2 levels in these cells and contributed to a reduction in cell death upon cell activation, in a dose dependent manner (10-1000 ng $\left.{ }^{\prime} \mathrm{ml}^{-1}\right)$ (89). Additionally, HIV-specific CD8+ T cells were shown to exhibit reduced levels of Bcl-2. When these cells were cultured with IL-15, Bcl-2 expression increased and this was associated with an attenuation of apoptosis in CD8 $+\mathrm{T}$ cell cultures (70). Lastly, in synovial cell cultures from rheumatoid arthritis patients, blocking of IL-15 activity caused a reduction in the expression Bcl-2 and Bcl-xl (52). The ability of IL-15 to attenuate TNF- $\alpha$ associated apoptotic signaling coupled with its association with Bcl-2, suggest IL-15 is an anti-apoptotic molecule that requires further investigation. 


\section{Reference List}

\section{Akbar AN, Borthwick NJ, Wickremasinghe RG, Panayoitidis P, Pilling D,} Bofill M, Krajewski S, Reed JC and Salmon M. Interleukin-2 receptor common gamma-chain signaling cytokines regulate activated $\mathrm{T}$ cell apoptosis in response to growth factor withdrawal: selective induction of anti-apoptotic (bcl-2, bcl-xL) but not pro-apoptotic (bax, bcl-xS) gene expression. Eur J Immunol 26: 294-299, 1996.

2. Allen DL, Linderman JK, Roy RR, Bigbee AJ, Grindeland RE, Mukku V and Edgerton VR. Apoptosis: a mechanism contributing to remodeling of skeletal muscle in response to hindlimb unweighting. Am J Physiol 273: C579C587, 1997.

\section{Alway SE, Coggan AR, Sproul MS, Abduljalil AM and Robitaille PM.} Muscle torque in young and older untrained and endurance-trained men. $J$ Gerontol A Biol Sci Med Sci 51: B195-B201, 1996.

4. Ansved T and Larsson L. Effects of ageing on enzyme-histochemical, morphometrical and contractile properties of the soleus muscle in the rat. J Neurol Sci 93: 105-124, 1989.

\section{Argiles JM, Lopez-Soriano J, Almendro V, Busquets S and Lopez-Soriano} FJ. Cross-talk between skeletal muscle and adipose tissue: a link with obesity? Med Res Rev 25: 49-65, 2005.

6. Armitage RJ, Macduff BM, Eisenman J, Paxton R and Grabstein KH. IL-15 has stimulatory activity for the induction of B cell proliferation and differentiation. J Immunol 154: 483-490, 1995. 
7. Bamford RN, DeFilippis AP, Azimi N, Kurys G and Waldmann TA. The 5' untranslated region, signal peptide, and the coding sequence of the carboxyl terminus of IL-15 participate in its multifaceted translational control. J Immunol 160: 4418-4426, 1998.

8. Berard M, Brandt K, Bulfone-Paus S and Tough DF. IL-15 promotes the survival of naive and memory phenotype CD8+ T cells. J Immunol 170: 5018$5026,2003$.

9. Bouchard A, Ratthe C and Girard D. Interleukin-15 delays human neutrophil apoptosis by intracellular events and not via extracellular factors: role of Mcl-1 and decreased activity of caspase-3 and caspase-8. J Leukoc Biol 75: 893-900, 2004.

10. Bruunsgaard $\mathbf{H}$. Effects of tumor necrosis factor-alpha and interleukin-6 in elderly populations. Eur Cytokine Netw 13: 389-391, 2002.

11. Bruunsgaard H, Andersen-Ranberg K, Hjelmborg JB, Pedersen BK and Jeune B. Elevated levels of tumor necrosis factor alpha and mortality in centenarians. Am J Med 115: 278-283, 2003.

12. Bruunsgaard H, Andersen-Ranberg K, Jeune B, Pedersen AN, Skinhoj P and Pedersen BK. A high plasma concentration of TNF-alpha is associated with dementia in centenarians. J Gerontol A Biol Sci Med Sci 54: M357-M364, 1999.

13. Bruunsgaard H, Ladelund S, Pedersen AN, Schroll M, Jorgensen T and Pedersen BK. Predicting death from tumour necrosis factor-alpha and interleukin-6 in 80-year-old people. Clin Exp Immunol 132: 24-31, 2003. 
14. Bruunsgaard H, Pedersen $\mathbf{M}$ and Pedersen BK. Aging and proinflammatory cytokines. Curr Opin Hematol 8: 131-136, 2001.

15. Budagian V, Bulanova E, Paus R and Bulfone-Paus S. IL-15/IL-15 receptor biology: A guided tour through an expanding universe. Cytokine Growth Factor Rev 17: 259-280, 2006.

16. Bulfone-Paus S, Bulanova E, Budagian V and Paus R. The interleukin15/interleukin-15 receptor system as a model for juxtacrine and reverse signaling. Bioessays 28: 362-377, 2006.

17. Bulfone-Paus S, Bulanova E, Pohl T, Budagian V, Durkop H, Ruckert R, Kunzendorf U, Paus R and Krause H. Death deflected: IL-15 inhibits TNFalpha-mediated apoptosis in fibroblasts by TRAF2 recruitment to the IL-15Ralpha chain. FASEB J 13: 1575-1585, 1999.

18. Bulfone-Paus S, Ungureanu D, Pohl T, Lindner G, Paus R, Ruckert R, Krause $\mathbf{H}$ and Kunzendorf $\mathbf{U}$. Interleukin-15 protects from lethal apoptosis in vivo. Nat Med 3: 1124-1128, 1997.

19. Burton JD, Bamford RN, Peters C, Grant AJ, Kurys G, Goldman CK, Brennan J, Roessler E and Waldmann TA. A lymphokine, provisionally designated interleukin $\mathrm{T}$ and produced by a human adult $\mathrm{T}$-cell leukemia line, stimulates T-cell proliferation and the induction of lymphokine-activated killer cells. Proc Natl Acad Sci U S A 91: 4935-4939, 1994.

20. Carbo N, Busquets S, van Royen M, Alvarez B, Lopez-Soriano FJ and Argiles JM. TNF-alpha is involved in activating DNA fragmentation in skeletal muscle. Br J Cancer 86: 1012-1016, 2002. 
21. Carbo N, Lopez-Soriano J, Costelli P, Busquets S, Alvarez B, Baccino FM, Quinn LS, Lopez-Soriano FJ and Argiles JM. Interleukin-15 antagonizes muscle protein waste in tumour-bearing rats. Br J Cancer 83: 526-531, 2000.

22. Carson WE, Giri JG, Lindemann MJ, Linett ML, Ahdieh M, Paxton R, Anderson D, Eisenmann J, Grabstein K and Caligiuri MA. Interleukin (IL) 15 is a novel cytokine that activates human natural killer cells via components of the IL-2 receptor. J Exp Med 180: 1395-1403, 1994.

23. Chan MH, Carey AL, Watt MJ and Febbraio MA. Cytokine gene expression in human skeletal muscle during concentric contraction: evidence that IL-8, like IL-6, is influenced by glycogen availability. Am J Physiol Regul Integr Comp Physiol 287: R322-R327, 2004.

24. Degens H and Alway SE. Skeletal muscle function and hypertrophy are diminished in old age. Muscle Nerve 27: 339-347, 2003.

25. Dirks A and Leeuwenburgh C. Apoptosis in skeletal muscle with aging. Am $J$ Physiol Regul Integr Comp Physiol 282: R519-R527, 2002.

26. Dirks AJ and Leeuwenburgh $\mathbf{C}$. The role of apoptosis in age-related skeletal muscle atrophy. Sports Med 35: 473-483, 2005.

27. Doherty TJ. Invited review: Aging and sarcopenia. J Appl Physiol 95: 1717$1727,2003$.

28. Doherty TJ, Vandervoort AA, Taylor AW and Brown A. Effects of motor unit losses on strength in older men and women. J Appl Physiol 74: 868-874, 1993. 
29. Dooms H, Desmedt M, Vancaeneghem S, Rottiers P, Goossens V, Fiers W and Grooten J. Quiescence-inducing and antiapoptotic activities of IL-15 enhance secondary CD4+ T cell responsiveness to antigen. J Immunol 161: 2141$2150,1998$.

30. Dooms H, Van Belle T, Desmedt M, Rottiers P and Grooten J. Interleukin-15 redirects the outcome of a tolerizing $\mathrm{T}$-cell stimulus from apoptosis to anergy. Blood 96: 1006-1012, 2000.

31. Dubois S, Magrangeas F, Lehours P, Raher S, Bernard J, Boisteau O, Leroy S, Minvielle S, Godard A and Jacques Y. Natural splicing of exon 2 of human interleukin-15 receptor alpha-chain mRNA results in a shortened form with a distinct pattern of expression. J Biol Chem 274: 26978-26984, 1999.

32. Dupont-Versteegden EE. Apoptosis in muscle atrophy: relevance to sarcopenia. Exp Gerontol 40: 473-481, 2005.

33. el Naggar EA, Kanda F, Okuda S, Maeda N, Nishimoto K, Ishihara H and Chihara K. Direct effects of tumor necrosis factor alpha (TNF-alpha) on L6 myotubes. Kobe J Med Sci 50: 39-46, 2004.

34. Fehniger TA and Caligiuri MA. Interleukin 15: biology and relevance to human disease. Blood 97: 14-32, 2001.

35. Figueras M, Busquets S, Carbo N, Barreiro E, Almendro V, Argiles JM and Lopez-Soriano FJ. Interleukin-15 is able to suppress the increased DNA fragmentation associated with muscle wasting in tumour-bearing rats. FEBS Lett 569: 201-206, 2004. 
36. Forsey RJ, Thompson JM, Ernerudh J, Hurst TL, Strindhall J, Johansson B, Nilsson BO and Wikby A. Plasma cytokine profiles in elderly humans. Mech Ageing Dev 124: 487-493, 2003.

37. Foulstone EJ, Meadows KA, Holly JM and Stewart CE. Insulin-like growth factors (IGF-I and IGF-II) inhibit C2 skeletal myoblast differentiation and enhance TNF alpha-induced apoptosis. J Cell Physiol 189: 207-215, 2001.

38. Furmanczyk PS and Quinn LS. Interleukin-15 increases myosin accretion in human skeletal myogenic cultures. Cell Biol Int 27: 845-851, 2003.

39. Garcia-Martinez C, Agell N, Llovera M, Lopez-Soriano FJ and Argiles JM. Tumour necrosis factor-alpha increases the ubiquitinization of rat skeletal muscle proteins. FEBS Lett 323: 211-214, 1993.

40. Garcia-Martinez C, Llovera M, Agell N, Lopez-Soriano FJ and Argiles JM. Ubiquitin gene expression in skeletal muscle is increased during sepsis: involvement of TNF-alpha but not IL-1. Biochem Biophys Res Commun 217: 839$844,1995$.

41. Garcia-Martinez C, Lopez-Soriano FJ and Argiles JM. Acute treatment with tumour necrosis factor-alpha induces changes in protein metabolism in rat skeletal muscle. Mol Cell Biochem 125: 11-18, 1993.

42. Ghaffari S, Jagani Z, Kitidis C, Lodish HF and Khosravi-Far R. Cytokines and BCR-ABL mediate suppression of TRAIL-induced apoptosis through inhibition of forkhead FOXO3a transcription factor. Proc Natl Acad Sci U S A 100: 6523-6528, 2003. 
43. Girard D, Paquet ME, Paquin R and Beaulieu AD. Differential effects of interleukin-15 (IL-15) and IL-2 on human neutrophils: modulation of phagocytosis, cytoskeleton rearrangement, gene expression, and apoptosis by IL15. Blood 88: 3176-3184, 1996.

44. Giresi PG, Stevenson EJ, Theilhaber J, Koncarevic A, Parkington J, Fielding RA and Kandarian SC. Identification of a molecular signature of sarcopenia. Physiol Genomics 21: 253-263, 2005.

45. Giri JG, Ahdieh M, Eisenman J, Shanebeck K, Grabstein K, Kumaki S, Namen A, Park LS, Cosman D and Anderson D. Utilization of the beta and gamma chains of the IL-2 receptor by the novel cytokine IL-15. EMBO J 13: 2822-2830, 1994.

46. Giri JG, Anderson DM, Kumaki S, Park LS, Grabstein KH and Cosman D. IL-15, a novel T cell growth factor that shares activities and receptor components with IL-2. J Leukoc Biol 57: 763-766, 1995.

47. Giri JG, Kumaki S, Ahdieh M, Friend DJ, Loomis A, Shanebeck K, DuBose R, Cosman D, Park LS and Anderson DM. Identification and cloning of a novel IL-15 binding protein that is structurally related to the alpha chain of the IL2 receptor. EMBO J 14: 3654-3663, 1995.

48. Grabstein KH, Eisenman J, Shanebeck K, Rauch C, Srinivasan S, Fung V, Beers C, Richardson J, Schoenborn MA, Ahdieh M and . Cloning of a T cell growth factor that interacts with the beta chain of the interleukin-2 receptor. Science 264: 965-968, 1994.

49. Harcourt LJ, Holmes AG, Gregorevic P, Schertzer JD, Stupka N, Plant DR and Lynch GS. Interleukin-15 administration improves diaphragm muscle 
pathology and function in dystrophic mdx mice. Am J Pathol 166: 1131-1141, 2005.

50. Hikida RS, Van Nostran S, Murray JD, Staron RS, Gordon SE and Kraemer WJ. Myonuclear loss in atrophied soleus muscle fibers. Anat Rec 247: 350-354, 1997.

51. Hiromatsu T, Yajima T, Matsuguchi T, Nishimura H, Wajjwalku W, Arai T, Nimura Y and Yoshikai Y. Overexpression of interleukin-15 protects against Escherichia coli-induced shock accompanied by inhibition of tumor necrosis factor-alpha-induced apoptosis. J Infect Dis 187: 1442-1451, 2003.

52. Kurowska M, Rudnicka W, Kontny E, Janicka I, Chorazy M, Kowalczewski J, Ziolkowska M, Ferrari-Lacraz S, Strom TB and Maslinski W. Fibroblastlike synoviocytes from rheumatoid arthritis patients express functional IL-15 receptor complex: endogenous IL-15 in autocrine fashion enhances cell proliferation and expression of Bcl-x(L) and Bcl-2. J Immunol 169: 1760-1767, 2002.

53. Kurys G, Tagaya Y, Bamford R, Hanover JA and Waldmann TA. The long signal peptide isoform and its alternative processing direct the intracellular trafficking of interleukin-15. J Biol Chem 275: 30653-30659, 2000.

54. Larsson L, Grimby $\mathbf{G}$ and Karlsson J. Muscle strength and speed of movement in relation to age and muscle morphology. J Appl Physiol 46: 451-456, 1979.

55. Leeuwenburgh C. Role of apoptosis in sarcopenia. J Gerontol A Biol Sci Med Sci 58: 999-1001, 2003. 
56. Leeuwenburgh C, Gurley CM, Strotman BA and Dupont-Versteegden EE. Age-related differences in apoptosis with disuse atrophy in soleus muscle. Am J Physiol Regul Integr Comp Physiol 288: R1288-R1296, 2005.

57. Li YP, Schwartz RJ, Waddell ID, Holloway BR and Reid MB. Skeletal muscle myocytes undergo protein loss and reactive oxygen-mediated NF-kappaB activation in response to tumor necrosis factor alpha. FASEB J 12: 871-880, 1998.

58. Llovera M, Garcia-Martinez C, Agell N, Lopez-Soriano FJ and Argiles JM. TNF can directly induce the expression of ubiquitin-dependent proteolytic system in rat soleus muscles. Biochem Biophys Res Commun 230: 238-241, 1997.

59. Llovera M, Garcia-Martinez C, Agell N, Marzabal M, Lopez-Soriano FJ and Argiles JM. Ubiquitin gene expression is increased in skeletal muscle of tumourbearing rats. FEBS Lett 338: 311-318, 1994.

60. Llovera M, Lopez-Soriano FJ and Argiles JM. Chronic tumour necrosis factoralpha treatment modifies protein turnover in rat tissues. Biochem Mol Biol Int 30: 29-36, 1993.

61. Llovera M, Lopez-Soriano FJ and Argiles JM. Effects of tumor necrosis factor-alpha on muscle-protein turnover in female Wistar rats. J Natl Cancer Inst 85: 1334-1339, 1993.

62. Lotem $\mathbf{J}$ and Sachs L. Cytokines as suppressors of apoptosis. Apoptosis 4: 187196, 1999.

63. Meadows KA, Holly JM and Stewart CE. Tumor necrosis factor-alpha-induced apoptosis is associated with suppression of insulin-like growth factor binding 
protein-5 secretion in differentiating murine skeletal myoblasts. J Cell Physiol 183: 330-337, 2000.

64. Morey-Holton ER and Globus RK. Hindlimb unloading rodent model: technical aspects. J Appl Physiol 92: 1367-1377, 2002.

65. Nieman DC, Davis JM, Brown VA, Henson DA, Dumke CL, Utter AC, Vinci DM, Downs MF, Smith JC, Carson J, Brown A, McAnulty SR and McAnulty LS. Influence of carbohydrate ingestion on immune changes after $2 \mathrm{~h}$ of intensive resistance training. J Appl Physiol 96: 1292-1298, 2004.

66. Nieman DC, Davis JM, Henson DA, Walberg-Rankin J, Shute M, Dumke CL, Utter AC, Vinci DM, Carson JA, Brown A, Lee WJ, McAnulty SR and McAnulty LS. Carbohydrate ingestion influences skeletal muscle cytokine mRNA and plasma cytokine levels after a 3-h run. J Appl Physiol 94: 1917-1925, 2003.

67. Ogata Y, Kukita A, Kukita T, Komine M, Miyahara A, Miyazaki S and Kohashi O. A novel role of IL-15 in the development of osteoclasts: inability to replace its activity with IL-2. J Immunol 162: 2754-2760, 1999.

68. Pedersen M, Bruunsgaard H, Weis N, Hendel HW, Andreassen BU, EIdrup E, Dela F and Pedersen BK. Circulating levels of TNF-alpha and IL-6-relation to truncal fat mass and muscle mass in healthy elderly individuals and in patients with type-2 diabetes. Mech Ageing Dev 124: 495-502, 2003.

69. Pelletier M, Ratthe C and Girard D. Mechanisms involved in interleukin-15induced suppression of human neutrophil apoptosis: role of the anti-apoptotic Mcl-1 protein and several kinases including Janus kinase-2, p38 mitogen- 
activated protein kinase and extracellular signal-regulated kinases-1/2. FEBS Lett 532: 164-170, 2002.

70. Petrovas C, Mueller YM, Dimitriou ID, Bojczuk PM, Mounzer KC, Witek J, Altman JD and Katsikis PD. HIV-specific CD8+ T cells exhibit markedly reduced levels of Bcl-2 and Bcl-xL. J Immunol 172: 4444-4453, 2004.

71. Phillips T and Leeuwenburgh C. Muscle fiber specific apoptosis and TNF-alpha signaling in sarcopenia are attenuated by life-long calorie restriction. FASEB J 19: 668-670, 2005.

72. Pistilli EE, Siu PM and Alway SE. Molecular regulation of apoptosis in fast plantaris muscles of aged rats. J Gerontol A Biol Sci Med Sci 61: 245-255, 2006.

73. Quinn LS, Anderson BG, Drivdahl RH, Alvarez B and Argiles JM. Overexpression of interleukin-15 induces skeletal muscle hypertrophy in vitro: implications for treatment of muscle wasting disorders. Exp Cell Res 280: 55-63, 2002.

74. Quinn LS, Haugk KL and Grabstein KH. Interleukin-15: a novel anabolic cytokine for skeletal muscle. Endocrinology 136: 3669-3672, 1995.

75. Quinn LS, Strait-Bodey L, Anderson BG, Argiles JM and Havel PJ. Interleukin-15 stimulates adiponectin secretion by 3T3-L1 adipocytes: Evidence for a skeletal muscle-to-fat signaling pathway. Cell Biol Int 2005.

76. Riechman SE, Balasekaran G, Roth SM and Ferrell RE. Association of interleukin-15 protein and interleukin-15 receptor genetic variation with resistance exercise training responses. J Appl Physiol 97: 2214-2219, 2004. 
77. Ruckert R, Asadullah K, Seifert M, Budagian VM, Arnold R, Trombotto C, Paus R and Bulfone-Paus S. Inhibition of keratinocyte apoptosis by IL-15: a new parameter in the pathogenesis of psoriasis? J Immunol 165: 2240-2250, 2000.

78. Sandmand M, Bruunsgaard H, Kemp K, Andersen-Ranberg K, Schroll M and Jeune B. High circulating levels of tumor necrosis factor-alpha in centenarians are not associated with increased production in $\mathrm{T}$ lymphocytes. Gerontology 49: 155-160, 2003.

79. Siu PM and Alway SE. Mitochondria-associated apoptotic signalling in denervated rat skeletal muscle. J Physiol 565: 309-323, 2005.

80. Siu PM, Pistilli EE and Alway SE. Apoptotic responses to hindlimb suspension in gastrocnemius muscles from young adult and aged rats. Am J Physiol Regul Integr Comp Physiol 2005.

81. Siu PM, Pistilli EE, Butler DC and Alway SE. Aging influences cellular and molecular responses of apoptosis to skeletal muscle unloading. Am J Physiol Cell Physiol 288: C338-C349, 2005.

82. Skurk C, Maatz H, Kim HS, Yang J, Abid MR, Aird WC and Walsh K. The Akt-regulated forkhead transcription factor FOXO3a controls endothelial cell viability through modulation of the caspase-8 inhibitor FLIP. J Biol Chem 279: 1513-1525, 2004.

83. Stewart CE, Newcomb PV and Holly JM. Multifaceted roles of TNF-alpha in myoblast destruction: a multitude of signal transduction pathways. J Cell Physiol 198: 237-247, 2004.

84. Tenover JL. Testosterone and the aging male. J Androl 18: 103-106, 1997. 
85. Tenover JS, Matsumoto AM, Plymate SR and Bremner WJ. The effects of aging in normal men on bioavailable testosterone and luteinizing hormone secretion: response to clomiphene citrate. J Clin Endocrinol Metab 65: 1118$1126,1987$.

86. Visser M, Pahor M, Taaffe DR, Goodpaster BH, Simonsick EM, Newman AB, Nevitt $M$ and Harris TB. Relationship of interleukin-6 and tumor necrosis factor-alpha with muscle mass and muscle strength in elderly men and women: the Health ABC Study. J Gerontol A Biol Sci Med Sci 57: M326-M332, 2002.

87. Waldmann TA and Tagaya Y. The multifaceted regulation of interleukin-15 expression and the role of this cytokine in NK cell differentiation and host response to intracellular pathogens. Annu Rev Immunol 17: 19-49, 1999.

88. Wickham C, Cooper C, Margetts BM and Barker DJ. Muscle strength, activity, housing and the risk of falls in elderly people. Age Ageing 18: 47-51, 1989.

89. Wu TS, Lee JM, Lai YG, Hsu JC, Tsai CY, Lee YH and Liao NS. Reduced expression of Bcl-2 in CD8+ T cells deficient in the IL-15 receptor alpha-chain. $J$ Immunol 168: 705-712, 2002. 
Figure 1: The intrinsic-mitochondrial apoptotic pathway

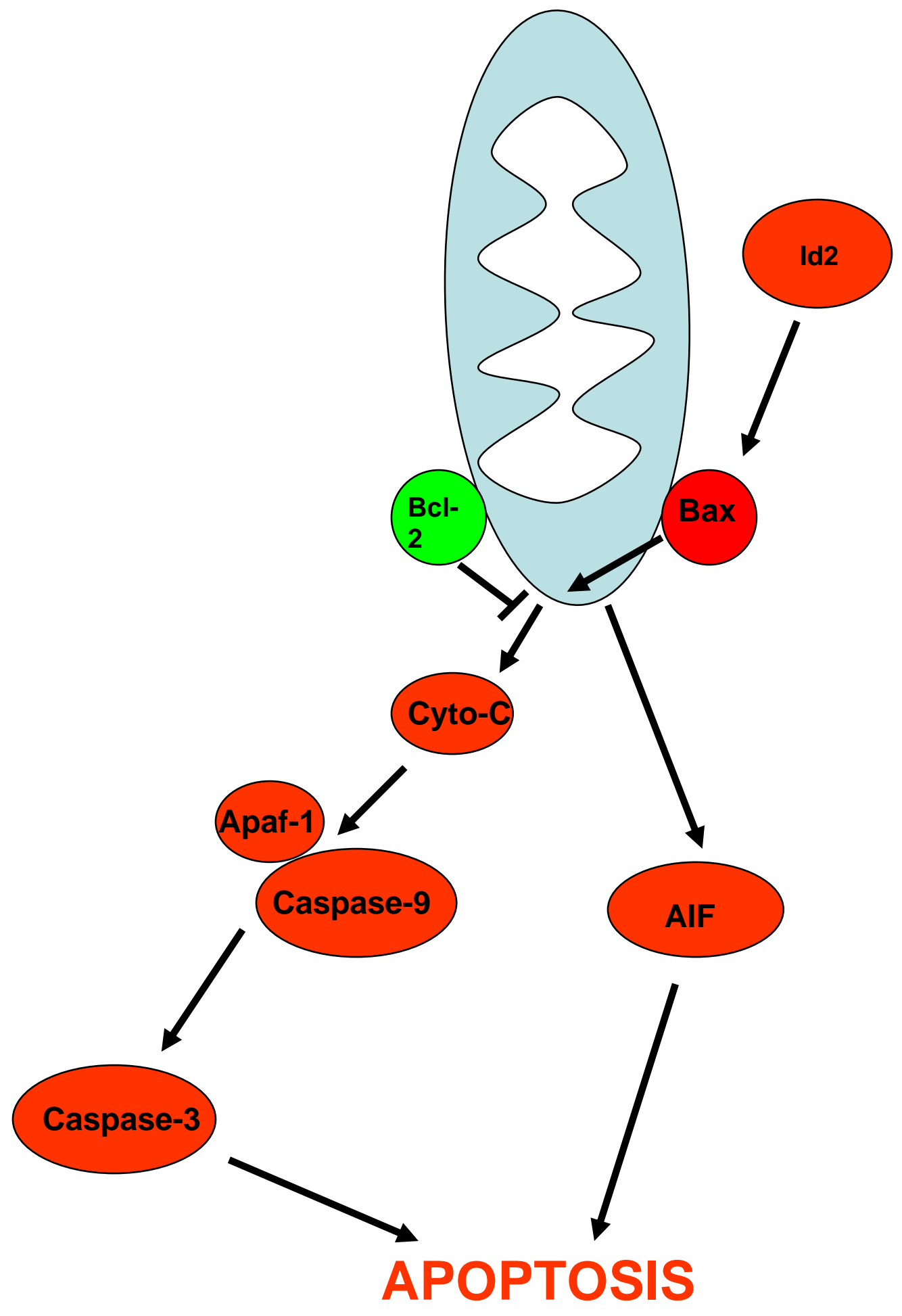


Figure 2: The extrinsic apoptotic pathway

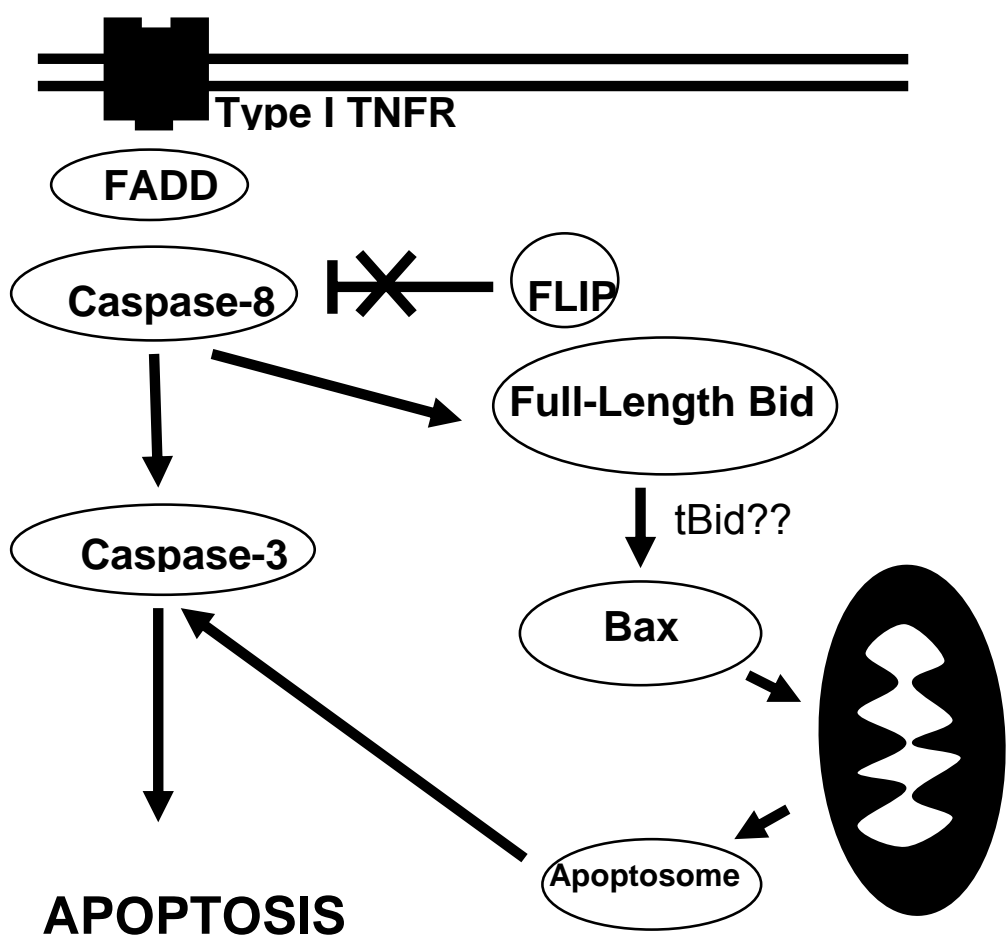




\title{
CHAPTER 1
}

Pistilli EE, Siu PM, and Alway SE. Molecular regulation of apoptosis in atrophied fast plantaris muscles of young and aged rats. Journal of Gerontology: Biological Sciences, 61(3): 245-255, 2006.

\begin{abstract}
This study tested the hypothesis that aging exacerbates apoptotic signaling in rat fast plantaris muscle during muscle unloading. Plantaris muscle mass was $22 \%$ less in aged animals and the apoptotic index was $600 \%$ greater, when compared to young adult animals. Following 14-days of hindlimb unloading, absolute plantaris muscle mass was $20 \%$ less in young adult animals with a corresponding $200 \%$ greater elevation of the apoptotic index. Unloading had no affect on muscle weight or apoptotic index of aged plantaris muscles. The changes in pro-apoptotic mRNA for Apaf-1, Bax, and Id2 were exacerbated with aging. Bax and Bcl-2 protein levels were also altered differently in aged muscle, compared to young. Significant positive correlations were observed between the changes in Id 2 and Bax mRNA, and Id 2 and caspase- 9 mRNA. These data suggest that a pro-apoptotic environment may contribute to aging-associated atrophy in fast skeletal muscle but apoptotic signaling differs by age.
\end{abstract}

KEY WORDS: $\quad$ sarcopenia, muscle atrophy, transcription factors, aging, unloading 


\section{INTRODUCTION}

Muscle mass and strength are reduced as a result of aging, a condition know as sarcopenia (1-5). Sarcopenia contributes to a loss of independence with advanced age and increases the risk of falling in the elderly (5). This is an important problem because hypokinesia is profound in older populations and aging increases the sensitivity of muscle fibers to inactivityinduced atrophy (6-9). Thus, it appears possible that superimposing disuse or immobility with sarcopenia (e.g., recovery from surgery or a fall) may further exacerbate the loss of muscle mass and strength.

Limb unloading is a common means to induce atrophy in skeletal muscles. In rodents, this is usually achieved by hindlimb suspension (10-15) or immobilization (16). Hindlimb suspension (HS) is a model of simulated microgravity that has been used to investigate skeletal muscle adaptations during non-weight-bearing conditions (17). The rapid loss of muscle fiber cross-sectional area during unloading indicates that the atrophying myofibers have activated pathways leading to decreased rates of protein synthesis and increased degradation of myofibrillar proteins $(18,19)$. The atrophy of antigravity hindlimb muscles, especially the soleus, is quite severe $(11,20-22)$ and this is associated with a down regulation of slow myosin heavy chain expression (23) and a decrease in the number of nuclei per muscle fiber (22). Furthermore, an increase in TUNEL (Terminal deoxynucleotidyl Transferase Biotin-dUTP Nick End Labeling) positive nuclei in slow rat skeletal muscle have been reported after HS leading to muscle atrophy as compared to control muscles (11). Recent reports have also demonstrated increases in pro-apoptotic proteins involved in the mitochondrial-associated apoptotic pathway in the soleus muscle (24), and the mixed fiber medial gastrocnemius muscle, as a result of both aging and limb unloading (25). These data suggest that some of the nuclei were lost via 
apoptosis. Nevertheless, much less is known about the predominately fast fiber containing plantaris muscle, where muscle mass losses are less severe as a result of aging and unloading $(10,12,16,26)$.

The degree of apoptosis depends on the balance between the activation of pro- and antiapoptotic genes. In general, shifts in this balance toward increasing pro-apoptotic genes are believed to promote muscle atrophy (27). Pro-apoptotic markers involved in the mitochondrialassociated apoptotic pathway in skeletal muscle can take part in a caspase-dependent or a caspase-independent pathway. The caspase-dependent pathway is initiated by the release of cytochrome-c from the mitochondrial intermembrane space which then forms a complex with apoptotic protease activating factor-1 (Apaf-1), dATP, and pro-caspase-9 (27-29), leading to the activation of caspase- 9 and other downstream caspases. In contrast, the caspase-independent pathway involves apoptosis inducing factor (AIF), which can translocate to the nucleus and initiate chromatin condensation and DNA fragmentation $(30,31)$. The release of these proapoptotic molecules is controlled by the BCL-2 family of proteins, with Bax and Bak promoting apoptosis and Bcl-2 inhibiting apoptosis (27). We have recently proposed a role for inhibitor of differentiation (Id) repressors in skeletal muscle apoptosis and sarcopenia (32). Id levels are correlated with muscle wasting (33), and we and others have shown increases in markers of apoptosis in muscles of aged animals $(32,34,35)$. Because we have found high levels of inhibitor of differentiation protein-2 (Id2) in the atrophic muscles of aged rodents $(32,33)$, we were interested in determining if Id2 might be involved in general pathways leading to apoptosis in muscle during periods of unloading, especially in aged animals.

The biochemical signals regulating apoptosis during aging and unloading, especially in fast skeletal muscles, have not been well studied. Therefore, in the current study we examined 
Id 2 and molecular markers of apoptosis in experimentally unloaded muscles of young adult and aged Fischer 344 x Brown Norway (FBN) rats, to determine if these conditions influence the degree of muscle atrophy via apoptotic pathways. We hypothesized that plantaris muscles from aged animals would exhibit increases in markers for apoptosis and that these changes would be exacerbated following HS. We therefore tested the hypothesis that plantaris muscles from young adult rats would not have marked elevations in mRNA levels for Id2 and pro-apoptotic genes, whereas, muscles from aged rats would have increased mRNA levels of Id 2 and pro-apoptotic genes that would be further altered following hindlimb unloading.

\section{METHODS}

Animal care and HS. All procedures followed the guidelines of the National Institutes of Health, and were approved by the Institutional Animal Care and Use Committee of the West Virginia University School of Medicine. Sixteen young adult (9 mo) and sixteen senescent (33 mo) male Fischer $344 \times$ Brown Norway rats were obtained from the National Institute on Aging barrier-raised colony that is housed at Harlan Animal Colonies (Indianapolis, IN). The animals were housed at $20-22^{\circ} \mathrm{C}$ in barrier-controlled conditions under a $12: 12$-h light-dark cycle. They were provided rat chow and water ad libitum.

The rats in each age group were randomly assigned to a hindlimb suspension (HS) group $(n=8)$ or a control group $(n=8)$. The HS animals were unloaded using the methods described previously (17) with modifications. Briefly, an adhesive (tincture of benzoin) was applied to the tail and allowed to dry. Orthopedic tape was applied along the proximal one-third of the tail, which distributed the load evenly and avoided excessive tension on a small area. The tape was placed through a wire harness that was attached to a fish line swivel at the top of a specially designed hindlimb suspension cage. This provided the rats with $360^{\circ}$ of movement around the 
cage. Sterile gauze was wrapped around the orthopedic tape and was subsequently covered with a thermoplastic material, which formed a hardened cast (Vet-Lite, Veterinary Specialty Products, Boca Raton, FL). The exposed tip of the tail remained pink, indicating that HS did not interfere with blood flow to the tail. The suspension height was monitored daily and adjusted to prevent the hindlimbs from touching any supportive surface, with care taken to maintain a suspension angle of approximately $30^{\circ}$ (17). The forelimbs maintained contact with a grid floor, which allowed the animals to move, groom themselves, and obtain food and water freely. Hindlimb suspension was maintained for a total of 14 days. Control rats maintained normal mobility and they moved unconstrained around their cages. Following 14 days of HS, rats were sacrificed with an overdose of xylazine and the plantaris muscles from the hindlimb were excised.

RT-PCR Estimates of mRNA. Semi-quantitative RT-PCR analysis was conducted as described in detail elsewhere (25). Frozen muscle samples $(\sim 50 \mathrm{mg})$ were homogenized in $1 \mathrm{ml}$ of TriReagent (Molecular Research Center, Cincinnati, OH) with a mechanical homogenizer. Total RNA was isolated by centrifugation and washed in ethanol according to the manufacturer's instructions. RNA was solubilized in $20 \mu \mathrm{l}$ of RNase-free $\mathrm{H}_{2} \mathrm{O}$. RNA was treated with Dnase I (Ambion, Austin TX) and reverse transcribed (RT) with random primers (Invitrogen/Life Technologies, Bethesda MD).

Primers were constructed from published sequences (Table 1). Primer pairs for the gene of interest were co-amplified with $18 \mathrm{~S}$ primer pairs and competimers to the $18 \mathrm{~S}$ primers, as an internal control, according to the manufacture's protocols (Ambion, TX). The number of PCR cycles was determined for each gene to insure analyses were done in the linear range of amplification. The signal from the gene of interest was expressed as a ratio to the $18 \mathrm{~S}$ signal 
from the same PCR product in order to eliminate any loading errors. The cDNA from all muscle samples were amplified simultaneously for a given gene. Following amplification, $20 \mu$ of each reaction was electrophoresed on $1.5 \%$ agarose gels. Gels were stained with ethidium bromide. PCR signals were captured with a digital camera (Kodak 290) and the signals were quantified in arbitrary units as optical density $\mathrm{x}$ band area, using Kodak image analysis software (Eastman Kodak Company, Rochester, NY).

Protein measures. Frozen muscle samples were used to obtain cytoplasmic protein to be used in western-blots. Muscle samples, approximately 50-75 mg, were homogenized in $1 \mathrm{ml}$ ice-cold lysis buffer $(10 \mathrm{mM} \mathrm{NaCl}, 1.5 \mathrm{mM} \mathrm{MgCl} 2,20 \mathrm{mM}$ HEPES at $\mathrm{pH} 7.4,20 \%$ glycerol, $0.1 \%$ Triton $\mathrm{X}-100$, and $1 \mathrm{mM}$ dithioreitol) to obtain cytoplasmic protein extracts according to the methods of Rothermel et al (36). Muscle homogenates were centrifuged at 3,000 rpm for 5-minutes at $4^{\circ} \mathrm{C}$. The supernatants were collected that contained the cytoplasmic protein fraction. The protein concentration of the total muscle homogenate was assayed spectrophotometrically at $562 \mathrm{~nm}$ (BioRad, SmartSpec 3000) ${ }^{\text {using }}$ a commercial bicinchoninic acid (BCA) method as recommended by the manufacturer (Pierce, Rockford, IL) with bovine serum albumin used as standards. Fifty micrograms of cytoplasmic protein was loaded into each lane of a $12 \%$ polyacrylamide gel and separated by routine SDS-polyacrylamide gel electrophoresis (PAGE) for 1.5 hours at $20^{\circ} \mathrm{C}$. Separated proteins were transferred to nitrocellulose membranes and verification of equivalent protein loading and transfer was verified by Ponceau S red (Sigma). The membranes were blocked at room temperature for $1 \mathrm{~h}$ in $5 \%$ non-fat milk (NFM) in tris-buffered saline containing 0.05\% Tween (TBS-T). Membranes were probed with anti-Bcl-2 mouse monoclonal antibody (1:200 dilution, sc-7382; Santa Cruz Biotechnology), and anti-Bax rabbit polyclonal antibody 
(1:200 dilution, sc-6236; Santa Cruz Biotechnology) diluted in TBS-T with 2\% NFM.

Secondary antibodies were conjugated to horseradish peroxidase (HRP; Chemicon) and signals were developed using a chemiluminescent substrate (ECL Advanced, Amersham Biosciences, Germany). Signals were visualized by exposing the membranes to X-ray films (BioMax MS-1; Eastman Kodak). Digital records were captured by a Kodak 290 camera and protein bands were quantified using 1-D imager analysis software (Eastman Kodak). Bands were quantified as optical density (OD) X band area and expressed as arbitrary units.

Cell death ELISA and calculation of apoptotic index. Cytoplasmic protein extracts were used to quantify DNA fragmentation in all muscle samples using a commercially available ELISA kit (Cell Death Detection ELISA, Roche Diagnostics, Mannheim, Germany). Briefly, the wells of a 96-well plate were coated with a primary anti-histone mouse monoclonal antibody. Following the addition of $100 \mu 1$ of each sample, a secondary anti-DNA mouse monoclonal antibody coupled to peroxidase was added to each well. The substrate, 2,2'-azino-di-(3ethylbenzthiazoline sulfonate) (ABST) was used to photometrically determine the amount of peroxidase retained in the immunocomplex. The color change of each well was determined at a wavelength of $405 \mathrm{~nm}$ using a Dynex MRX plate reader and computer software (Revelation, Dynatech Laboratories, CA). The resulting OD was normalized to the protein concentration of each sample and recorded as the apoptotic index $\left(\mathrm{OD}_{405} \cdot \mathrm{mg}\right.$ protein $\left.{ }^{-1}\right)$.

In situ TdT-Mediated dUTP Nick End Labeling (TUNEL). Apoptotic nuclei of myogenic origin were assessed using a fluorometric TdT-mediated dUTP nick end labeling (TUNEL) detection kit according to the manufacture's instructions (Roche Applied Science, Indianapolis, 
IN). Frozen 10- $\mu \mathrm{m}$-thick muscle cross-sections of the medial gastrocnemius muscle from control young and aged rats were cut in a cryostat at $-22^{\circ}$ and placed on the same glass slide to control for differences in tissue processing. Muscle characteristics and apoptotic data from the medial gastrocnemius muscle have been described previously(25). Slides were air dried, fixed in $4 \%$ paraformaldehyde in PBS at room temperature, permeabilized in $0.2 \%$ Triton X-100 in $0.1 \%$ sodium citrate at $4^{\circ} \mathrm{C}$ for 2-minutes, and incubated in TUNEL reaction mixture in a humidified chamber at $37^{\circ} \mathrm{C}$ for $1 \mathrm{~h}$ in the dark. Negative control experiments were performed in which the TdT enzyme was not added to the TUNEL reaction mixture. Sections were then incubated in an anti-laminin mouse monoclonal antibody followed by an anti-mouse IgG Cy3 conjugate $\mathrm{F}\left(\mathrm{ab}^{\prime}\right) 2$ fragment incubation (1:200 dilution, C2182, Sigma). Sections were mounted with 4',6diamidino-2-phenylindole (DAPI) mounting medium (Vectashield mounting medium, Vector Laboratories). Images were visualized under a fluorescent microscope at an objective magnification of $40 \mathrm{X}$ and at the following excitation wavelengths: $330-380 \mathrm{~nm}$ for DAPI blue fluorescence, $450-490 \mathrm{~nm}$ for green fluorescence, and 485-585nm for Cy3 red fluorescence. Images were obtained using a SPOT RT camera (Diagnostic Instruments, Sterling Heights, MI) and SPOT RT software (Universal Imaging, Downingtown, PA) was used to superimpose the images.

Immunofluorescent Staining. Frozen $10-\mu \mathrm{m}$-think muscle cross-sections of the medial gastrocnemius muscle from control young and aged rats were cut in a cryostat at $-22^{\circ}$ and placed on the same glass slide to control for differences in tissue processing. Slides were air dried at room temperature and fixed in ice-cold acetone:methanol (50:50), permeabilized in $0.2 \%$ Triton $\mathrm{X}-100$ in $0.1 \%$ sodium citrate at $4^{\circ} \mathrm{C}$ for 5 -minutes, and blocked in $1.5 \%$ normal goat serum at 
room temperature for 15-minutes in a humidified chamber. A double-label protocol was utilized to visualize pro-apoptotic Bax protein as well as the basal lamina of individual muscle fibers. After washing in PBS, sections were incubated in an anti-Bax rabbit polyclonal antibody (1:20 dilution, SC-, Santa Cruz Biotechnology) followed by addition of an anti-rabbit fluorescent antibody. The tissue sections were washed in PBS and then incubated in anti-laminin mouse monoclonal antibody (2E8, Hybridoma Bank, IA) followed by an anti-mouse IgG Cy3 conjugate F(ab')2 fragment incubation (1:200 dilution, C2182, Sigma). Sections were mounted with 4',6diamidino-2-phenylindole (DAPI) mounting medium (Vectashield mounting medium, Vector Laboratories). Images were visualized under a Nikon SE800 fluorescent microscope at an objective magnification of $40 \mathrm{X}$ and at the following excitation wavelengths: $330-380 \mathrm{~nm}$ for DAPI blue fluorescence, 450-490nm for green fluorescence, and 485-585nm for Cy3 red fluorescence. Images were obtained using a SPOT RT camera (Diagnostic Instruments, Sterling Heights, MI) and SPOT RT software (Universal Imaging, Downingtown, PA) was used to merge all images.

Statistical analysis. Statistical analyses were performed using the SPSS software package, version 10.0. Data were examined using a two-way ANOVA to analyze the main effects of age and unloading and the age $x$ unloading interaction with significance set at $p<0.05$. Group differences were examined using a one-way ANOVA and Tukey's post-hoc test. Data are presented as MEANS $\pm \mathrm{SE}$. Relationships between given variables were examined by computing the Pearson correlation coefficient. 


\section{RESULTS}

Body weight. Body weight was greater in aged rats compared with young adult rats (aged control, $539 \pm 16 \mathrm{~g}$; young adult control, $374 \pm 25 \mathrm{~g}$ ). Two weeks of HS significantly reduced body weights by $21 \%$ and $15 \%$ in young adult rats $(295 \pm 13)$ and in aged rats $(457 \pm 11 \mathrm{~g})$, respectively.

Muscle characteristics. In aged rats, the absolute plantaris muscle wet weight was $22 \%$ less when compared to young adult rats (Figure 1A). When muscles were normalized to bodyweight, plantaris muscles from aged rats were $47 \%$ less than muscles from young adult rats, suggesting a preferential loss of muscle mass with aging (Figure 1B). Following 2-weeks of HS, the absolute wet weight of plantaris muscles from young adult rats was $20 \%$ lower than young adult control rats. In contrast, 2-weeks of HS had no effect on the absolute wet weight of plantaris muscles from aged rats, when compared to aged controls (Figure 1A). Muscle protein content was $29 \%$ less in aged plantaris muscles compared to young adult plantaris muscles, suggesting increases in protein degradation and/or decreases in protein synthesis as a result of advanced age. Two weeks of HS did not significantly affect muscle protein content in the plantaris muscles in either young adult or aged rats (Figure 1C).

Apoptotic Index and Fluorescent TUNEL Assay. The cell death ELISA assay showed a greater apoptotic index $(600 \%)$ in plantaris muscles from aged rats when compared to young adult rats. Following 2-weeks of HS, the apoptotic index was $200 \%$ greater in plantaris muscles from young adult rats compared to muscles from young adult control rats. In contrast, 2-weeks of HS did not affect the apoptotic index in aged plantaris muscles, when compared to aged 
control muscles (Figure 2A). Fluorescent images demonstrated the presence of apoptotic TUNEL-positive nuclei under the basal lamina in aged muscles, while young adult muscles showed very few TUNEL-positive nuclei (Figure 2B and 2C).

mRNA and protein alterations in the BCL-2 family markers. In the current study, the mRNA and protein contents of Bax and Bcl-2 were measured as markers promoting and attenuating apoptosis, respectively (Figure 3). As a result of aging, Bax mRNA and protein content, and Bcl-2 protein content were greater in aged plantaris muscles when compared to young adult control muscles. Following 2-weeks of HS, Bax mRNA was $120 \%$ and 25\% greater in young adult and aged plantaris muscles, respectively (Figure 3A). Bcl-2 mRNA and protein content were $44 \%$ less and $200 \%$ greater in young adult plantaris muscles following HS and $61 \%$ and $110 \%$ greater in aged plantaris muscles following HS (Figure 3C and 3D). Fluorescent images also demonstrated intense cytoplasmic staining for pro-apoptotic Bax protein in muscle fibers from aged animals, while staining was very faint and often not detectable in fibers from young adult muscles (Figure 4A and 4B).

mRNA alterations of apoptotic genes. Specific pro-apoptotic markers involved in the mitochondrial-associated apoptotic pathway were examined for their contribution to changes observed in young and aged plantaris muscles (Figure 5). As a result of aging, Id2 mRNA was $100 \%$ greater in aged plantaris muscles when compared to young adult control muscles. When normalized to control muscles, Id 2 mRNA was unchanged in young adult plantaris muscles following HS, but was $110 \%$ greater in aged plantaris muscles following HS compared to aged control muscle (Figure 5A). Following 2-weeks of HS, AIF mRNA was greater in young adult 
and aged plantaris muscles, compared to control muscles (Figure 5B). The pro-apoptotic marker, Apaf-1 was 120\% greater in aged plantaris muscles following HS (Figure 5C). Caspase-9 mRNA was not affected by 2-weeks of HS in young adult or aged muscles (Figure 5D).

Relationships between markers of apoptosis. The relationships of these apoptotic markers were analyzed by computing the Pearson correlation coefficient. Significant positive correlations were observed between $\operatorname{Id} 2$ and $\operatorname{Bax} \operatorname{mRNA}(\mathrm{r}=0.716, \mathrm{p}=0.002)$ (Figure 6A), and Id 2 and caspase-9 mRNA $(r=0.500, p=0.049)$ (Figure 6B).

\section{DISCUSSION}

The aging process is associated with a reduction in muscle mass and strength (sarcopenia) (1-5) which can be exacerbated with reduced activity patterns $(6-8,14)$. In this study, we sought to determine if apoptosis contributed to the muscle atrophy observed in fast fiber containing muscles as a result of aging, and if reduced activity (HS) influenced these apoptotic changes. The present study demonstrates that muscle atrophy of the plantaris muscle is partly mediated by increases in the presence of apoptosis in muscles from aged rats, and that inactivity can exacerbate the alterations in some of the markers examined, specifically Id 2 and Apaf-1. Further, young adult plantaris muscles show elevations in the mitochondrial apoptotic pathway following HS, and these changes are similar to those observed in aged control plantaris muscles. To our surprise, superimposing HS with aging did not stimulate further losses of muscle mass in the plantaris muscle, as has been shown previously in the soleus muscle (24) and the medial gastrocnemius muscle (25). These results in the fast fiber plantaris muscle warrant 
further investigation, as muscle loss via unloading and via sarcopenia involve differing processes that may affect the degree of atrophy observed.

Apoptotic pathways contribute to sarcopenia. This study attempted to simulate sarcopenia and hypokinesia that is commonly observed in elderly humans by using a rodent model of unloading in young adult and aged animals. The contribution of apoptotic processes to the myonuclear and myofiber loss observed with aging is actively being investigated and still remains to be fully elucidated. This study provides evidence that aging-related muscle loss is associated with an increase in pro-apoptotic processes. The main effect of aging on muscle atrophy $(\mathrm{p}<0.001)$ and the incidence of apoptosis $(\mathrm{p}<0.001)$ were both highly significant, as the aged control plantaris muscles were less than young control muscles when expressed either as absolute muscle weight (22\%) or normalized to body weight (47\%) and the apoptotic index was $500 \%$ greater in aged plantaris muscles. Apoptotic nuclei, identified through TUNEL staining, were also visualized under the basal lamina indicating significant nuclear apoptosis in aged skeletal muscle. These data support previous findings of elevated apoptosis in the predominately slow-fiber containing soleus muscle (24) and the mixed fiber containing gastrocnemius muscle (25) with aging, and suggest that an apoptotic program is conserved across muscles of differing fiber type and activity patterns.

Although the role of apoptosis in mature skeletal muscle remains poorly understood, it has been suggested that aged skeletal muscle has a greater potential to undergo apoptotic processes (24). Leeuwenburgh et al. (24) demonstrated specific elevations of EndoG, a caspaseindependent marker, in aged soleus muscles. In the present study, the basal levels of proapoptotic Bax mRNA and protein in aged plantaris muscles was more than double that of young 
adult plantaris muscles, supporting previous findings from our laboratory in the medial gastrocnemius muscle (25). Additionally, fluorescent images revealed a widespread cytoplasmic localization of Bax protein in aged skeletal muscle, compared to young muscle. These increases in pro-apoptotic markers within aged skeletal muscle could potentially enhance muscle loss following a further apoptotic stimulus. Interestingly, aged skeletal muscle also seems to undergo adaptations to counteract this increased apoptotic potential by upregulating anti-apoptotic proteins, such as Bcl-2. Although this attempt is largely overruled, it highlights the differences inherent in aged skeletal muscle when compared to young adult.

Differences in unloading-induced apoptosis with age. The results of this study show that in response to unloading, aged plantaris muscles induce a molecular program favoring apoptosis that differs from young adult plantaris muscle. Aged plantaris muscles initiated an up-regulation of Apaf-1 mRNA in response to HS with no increases observed in the young tissue. Proapoptotic Bax mRNA and protein were increased to a greater extent in plantaris muscles from young adult rats following HS, when compared to aged rats. However, this effect was due to a greater basal level of Bax in the aged control plantaris muscle. Thus, an increase in apoptosis via the caspase-dependent pathway and that components of the mitochondrial-associated apoptotic pathway are regulated at the pre-translational level differently with age. An interesting finding of this study was the increase in anti-apoptotic Bcl-2 mRNA and protein in the aged plantaris muscle following HS, supporting previous findings in our laboratory in the medial gastrocnemius muscle (25) and when using an avian model of unloading (37). Bcl-2, a member of the BCL-2 family, opposes mitochondrial-mediated apoptosis by inhibiting cytochrome c release from the mitochondria (27). Young adult plantaris muscle showed a reduced expression of Bcl-2 mRNA 
following unloading, suggestive of a pro-apoptotic environment. However, Bcl-2 mRNA and protein were $61 \%$ and $100 \%$ greater in aged plantaris muscles, respectively, following HS when compared to aged control muscles. This response is suggestive of an adaptation in aged skeletal muscle at the molecular level, possibly as an attempt to counteract unloading induced apoptosis.

The lack of muscle atrophy in the aged plantaris muscle following HS was surprising and warrants further investigation. Although these data conflict with previous data from our lab (10, 12), they are consistent with data published by Thompson et al (14). Following 1-week of HS in 30-month old FBN rats, Thompson and colleagues (14) reported non-significant reductions in both absolute and relative plantaris muscle mass. Animal to animal variability, environmental disturbances, and differences in unloading techniques could potentially alter the physiological response to HS (16). The $22 \%$ lower muscle weight in control muscles of the old rats in our current study as compared to the young adult rats represented sarcopenia, rather than any change over the 14 days of the study. The loss in muscle due to HS was not statistically significant ($12 \%)$ in the aged rats but the HS-induced muscle loss was significant (-20\%) in the plantaris of young adult rats. These HS-associated losses in muscle mass represent "real" losses of muscle, rather than a failure to grow during 14 days of the experimental manipulation. We base these conclusions on observations made in another pilot study (unpublished data) in rats that were 6 months and 33 months of age. In this cohort, bodyweight increased by $6.3 \pm 1.3 \%$ and $-0.8 \pm 0.2$ $\%$ over 14 days in caged control young adult and old rats, respectively. In this pilot study we found that plantaris muscle weight did not change (increase of 1.6\%) in young adult rats (6 mo of age) confined to their cages for 14 days as compared to rats that were sacrificed 14 days earlier (i.e. at day 0). We would not expect that the 9 mo old rats in our current study would grow more rapidly than 6 mo old rats evaluated in this pilot study, so it is unlikely that 
significant muscle growth occurred in the 9 mo old rats used in the present study over the 14 days of the study. In a similar pattern, the plantaris wet weight of aged animals (33 mo of age) was not different in animals sacrificed at day $0(n=4)$ from those sacrificed after 14 days $(n=4)$ of caged activity (-0.4\% decrease).

Although we cannot rule out the possibility that a small reduction in the muscle mass of HS vs. control animals was due to suppressed growth over 14 days, our data would suggest that this possibility is insufficient to explain our data. We make this conclusion because: (i) our pilot data show that the oldest animals do not grow significantly over 14 days (i.e., no muscle or body weight increases), and (ii) the increases in the muscle weight of the youngest animals in our pilot study were likely very modest and well below the $20 \%$ decrease in muscle mass due to HS in the young rats in the current study. Furthermore, our current data support the idea that muscle loss was due in part from increasing apoptotic signaling because there would be no reason to anticipate elevated apoptosis during a time of muscle growth. In fact, we have recently shown evidence that pro-apoptotic signaling decreases during periods of rapid muscle growth induced by overload $(38,39)$. Thus, we interpret the data from our current study to indicate that HS induced "true" losses in muscle mass and not just a suppression of normal growth.

It was unexpected that the pro-apoptotic markers Apaf-1, AIF and Id2, were greater in the aged plantaris muscle following HS even though the apoptotic index was not elevated. We favor the explanation that the increase in pro-apoptotic markers results in an intracellular "environment" which is poised for apoptosis to occur, although this final step was not fully engaged during HS in aged plantaris muscles. One possible explanation for this discrepancy would be elevations in apoptotic inhibitor proteins, such as X-linked inhibitor of apoptosis protein (XIAP), which has been shown to increase to a greater extent in unloaded muscles of 
aged vs. young adult birds, presumably as a means to offset apoptosis (38). An alternate explanation is that some of these pro-apoptotic markers may not always induce apoptosis just because they are present. For example, in addition to the subsequent cleavage and activation of pro-caspase-9 upon apoptosome formation with Apaf-1, caspase- 9 can also be activated via an additional pathway independent of Apaf-1 in muscle cells (40, 41). Furthermore, Apaf-1 is dispensable for apoptosis induced by cytotoxic drugs or overexpression of the transcription factor, E2F1, in primary myoblasts but not fibroblasts, whereas caspase-9 is required in both cell types (40). Finally, although cytoplasmic but not nuclear localization of Id2 is linked to apoptosis (42), Id2 also increases during periods of loading (39), and is associated with activation of satellite cells (43) to stimulate the anti-apoptotic event of muscle hypertrophy. Further work is needed to determine if unloading in aging muscles results in changes in the levels, compartmentalization, localization or configuration of Id2 and/or other pro-apoptotic markers, which may result in these markers having anti-apoptotic effects and offsetting the proapoptotic environment imposed by aging.

Id2 and apoptosis. Id 2 is a negative regulator of basic helix-loop-helix proteins, including the myogenic regulatory factors MyoD and myogenin $(32,33)$. The Id proteins bind to and sequester E-proteins, inhibiting MRF binding and subsequent muscle-specific transcription. Data from our laboratory have led to the hypothesis of a dual role for Id2, based on the compartmentalization of Id2 within myocytes. In general, cytoplasmic Id2 appears to promote apoptotic processes and nuclear Id 2 promotes proliferation and inhibits apoptosis through interactions with genes specific to these processes $(32,42)$. 
Increases in mRNA and protein levels of the Id proteins correlate with aging associated muscle loss in the hindlimb muscles of aged rats $(32,33)$. Furthermore, Id 2 has been studied in a model of unloading following stretch-overload induced muscle hypertrophy (42). Cytoplasmic Id 2 protein levels were greater in young unloaded patagialis (PAT) muscles compared to contralateral control muscles. Additionally, these increases in Id 2 were positively correlated with other pro-apoptotic markers, such as Bax, AIF, p53 and the TUNEL index and negatively correlated with anti-apoptotic Bcl-2 (42). Thus, the subcellular partitioning of Id2 into the nucleus or the cytoplasm can lead to differential effects within skeletal muscle (42). Although these are correlational data and therefore do not show a cause-and-effect relationship between cytoplasmic Id2 and apoptosis, they do support previous data showing an association of Id2 and Bax associated apoptosis (44). Indeed, the changes in Id 2 mRNA observed in the current study were significantly correlated with changes in the pro-apoptotic markers Bax and caspase-9. These data add to the proposed ability of Id 2 to promote apoptosis during aging and unloading, possibly through the caspase-dependent pathway.

Summary. The results of the present study support the hypothesis that sarcopenia is associated with increases in markers of apoptosis and that nuclei of aged myocytes are susceptible to apoptosis. Additionally, we show that the fast plantaris muscles of aged rats responded differently to 2-weeks of HS when compared to young adult rats. Increases in Id2 mRNA were also noted in aged plantaris muscle following HS, supporting previous results $(32,33)$, with positive correlations observed between Id 2 and Bax and caspase-9. These results are consistent with the hypothesis that an increase in Id2 transcript levels, as observed with aging, may contribute to muscle mass losses in the aged plantaris muscle. In addition to these changes, an 
aging adaptation of skeletal muscle was identified in which anti-apoptotic Bcl-2 was upregulated during unloading. These changes highlight the inherent differences between young and aged skeletal muscle and provide further evidence that apoptotic mechanisms are distinct with aging.

\section{Acknowledgments}

The study was supported by NIH: National Institute on Aging Grant R01AG021530. 2E8 developed by Eva Engvall, Ph.D., La Jolla Cancer Research Foundation, La Jolla, CA was obtained from the Developmental Studies Hybridoma Bank developed under the auspices of the NICHD and maintained by the Department of Biological Sciences, The University of Iowa, Iowa City, IA 52242. 


\section{REFERENCES}

1. Alway, S. E., Coggan, A. R., Sproul, M. S., Abduljalil, A. M., and Robitaille, P. M. (1996) Muscle torque in young and older untrained and endurance-trained men. $J$ Gerontol 51, B195-B201

2. Daw, C. K., Starnes, J. W., and White, T. P. (1988) Muscle atrophy and hypoplasia with aging: impact of training and food restriction. J Appl Physiol 64

3. Degens, H., and Alway, S. E. (2003) Skeletal muscle function and hypertrophy are diminished at old age. Muscle Nerve 27, 339-347

4. Larsson, L., Grimby, G., and Karlsson, J. (1979) Muscle strength and speed of movement in relation to age and muscle morphology. J Appl Physiol 46, 451-456

5. Wickham, C., C., C., Margetts, B. M., and Barker, D. J. (1989) Muscle strength, activity, housing, and the risk of falls in elderly people. Age Ageing 18, 47-51

6. Stump, C. S., Tipton, C. M., and Henriksen, E. J. (1997) Muscle adaptations to hindlimb suspension in mature and old Fischer 344 rats. J Appl Physiol 82, 1875-1881

7. Alley, K. A., and Thompson, L. V. (1997) Influence of simulated bed rest and intermittent weight bearing on single skeletal muscle fiber function in aged rats. Arch Phys Med Rehabil 78, 19-25

8. Delp, M. D., Brown, M., Laughlin, M. H., and Hasser, E. M. (1995) Rat aortic vasoreactivity is altered by old age and hindlimb unloading. J Appl Physiol 78, 20792086

9. Thompson, L. V., and Brown, M. (1999) Age-related changes in contractile properties of single skeletal fibers from aged soleus muscle. J Appl Physiol 86, 881-886 
10. Chen, K. D., and Alway, S. E. (2000) A physiological level of clenbuterol does not prevent atrophy or loss of force in skeletal muscle of old rats. J Appl Physiol 89, 606-612

11. Allen, D. L., Linderman, J. K., Roy, R. R., Bigbee, A. J., Grindeland, R. E., Mukku, V., and Edgerton, V. R. (1997) Apoptosis: a mechanism contributing to remodeling of skeletal muscle in response to hindlimb unweighting. Am J Physiol 273, C579-C587

12. Alway, S. E., Lowe, D. A., and Chen, K. D. (2001) The effects of age and hindlimb suspension on the levels of expression of the myogenic regulatory factors MyoD and myogenin in rat fast and slow skeletal muscles. Exp Physiol 86, 509-517

13. Chen, K. D., and Alway, S. E. (2001) Clenbuterol reduces soleus muscle fatigue during disuse in aged rats. Muscle Nerve 24, 211-222

14. Thompson, L. V., Johnson, S. A., and Shoeman, J. A. (1998) Single soleus muscle fiber function after hindlimb unweighting in adult and aged rats. J Appl Physiol 84, 1937-1942

15. Thomason, D. B., and Booth, F. W. (1990) Atrophy of the soleus muscle by hindlimb suspension. J Appl Physiol 68, 1-12

16. Fitts, R. H., Metzger, J. M., Riley, D. A., and Unsworth, B. R. (1986) Models of disuse: a comparison of hindlimb suspension and immobilization. J Appl Physiol 60, 1946-1953

17. Morey-Holton, E. R., and Globus, R. K. (2001) Hindlimb unloading rodent model: technical aspects. J Appl Physiol 92, 1367-1377

18. Price, S. R., and Mitch, W. E. (1998) Mechanisms stimulating protein degradation to cause muscle atrophy. Curr Opin Clin Nutr Metab Care 1, 79-83

19. Zarzhevsky, N., Menashe, O., Carmeli, E., Stein, H., and Reznick, A. Z. (2001) Capacity for recovery and possible mechanisms in immobilization atrophy of young and old animals. Ann NY Acad Sci 928, 212-225 
20. McDonald, K. S., Blaser, C. A., and Fitts, R. H. (1994) Force-velocity and power characteristics of rat soleus muscle fibers after hindlimb suspension. J Appl Physiol 77, $1609-1616$

21. Allen, D. L., Roy, R. R., and Edgerton, V. R. (1999) Myonuclear domains in muscle adaptation and disease. Muscle Nerve 22, 1350-1360

22. Hikida, R. S., Van Nostran, S., Murray, J. D., Staron, R. S., Gordon, S. E., and Kraemer, W. J. (1997) Myonuclear loss in atrophied soleus muscle fibers. Anat Rec 247, 350-354

23. Fauteck, S. P., and Kandarian, S. C. (1995) Sensitive detection of myosin heavy chain composition in skeletal muscle under different loading conditions. Am J Physiol 268, C419-C424

24. Leeuwenburgh, C., Gurley, C. M., Strotman, B. A., and Dupont-Versteegden, E. E. (2005) Age-related differences in apoptosis with disuse atrophy in soleus muscle. Am J Physiol 288, R1288-R1296

25. Siu, P. M., Pistilli, E. E., and Alway, S. E. (2005) Apoptotic responses to hindlimb suspension in gastrocnemius muscles from young and aged rats. Am J Physiol 289, R1015-1026.

26. Ohira, Y., Yoshinaga, T., Nomura, T., Kawano, F., Ishihara, A., Nonaka, I., Roy, R. R., and Edgerton, V. R. (2002) Gravitational unloading effects on muscle fiber size, phenotype, and myonuclear number. Adv Space Res 30, 777-781

27. Adams, V., Gielen, S., Ham, b., R., and Schuler, G. (2001) Apoptosis in skeletal muscle. Frontiers Bioscience 6, 1-11 
28. Li, P., Nijhawan, D., Budihardjo, L., Srinivasula, S. M., Ahmad, M., Alnemri, E. S., and Wang, X. (1997) Cytochrome c and dATP-dependent formation of Apaf-1/caspase-9 complex initiates an apoptotic protease cascade. Cell 91, 479-489

29. Zou, H., Li, Y., Liu, X., and Wang, X. (1999) An Apaf-1-cytochrome c multimeric complex is a functional apoptosome that activates pro-caspase-9. J Bio Chem 274, 1154911556

30. Daugas, E., Nochy, D., Ravagnan, L., Loeffler, M., Susin, S. A., Zamzami, N., and Kroemer, G. (2000) Apoptosis-inducing factor (AIF): a ubiquitous mitochondrial oxidoreductase involved in apoptosis. FEBS Lett 476, 118-123

31. Susin, S. A., Zamzami, N., Castedo, M., Hirsch, T., Marchetti, P., Macho, A., Daugas, E., Geuskens, M., and Kroemer, G. (1996) Bcl-2 inhibits the mitochondrial release of an apoptogenic protease. J Exp Med 184, 1331-1341

32. Alway, S. E., Degens, H., Krishnamurthy, G., and Smith, C. A. (2002) Potential role for Id myogenic repressors in apoptosis and attenuation of hypertrophy in muscles of aged rats. Am J Physiol 283, C66-C76

33. Alway, S. E., Degens, H., Lowe, D. A., and Krishnamurthy, G. (2002) Increased myogenic repressor Id mRNA and protein levels in hindlimb muscles of aged rats. Am J Physiol 282, R411-R422

34. Dirks, A., and Leeuwenburgh, C. (2002) Apoptosis in skeletal muscle with aging. Am J Physiol 282, R519-R527

35. Pollack, M., Phaneuf, S., Dirks, A., and Leeuwenburgh, C. (2002) The role of apoptosis in the normal aging brain, skeletal muscle, and heart. Ann NY Acad Sci 959, 93-107 
36. Rothermel, B., Vega, R. B., Yang, J., Wu, H., Bassel-Duby, R., and Williams, R. S. (2000) A protein encoded within the Down syndrome critical region is enriched in striated muscles and inhibits calcineurin signaling. J Biol Chem 24, 8719-8725

37. Siu, P. M., Pistilli, E. E., Butler, D. C., and Alway, S. E. (2005) Aging influences cellular and molecular response of apoptosis to skeletal muscle unloading. Am J Physiol 288, C338-C349

38. Siu, P. M., Pistilli, E. E., Ryan, M. J., and Alway, S. E. (2005) Aging sustains the hypertrophy-associated elevation of apoptotic suppressor X-linked inhibitor of apoptosis protein (XIAP) in skeletal muscle during unloading. J Gerontol 60, 976-983

39. Siu, P. M., and Alway, S. E. (2005) Subcellular responses of p53 and Id2 in fast and slow skeletal muscle in response to stretch-induced overload. J Appl Physiol 99, 1897-904.

40. Ho, A. T., Li, Q. H., Hakem, R., Mak, T. W., and Zacksenhaus, E. (2004) Coupling of caspase-9 to Apaf-1 in response to loss of pRb or cytotoxic drugs is cell-type-specific. EMBO J 23, 460-472

41. Ho, A. T., and Zacksenhaus, E. (2004) Splitting the apoptosome. Cell Cycle 3, 446-448

42. Siu, P. M., and Alway, S. E. (2005) Id2 and p53 participate in apoptosis during unloading-induced muscle atrophy. Am J Physiol 288, C1058-C1073

43. Alway, S. E., Martyn, J. K., Ouyang, J., Chaudhrai, A., and Murlasits, Z. S. (2003) Id2 expression during apoptosis and satellite cell activation in unloaded and loaded quail skeletal muscles. Am J Physiol 284, R540-R549

44. Florio, M., Hernandez, M. C., Yang, H., Shu, H. K., Cleveland, J. L., and Isreal, M. A. (1998) Id2 promotes apoptosis by a novel mechanism independent of dimerization to basic helix-loop-helix factors. Mol Cell Biol 18, 5435-5444 
Figure 1
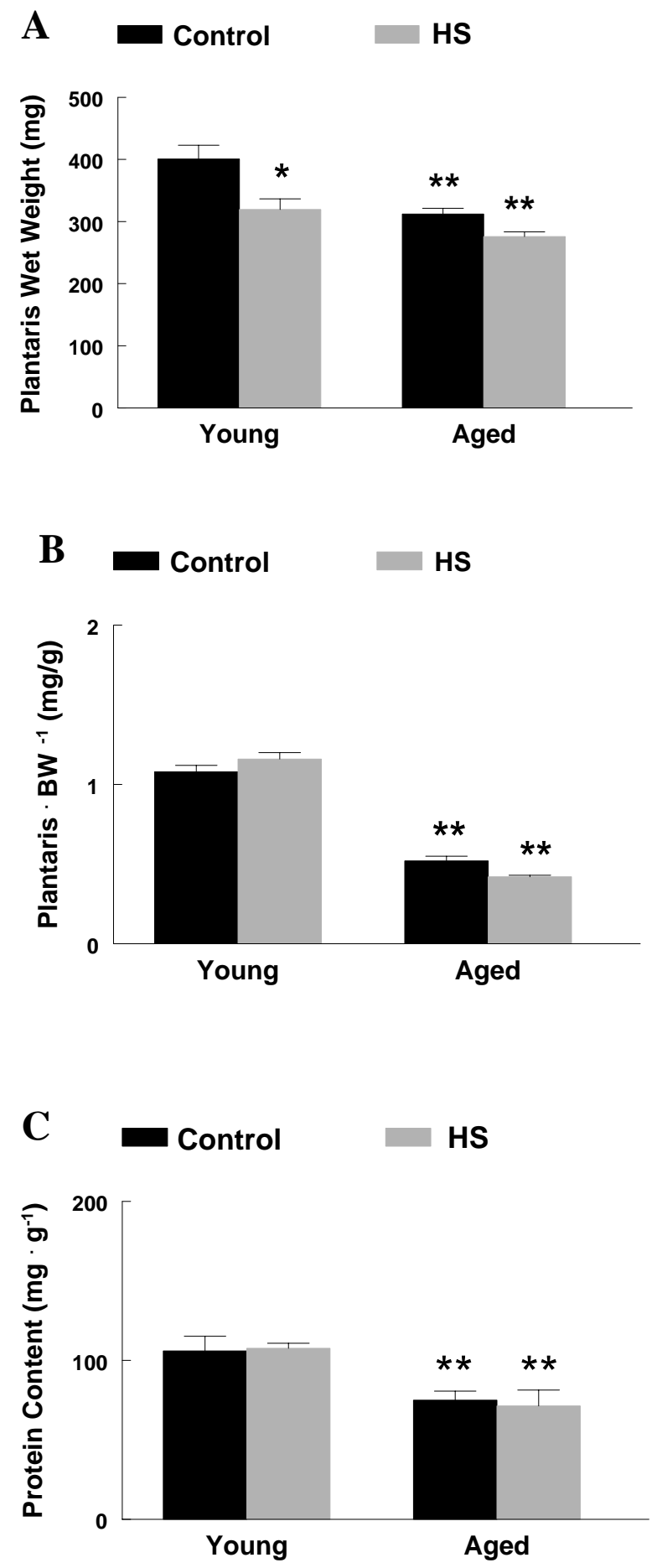
Legend for Figure 1. Plantaris muscle characteristics. A) Absolute plantaris muscle wet weight. Plantaris muscles from young and aged animals expressed as mg of tissue. B) Normalized plantaris muscle weight $\left(\mathrm{mg}^{\cdot} \mathbf{g}^{-\mathbf{1}}\right)$. Plantaris muscles from young and aged animals were normalized to the animal body weight in grams. C) Plantaris muscle protein content $\left(\mathbf{m g} \cdot \mathbf{g}^{\mathbf{- 1}}\right)$. Plantaris protein content was determined in young and aged plantaris muscles following HS. $* *$ Significant effect of aging $(\mathrm{p}<0.05)$. Data are presented as means \pm SE. 
Figure 2

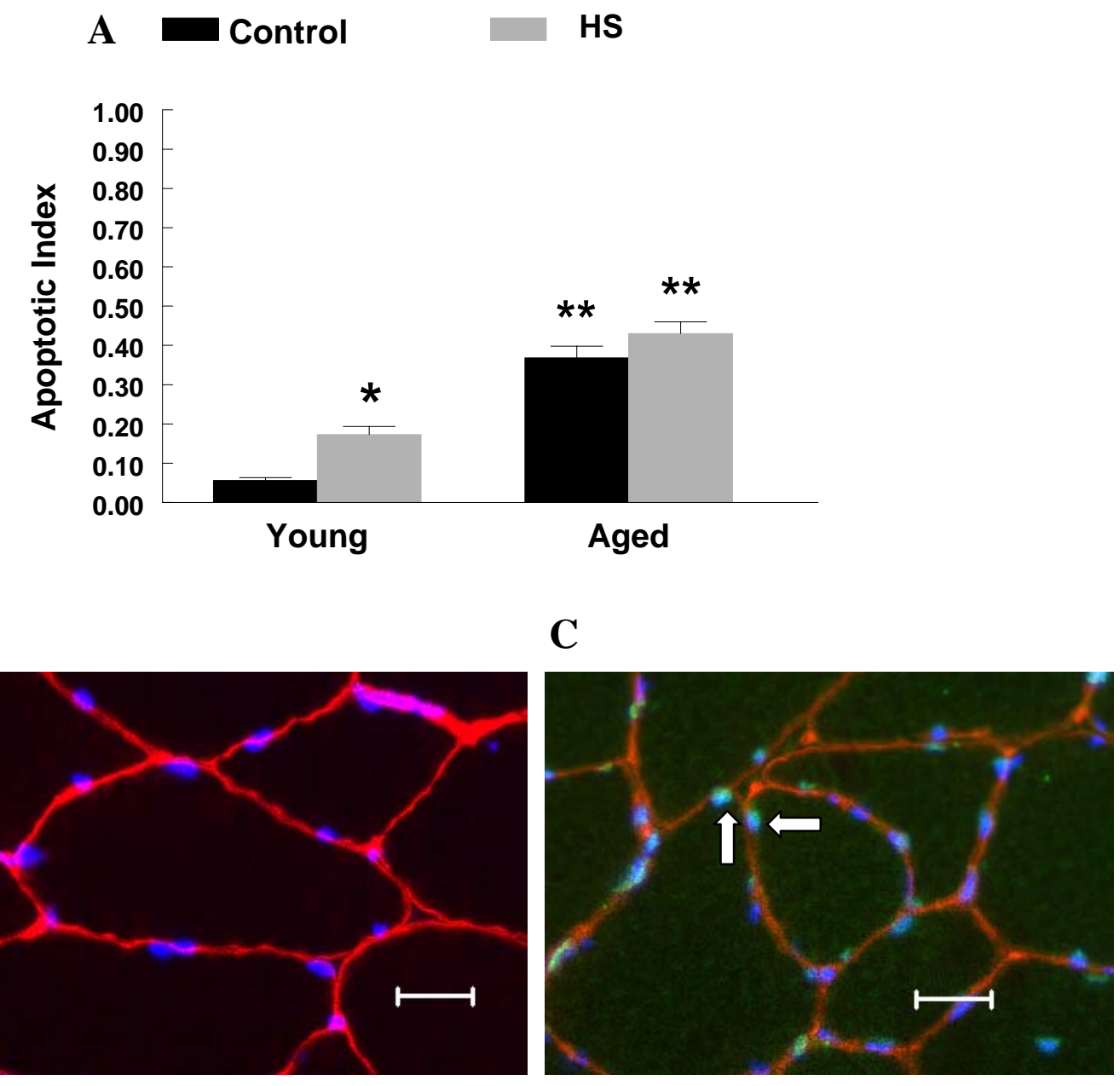




\section{Legend for Figure 2. Incidence of apoptosis. A) Apoptotic Index (OD405 ${ }^{\circ} \mathrm{mg} \mathrm{protein}^{-1}$ ).}

The extent of DNA fragmentation was assayed using a cell death ELISA kit. * Significant effect of HS $(p<0.05) . * *$ Significant effect of aging $(p<0.05)$. Data are presented as means \pm SE. B) Fluorescent TUNEL stain in young control muscle. TUNEL staining was utilized to determine the extent of nuclear apoptosis in gastrocnemius muscles from young animals. Muscle fiber borders were visualized using a rat laminin antibody and non-apoptotic nuclei were visualized using DAPI. The image was obtained at an objective magnification of 40X. Bar, $10 \mu \mathrm{m}$. C) Fluorescent TUNEL stain in aged control muscle. TUNEL staining was utilized to determine the extent of nuclear apoptosis in gastrocnemius muscles from old animals. Muscle fiber borders were visualized using a rat laminin antibody. All nuclei were stained with DAPI. Arrows highlight TUNEL positive nuclei. Non-apoptotic nuclei were TUNEL negative. The image was obtained at an objective magnification of $40 \mathrm{X}$. Bar, $10 \mu \mathrm{m}$. 
Figure 3
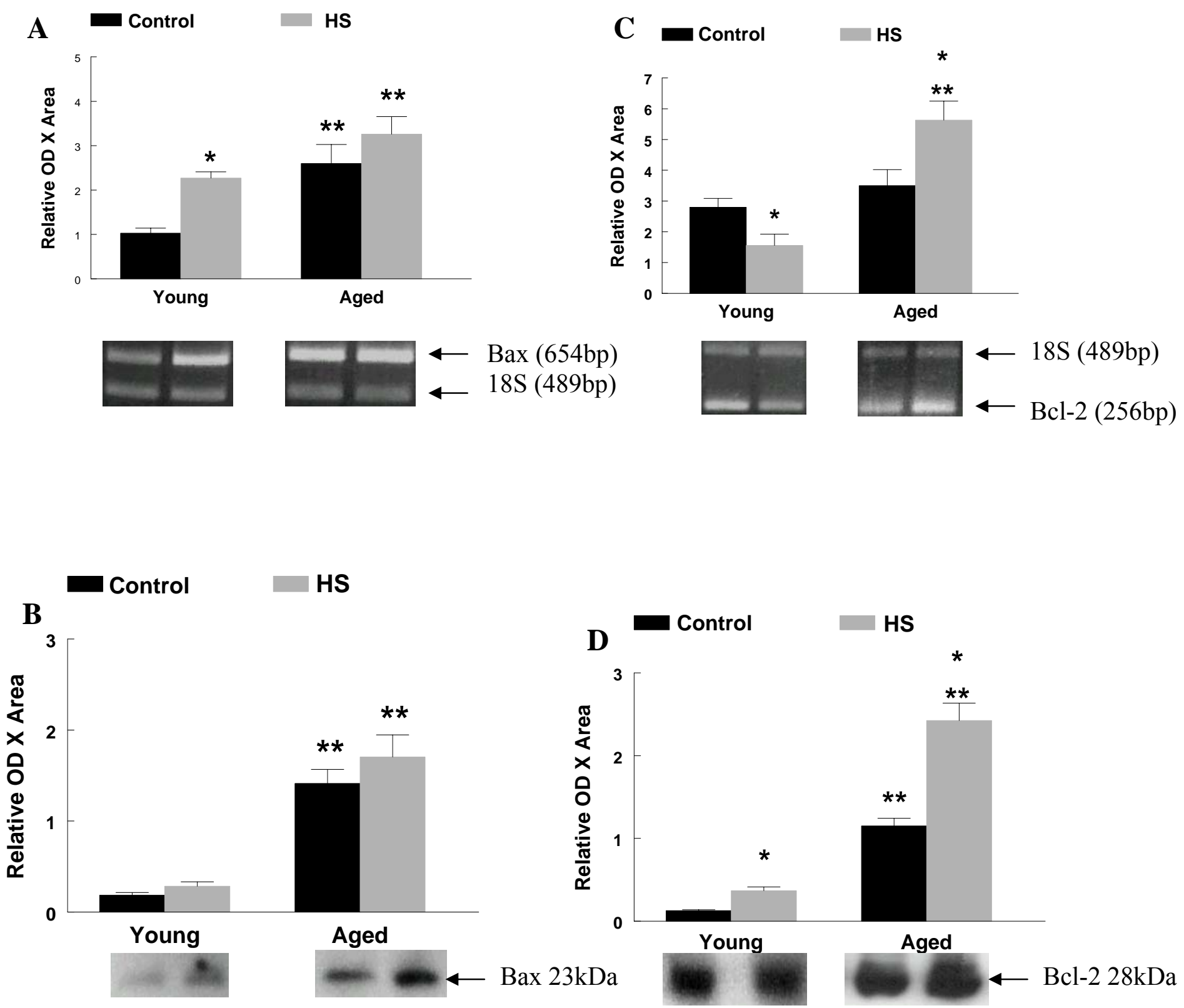
Legend for Figure 3. Bax and Bcl-2 mRNA and protein content. A) Bax mRNA. The mRNA content for pro-apoptotic Bax was determined by RT-PCR, with PCR products normalized to the $18 \mathrm{~S}$ gene. Representative agarose gel images following electrophoresis are displayed for each group. B) Bax protein content. The protein content of pro-apoptotic Bax was determined by western immunoblot. Representative blots following antibody incubation are displayed. C) Bcl-2 mRNA. The mRNA content for anti-apoptotic Bcl-2 was determined by RT-PCR, with PCR products normalized to the $18 \mathrm{~S}$ gene. Representative agarose gel images following electrophoresis are displayed for each group. D) Bcl-2 protein content. The protein content of anti-apoptotic Bcl-2 was determined by western immunoblot. Representative blots following antibody incubation are displayed. * Significant effect of $\mathrm{HS}(\mathrm{p}<0.05)$. ** Significant effect of aging $(\mathrm{p}<0.05)$. Data are presented as means \pm SE. 


\section{Figure 4}

A

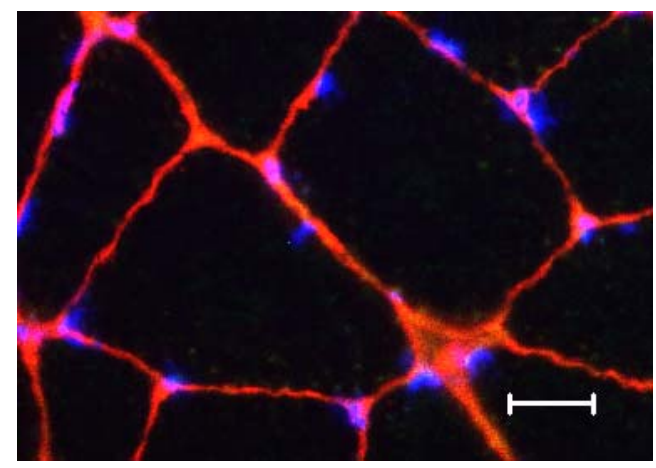

B

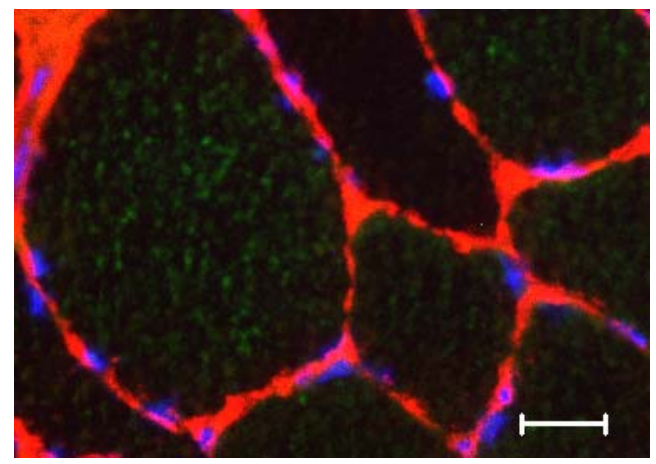

\section{Legend for Figure 4. Bax protein localization. A) Fluorescent image of Bax protein in} young control muscle. The extent of cytoplasmic Bax protein was determined using fluorescence microscopy. A faint Bax stain was visualized in gastrocnemius muscles from young animals. Muscle fiber borders were visualized using a rat laminin antibody and nonapoptotic nuclei were visualized using DAPI. The image was obtained at an objective

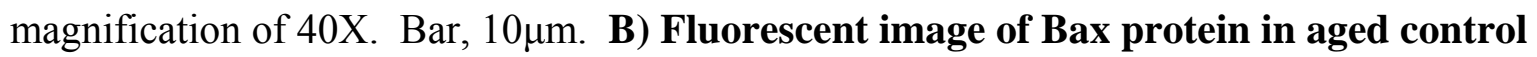
muscle. The extent of cytoplasmic Bax protein was determined using fluorescence microscopy. Bax protein was visualized throughout the cytoplasm of aged muscle fibers. Muscle fiber borders were visualized using a rat laminin antibody and non-apoptotic nuclei were visualized using DAPI. The image was obtained at an objective magnification of 40X. Bar, $10 \mu \mathrm{m}$. 
Figure 5
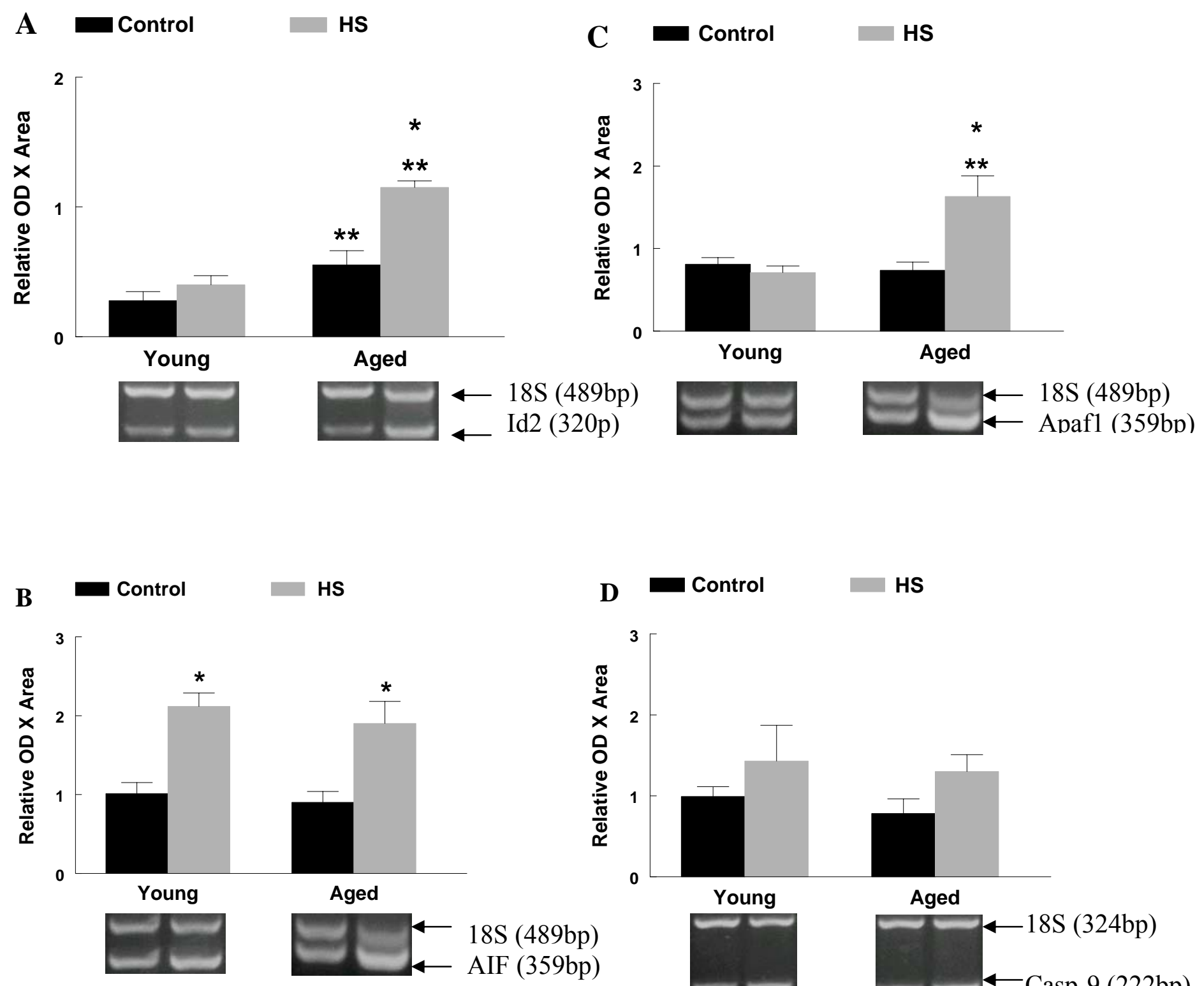

D Control HS

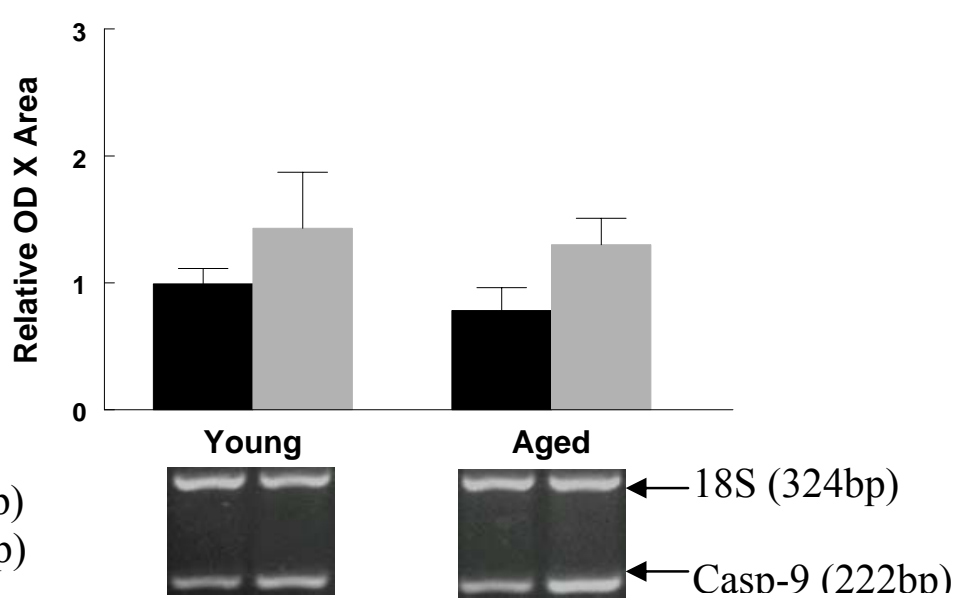


Legend for Figure 5. mRNA expression of selected apoptotic markers. A) Id2 mRNA. The mRNA content for Id2 was determined by RT-PCR, with PCR products normalized to the $18 \mathrm{~S}$ gene. Representative agarose gel images following electrophoresis are displayed for each group. B) AIF mRNA. The mRNA content for AIF was determined by RT-PCR, with PCR products normalized to the $18 \mathrm{~S}$ gene. Representative agarose gel images following electrophoresis are displayed for each group. C) Apaf-1 mRNA. The mRNA content for Apaf-1 was determined by RT-PCR, with PCR products normalized to the $18 \mathrm{~S}$ gene. Representative agarose gel images following electrophoresis are displayed for each group. D) Caspase-9 mRNA. The mRNA content for caspase-9 was determined by RT-PCR, with PCR products normalized to the $18 \mathrm{~S}$ gene. Representative agarose gel images following electrophoresis are displayed for each group. * Significant effect of HS $(\mathrm{p}<0.05)$. ** Significant effect of aging $(\mathrm{p}<0.05)$. Data are presented as means $\pm \mathrm{SE}$. 
Figure 6

A

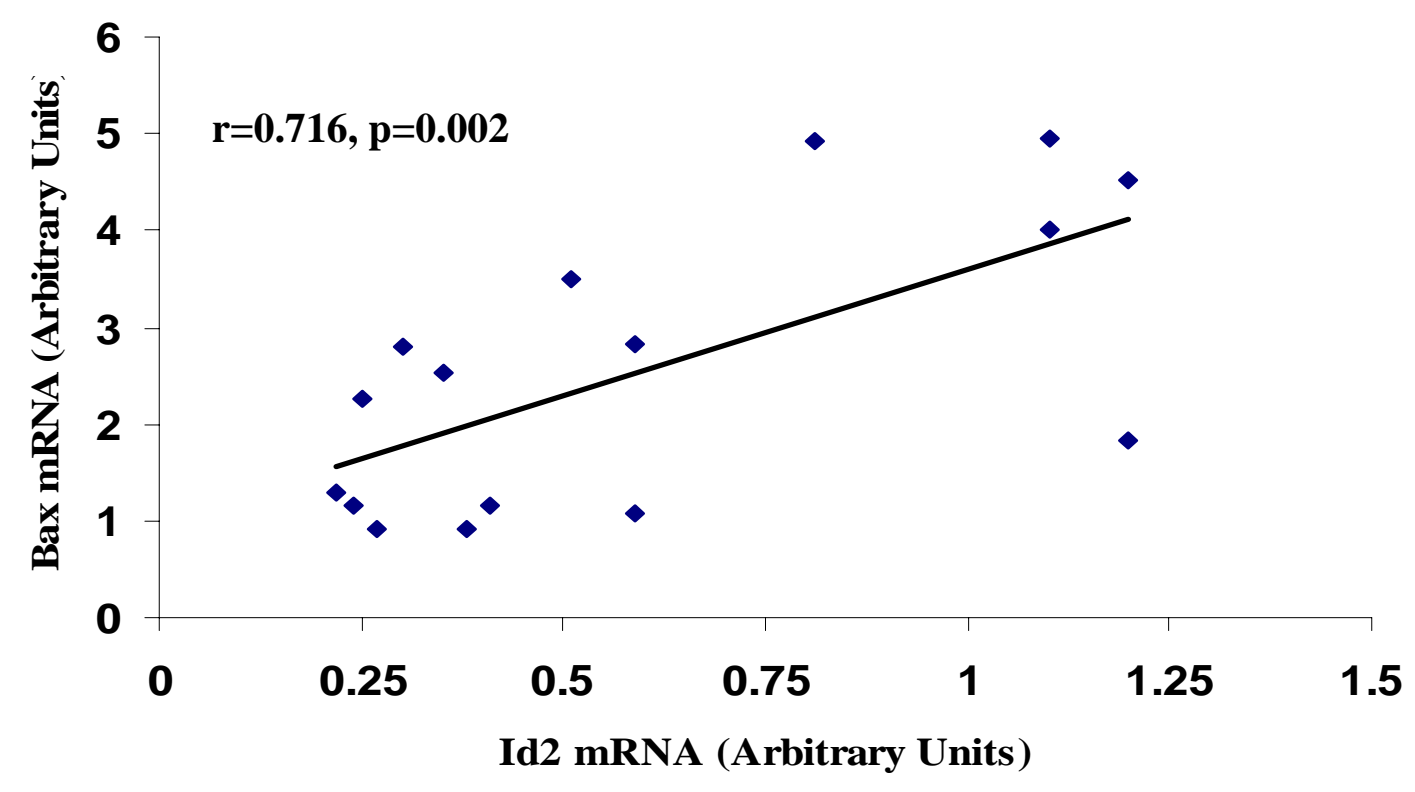

B

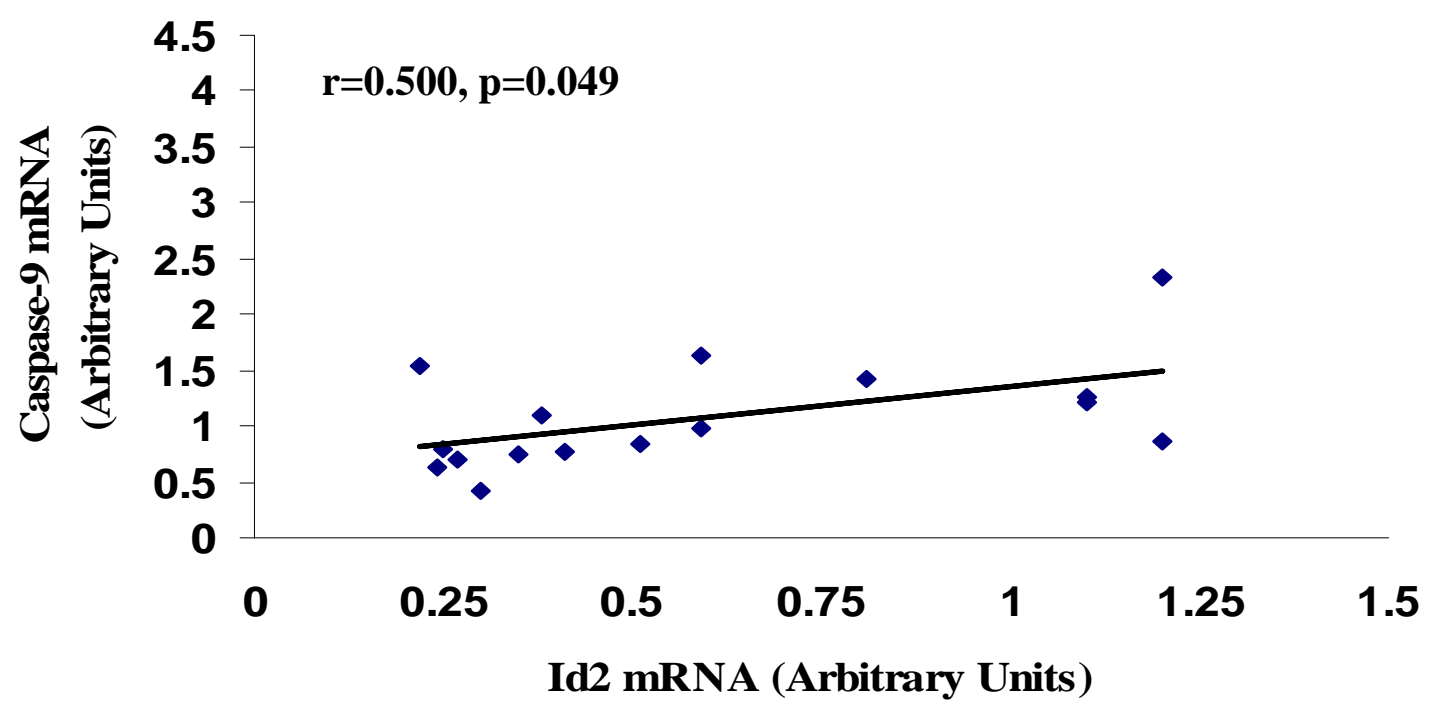


Legend for Figure 6. Correlational analyses. A) Correlational analysis of Bax and Id2

mRNA. The relationship between the changes in Bax mRNA and Id 2 mRNA were determined by calculating the Pearson correlation coefficient. B) Correlational analysis of Caspase-9 and Id2 mRNA. The relationship between the changes in Caspase-9 mRNA and Id2 mRNA were determined by calculating the Pearson correlation coefficient. 
Table 1. Primers used for PCR amplifications of cDNA

\begin{tabular}{|c|c|c|c|c|c|c|c|}
\hline Product & $\begin{array}{l}\text { Accession } \\
\text { No. }\end{array}$ & Sequence & Position & $\mathrm{T}_{\mathrm{A}}{ }^{\circ} \mathrm{C}$ & $\begin{array}{l}\text { PCR } \\
\text { Length } \\
\text { (bp) }\end{array}$ & $\begin{array}{l}\text { Restriction } \\
\text { Enzyme }\end{array}$ & $\begin{array}{l}\text { Restriction } \\
\text { Products } \\
\text { (bp) }\end{array}$ \\
\hline Id 2 & NM_013060 & $\begin{array}{l}\text { F: 5'-GAATTCTCAGCATGAAAGCTTTCAGCC-3' } \\
\text { R: 5'-CTCGAGATTCAGCCACAGAGCGCT-3' }\end{array}$ & $\begin{array}{l}365-385 \\
664-684\end{array}$ & 52.7 & 320 & AluI & 262,68 \\
\hline Apaf-1 & AF218388 & $\begin{array}{l}\text { F: 5'-CGGCCCTGCGCATCTGATTCAT-3' } \\
\text { R: 5'-GGGCGAACGACTAAGCGGGACAG-3' }\end{array}$ & $\begin{array}{l}1623-1644 \\
1888-1910\end{array}$ & 57.8 & 288 & AluI & 193,95 \\
\hline$\overline{\mathrm{AIF}}$ & AF375656 & $\begin{array}{l}\text { F: 5'-CCGGCTTCCAGGCAACTTGTTCC-3' } \\
\text { R: 5'-CCCGGATGGATCTAGCTGCTGCA-3' }\end{array}$ & $\begin{array}{l}93-115 \\
429-451\end{array}$ & 58.1 & 359 & KpnI & 290,69 \\
\hline Caspase 9 & NM_031632 & $\begin{array}{l}\text { F: 5'-GGCCGGTGGACATTGGTTCTGG-3' } \\
\text { R: 5'-CCATGAAGCGCAGCCAGCAGAA-3' }\end{array}$ & $\begin{array}{l}543-564 \\
743-764\end{array}$ & 60.1 & 222 & BamHI & 130,92 \\
\hline Bax & AF235993 & 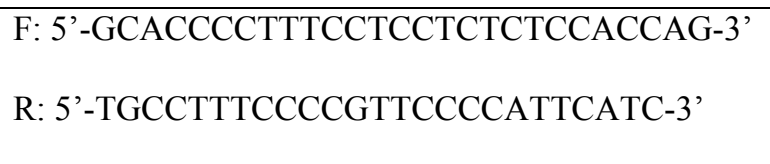 & $\begin{array}{l}462-488 \\
1091-1115\end{array}$ & 55 & 654 & $\begin{array}{l}\text { BamHI } \\
\text { BstXI }\end{array}$ & $\begin{array}{l}445,209 \\
521,133\end{array}$ \\
\hline Bcl-2 & U34964 & $\begin{array}{l}\text { F: 5'-CGGGCTGGGGATGACTTCTCTC-3' } \\
\text { R: 5'-GCCGGTTCAGGTACTCAGTCAT-3' }\end{array}$ & $\begin{array}{l}286-307 \\
520-541\end{array}$ & 59.1 & 256 & AluI & 196,60 \\
\hline
\end{tabular}

$\mathrm{T}_{\mathrm{A}}$, annealing temperature; Id2, inhibitor of differentiation protein 2; Apaf-1, apoptotic protease activating factor 1; AIF, apoptosis inducing factor. 


\title{
CHAPTER 2
}

Pistilli EE, Jackson JR, and Alway SE. Death receptor-associated pro-apoptotic signaling in aged skeletal muscle. Apoptosis, 11(12), 2115-2126, 2006.

\begin{abstract}
Tumor necrosis factor-alpha (TNF- $\alpha$ ) is elevated in the serum as a result of aging and it promotes pro-apoptotic signaling upon binding to the type I TNF receptor. It is not known if activation of this apoptotic pathway contributes to the well-documented ageassociated decline in muscle mass (i.e. sarcopenia). We tested the hypothesis that skeletal muscles from aged rodents would exhibit elevations in markers involved in the extrinsic apoptotic pathway when compared to muscles from young adult rodents, thereby contributing to an increased incidence of nuclear apoptosis in these muscles. The plantaris (fast) and soleus (slow) muscles were studied in young adult (5-7 mo, $\mathrm{n}=8)$ and aged (33 mo, n=8) Fischer 344 x Brown Norway rats. Muscles from aged rats were significantly smaller while exhibiting a greater incidence of apoptosis. Furthermore, muscles from aged rats had higher type I TNF receptor and Fas associated death domain protein (FADD) mRNA, protein contents for FADD, BCL-2 Interacting Domain (Bid), FLICE-inhibitory protein (FLIP), and enzymatic activities of caspase-8 and caspase-3 than muscles from young adult rats. Significant correlations were observed in the plantaris muscle between caspase activity and muscle weight and the apoptotic index, while similar relationships were not found in the soleus. These data demonstrate that pro-apoptotic signaling downstream of the TNF receptor is active in aged muscles. Furthermore, our data extend the previous demonstration that type II fibers are preferentially affected by aging and support the hypothesis that type II fiber containing
\end{abstract}


skeletal muscles may be more susceptible to muscle mass loses via the extrinsic apoptotic pathway. 


\section{INTRODUCTION}

The aging-associated loss of muscle mass and strength (i.e., sarcopenia), is an unavoidable consequence of advanced age. Although this phenomenon is well documented in animal and human studies, the underlying mechanisms leading to sarcopenia remain to be fully elucidated. The contributing mechanism(s) leading to sarcopenia are multi-factorial and may include: denervation and reinnervation of motor units, especially within skeletal muscles composed of a high degree of type II muscle fibers $^{1-3}$; an alteration in the hormonal milieu in which anabolic hormone concentrations progressively decline $e^{4,5}$; elevated concentrations of inflammatory mediators that are not only associated with disease states, but also occur in healthy older adults ${ }^{6-13}$; and myonuclear loss through apoptotic mechanisms ${ }^{14-19}$.

The process of nuclear apoptosis has been shown to contribute to skeletal muscle mass losses during disease states ${ }^{20}$, periods of inactivity ${ }^{15,17,21}$, and as a result of aging ${ }^{14}$. The presence of apoptotic nuclei within skeletal myofibers has been welldocumented $^{18,22,23}$, although the precise signaling mechanisms that result in these nuclear losses are just beginning to be fully understood. Pro-apoptotic signaling has been shown to arise from mitochondria in aged skeletal muscles ${ }^{14,15,17}$ and this has been termed the intrinsic apoptotic pathway. Pro-apoptotic members of the BCL-2 family of proteins, such as Bax and Bak, can promote cytochrome-c release from the mitochondrial intermembrane space initiating a caspase cascade resulting in apoptotic myonuclear loss 24. Although it appears that this intrinsic apoptotic program is well-conserved across muscles of differing fiber type and contractile activity, a pro-apoptotic environment 
appears to exist in aged skeletal muscles that can exacerbate myonuclear loss following apoptotic stimuli ${ }^{15,17}$.

The contribution of the extrinsic apoptotic pathway to skeletal muscle mass losses, especially during aging, has been less studied ${ }^{25}$. The increase in circulating concentrations of the cytokine, tumor necrosis factor-alpha (TNF- $\alpha$ ), may initiate proapoptotic signaling upon binding to the type I TNF receptor (TNFR). Upon binding, a death inducing signaling complex (DISC) is formed at the cytoplasmic portion of the TNFR, composed of adaptor proteins such as Fas associated death domain protein (FADD), TNFR associated death domain protein (TRADD) and procaspase-8 (reviewed in $^{26}$ ). Formation of the DISC stimulates cleavage of procaspase- 8 into the functional initiator caspase-8. Once cleaved, caspase- 8 stimulates cleavage and activation of the executioner caspase-3, which is directly linked to pro-apoptotic changes. Thus, this pathway represents an extrinsic pathway of apoptosis activated by binding of a ligand (TNF- $\alpha)$ to a cell surface death receptor (type-I TNFR).

The purpose of this study was to determine if the extrinsic apoptotic pathway is an active process in aged skeletal muscle and would thus be a contributing mechanism of sarcopenia. Using an accepted rodent model of aging, the plantaris and soleus muscles from young adult (5-7mo.) and aged (33mo.) Fischer 344 X Brown Norway rats (FBN) were examined for the incidence of apoptosis as well as mRNA expression and protein content of markers downstream of the type I TNFR. We hypothesized that skeletal muscles from aged rodents would exhibit elevations in markers involved in the extrinsic apoptotic pathway when compared to muscles from young adult rodents, which would contribute to an increased incidence of apoptosis in these muscles. As such, these data 
demonstrate that not only is the extrinsic apoptotic pathway an active process within aged skeletal muscle, but our data support the hypothesis that cross-talk between this pathway and the mitochondrial intrinsic pathway may occur through the pro-apoptotic protein BCL-2 Interacting Domain (Bid).

\section{METHODS}

Experimental Animals. All procedures followed the guidelines of the National Institutes of Health, and were approved by the Institutional Animal Care and Use Committee of the West Virginia University School of Medicine. Eight young adult (5-7 mo.) and eight senescent (33 mo.) male Fischer 344 x Brown Norway $(\mathrm{FBN})$ rats were obtained from the National Institute on Aging barrier-raised colony that is housed at Harlan Animal Colonies (Indianapolis, IN). The animals were housed at $20-22^{\circ} \mathrm{C}$ in barrier-controlled conditions under a 12:12-h light-dark cycle. They were provided rat chow and water ad libitum.

Experimental animals were sacrificed with an overdose of a xylazine (100 mg • $\mathrm{ml}^{-1}$ ) and ketamine $\left(50 \mathrm{mg} \cdot \mathrm{ml}^{-1}\right)$ 1:1 mixture diluted in sterile PBS. The plantaris and soleus muscles were removed from each hindlimb and trimmed of visible connective tissue. Immediately upon dissection, muscles were flash frozen in isopentane cooled to the temperature of liquid nitrogen and subsequently stored at $-80^{\circ} \mathrm{C}$ until biochemical analyses were performed.

Semi-quantitative estimates of mRNA. Semi-quantitative reverse transcriptionpolymerase chain reaction (RT-PCR) analysis was conducted to examine transcriptional 
changes in markers of the extrinsic pathway. Briefly, frozen muscle samples $(\sim 50 \mathrm{mg})$ were homogenized in $1 \mathrm{ml}$ of TriReagent (Molecular Research Center, Cincinnati, OH) with a mechanical homogenizer. Total RNA was isolated by centrifugation and washed in ethanol according to the manufacturer's instructions. RNA was solubilized in $20 \mu \mathrm{l}$ of RNase-free $\mathrm{H}_{2} \mathrm{O}$. RNA was treated with Dnase I (Ambion, Austin, TX) and reverse transcribed (RT) with random primers (Invitrogen/Life Technologies, Bethesda MD) to make complimentary DNA (cDNA).

Primers were constructed from published sequences (Table 1). Primer pairs for the genes of interest were co-amplified in the same reaction tube with $18 \mathrm{~S}$ primer pairs and competimers to the $18 \mathrm{~S}$ primers (Ambion, Austin, TX). Two different $18 \mathrm{~S}$ primer pairs that produced either 324 base pair (bp) or 489bp bands following PCR amplification were utilized, depending on the bp size of the gene of interest. The number of PCR cycles was determined for each gene to ensure analyses were done in the linear range of amplification. The signal from the gene of interest was expressed as a ratio to the $18 \mathrm{~S}$ signal from the same PCR reaction in order to eliminate any loading or amplification errors. Previous studies from our laboratory have shown that ribosomal 18S RNA is suitable as an internal control for RT-PCR and does not change as a result of aging or following muscular atrophic stimuli ${ }^{17}$. Following amplification, $20 \mu 1$ of each reaction was electrophoresed on $1.5 \%$ agarose gels. Gels were stained with ethidium bromide. PCR signals were captured with a digital camera (Kodak 290) and the signals were quantified in arbitrary units as optical density $\mathrm{x}$ band area, using Kodak image analysis software (Eastman Kodak Company, Rochester, NY). 
Quantitative Real-Time PCR Verification of RT-PCR. Real-time quantitative PCR was utilized as another approach to examine transcript levels in muscles of aged rats. All experiments were performed using the Applied Biosystems 7500 Real-Time PCR system which utilizes TaqMan gene expression assays. Each well of a 96-well optical reaction plate contained: 12.5 $\mu 1$ TaqMan Universal PCR Master Mix (Applied Biosystems, Foster City, CA), 1.8 $\mu 1$ TaqMan Gene Expression Assays, 9.7 $\mu 1$ sterile $\mathrm{H}_{2} \mathrm{O}$, and $1.0 \mu 1 \mathrm{cDNA}$. In addition to test samples, each plate contained no template controls and no primer controls. All samples were examined in duplicate and 18S ribosomal RNA (Applied Biosystems, Foster City, CA) was used as an endogenous control. Data were analyzed using the $\triangle \mathrm{CT}$ method that has been shown to produce comparable results to an absolute quantification procedure ${ }^{27}$ and has been previously used to examine cytokine mRNA levels in skeletal muscle ${ }^{28,29}$. Two different fluorescent dyes were utilized to examine the genes of interest (FAM) and the 18S RNA control (VIC). The $\Delta \mathrm{CT}$ was calculated for each sample using the following equation: ( $\left.\mathrm{CT}_{\mathrm{FAM}}-\mathrm{CT}_{\mathrm{VIC}}\right)$. The $\Delta \Delta \mathrm{CT}$ was then calculated using the following equation: $\left(\Delta \mathrm{CT}_{\text {Calibrator }}-\Delta \mathrm{CT}_{\text {Sample }}\right) . \quad$ The $\Delta \Delta \mathrm{CT}$ was then calculated using the following equation: $\left(\Delta \mathrm{CT}_{\text {Sample }}-\Delta \mathrm{C} \mathrm{T}_{\text {Calibrator }}\right)$. In this study, the young samples served as the calibrator to determine mRNA expression in aged samples relative to young. The fold-induction or relative quantification (RQ) was calculated using the formula: $2^{-(\triangle \Delta \mathrm{CT})}$. Using this calculation, the young samples had an RQ value of 1.0 with all aged samples expressed relative to this value.

Protein measures. The cytoplasmic protein fragment was isolated from frozen muscle samples according to procedures reported previously in our laboratory ${ }^{16,21}$. Briefly, 
muscle samples ( 50-75 mg), were homogenized in $1 \mathrm{ml}$ of ice-cold lysis buffer $(10 \mathrm{mM}$ $\mathrm{NaCl}, 1.5 \mathrm{mM} \mathrm{MgCl}_{2}, 20 \mathrm{mM}$ HEPES at $\mathrm{pH} 7.4,20 \%$ glycerol, $0.1 \%$ Triton $\mathrm{X}-100$, and $1 \mathrm{mM}$ dithioreitol) to obtain cytoplasmic protein extracts according to the methods of Rothermel et al $^{30}$. Muscle homogenates were centrifuged at 3,000 rpm for 5-minutes at $4^{\circ} \mathrm{C}$. The supernatants were collected that contained the cytoplasmic protein fraction. The protein concentration of the total muscle homogenate was assayed spectrophotometrically at $562 \mathrm{~nm}$ (BioRad, SmartSpec 3000) using a commercial bicinchoninic acid (BCA) method as recommended by the manufacturer (Pierce, Rockford, IL) with bovine serum albumin used as standards. Thirty micrograms of cytoplasmic protein was loaded into each lane of a pre-cast 4-12\% NuPAGE Bis-Tris gel (Invitrogen, Carlsbad, CA) and separated by routine SDS-polyacrylamide gel electrophoresis (PAGE) for 1.5 hours at $20^{\circ} \mathrm{C}$. The proteins were transferred to nitrocellulose membranes and verification of equivalent protein loading and transfer was verified by Ponceau S red (Sigma). The membranes were blocked at room temperature for $1 \mathrm{~h}$ in $5 \%$ non-fat milk (NFM) in tris-buffered saline containing $0.05 \%$ Tween (TBST). Membranes were probed with the following primary antibodies overnight at $4{ }^{\circ} \mathrm{C}$ : TNFR rabbit polyclonal antibody (1:1000 dilution, sc-7895, Santa Cruz Biotechnology, Santa Cruz, CA), Bid rabbit polyclonal antibody (1:750 dilution, sc-11423, Santa Cruz), FADD rabbit polyclonal antibody (1:1000 dilution, ab19891, AbCam Inc., Cambridge, MA), and FLICE-inhibitory protein (FLIP) polyclonal antibody (1:500 dilution, ab4042, AbCam Inc.) diluted in TBS-T with 5\% NFM. A cytoskeletal $\beta$-tubulin antibody (1:500 dilution, ab6160, AbCam) was used as a loading control. Secondary antibodies were conjugated to horseradish peroxidase (HRP; Chemicon) and signals were developed 
using a chemiluminescent substrate (ECL Advanced, Amersham Biosciences/ GE Healthcare Bio-Sciences Corp, Piscataway, NJ). Signals were visualized by exposing the membranes to X-ray films (BioMax MS-1; Eastman Kodak, Rochester, NY). Digital records were captured by a Kodak 290 camera and protein bands were quantified using 1D imager analysis software (Eastman Kodak). Bands were quantified as optical density (OD) $\mathrm{X}$ band area, normalized to $\beta$-tubulin bands, and expressed as arbitrary units.

Cell death ELISA and calculation of apoptotic index. Cytoplasmic protein extracts were used to quantify DNA fragmentation in all muscle samples using a commercially available ELISA kit (Cell Death Detection ELISA, Roche Diagnostics, Mannheim, Germany). Briefly, the wells of a 96-well plate were coated with a primary anti-histone mouse monoclonal antibody. Following the addition of $100 \mu$ l of each sample, a secondary anti-DNA mouse monoclonal antibody coupled to peroxidase was added to each well. The substrate, 2,2'-azino-di-(3-ethylbenzthiazoline sulfonate) (ABST) was used to photometrically determine the amount of peroxidase retained in the immunocomplex. The color change of each well was determined at a wavelength of 405nm using a Dynex MRX plate reader and computer software (Revelation, Dynatech Laboratories, CA). The resulting optical density (OD) was normalized to the protein concentration of each sample and recorded as the apoptotic index $\left(\mathrm{OD}_{405} \mathrm{mg}\right.$ protein $\left.^{-1}\right)$.

Fluorometric Caspase-Activity Assay. The activity of caspase- 8 and caspase- 3 was examined using commercially available fluorogenic substrates (caspase-8/10 AC-IETDAMC, caspase-3 AC-DEVD-AFC, Alexis Biochemical, San Diego, CA). Previous 
research has demonstrated that embryonic, but not adult skeletal muscle, contains detectable levels of caspase-10, thus allowing the assumption that the caspase- $8 / 10$

substrate is specific to the activity of caspase- 8 in this study ${ }^{31}$. To each well of a 96 -well fluorescent microplate (Nalgene Nunc Int., Rochester, NY) was added 50 $\mu 1$ of caspase activity buffer, $50 \mu \mathrm{l}$ of cytoplasmic protein without protease inhibitor from each muscle, and $10 \mu 1$ of substrate $(1 \mathrm{mM})$. Samples were incubated at $37^{\circ} \mathrm{C}$ for 2 -hours with caspase activity accessed using a fluorescent microplate reader at the following wavelengths: caspase-8 excitation 380nm and emission 460nm; caspase- 3 excitation 400nm and emission $505 \mathrm{~nm}$. Caspase activity was quantified by subtracting OD readings at time 2hour from the initial reading at time 0 -hour. The resulting optical density was normalized to the protein concentration of each muscle sample to provide a caspase activity index $\left(\mathrm{OD} \cdot \mathrm{mg} \operatorname{protein}^{-1}\right)$

Statistics. Statistical analyses were performed using the SPSS software package, version 10.0. Data are presented as MEANS $\pm \mathrm{SE}$. Mean values from young adult and aged muscles were compared using independent t-tests with significance set a $\mathrm{p}<0.05$. Relationships between given variables were examined by computing the Pearson correlation coefficient.

\section{RESULTS}

Bodyweight and Muscle Characteristics. Bodyweight was $47 \%$ greater in aged rats compared to young adult rats (Figure 1A). Absolute plantaris and soleus muscle wet weights from aged animals were $21 \%$ and $15 \%$ less, respectively, than muscles from 
young adult animals (Figure 1B). When expressed relative to bodyweight, plantaris and soleus muscle weights from aged animals were $47 \%$ and $41 \%$ less, respectively, than muscles from young adult animals (Figure 1C).

Apoptotic Index. A cell death ELISA kit was used to quantify the incidence of DNA fragmentation in plantaris and soleus muscle homogenates. The apoptotic index was $600 \%$ greater in aged plantaris muscles and 300\% greater in aged soleus muscles, when compared to muscles from young adult animals (Figure 1D).

mRNA Alterations in Components of the Death Receptor Pathway. The mRNA changes for TNF- $\alpha$ and the type I TNFR, as well as components known to be involved in the apoptotic signaling downstream of the TNFR, were analyzed in hindlimb muscles from young adult and aged rats to determine whether they were regulated at a transcriptional level. No differences in the mRNA concentration of TNF- $\alpha$ were observed when comparing plantaris and soleus muscles from young adult and aged rodents (Figure 2A). However, mRNA for the type I TNFR was $43 \%$ and $60 \%$ greater in aged plantaris and soleus muscles, respectively, when compared to young adult muscles (Figure 2B). The mRNA signal for TRADD was unchanged in young adult and aged plantaris and soleus muscles (Figure 2C). In contrast, the mRNA for FADD was 50\% and $94 \%$ greater in aged plantaris and soleus muscles, respectively, when compared to young adult muscles (Figure 2D). 
As a second approach, mRNA was measured by real-time semi-quantitative PCR. Generally, there was greater variability in the genes of interest when assessed by the realtime method than in the semi-quantitative approach. In all cases, the changes in mRNA expression as assessed by $2^{-(\Delta \Delta \mathrm{CT})}$ did not reach significance. Specifically, the RQ values for each gene of interest were: TNF- $\alpha$ (young PL $=1.0 \pm 0.19$; aged PL $=0.23 \pm 0.27$; young $\mathrm{SOL}=1.0 \pm 0.17$; aged $\mathrm{SOL}=0.69 \pm 0.34), \mathrm{TNFR}($ young $\mathrm{PL}=1.0 \pm 0.13$; aged $\mathrm{PL}=0.35 \pm 0.32$; young $\mathrm{SOL}=1.0 \pm 0.13$; aged $\mathrm{SOL}=1.0 \pm 0.24), \mathrm{FADD}($ young $\mathrm{PL}=$ $1.0 \pm 0.19 ;$ aged $\mathrm{PL}=0.24 \pm 0.23 ;$ young $\mathrm{SOL}=1.0 \pm 0.11$; aged $\mathrm{SOL}=0.47 \pm 0.30)$, TRADD (young $\mathrm{PL}=1.0 \pm 0.11$; aged $\mathrm{PL}=0.39 \pm 0.24$; young $\mathrm{SOL}=1.0 \pm 0.15$; aged $\mathrm{SOL}=0.67 \pm 0.27)$

Protein Alterations in Components of the Death Receptor Pathway. Based on the observed alterations in mRNA concentrations, western immunoblot analyses were performed for the TNFR and FADD as well as pro-apoptotic Bid and anti-apoptotic FLIP proteins. No differences were observed in the protein content for the soluble TNFR when comparing young adult and aged plantaris and soleus muscles (Figure 3A). Consistent with mRNA changes as assessed by the RT-PCR method, the protein content of FADD was greater in aged plantaris and soleus muscles when compared to young adult muscles (Figure 3B). In a similar fashion, plantaris and soleus muscles from aged rodents had a higher protein content full-length Bid, when compared to young adult muscles (Figure 3C). The anti-apoptotic protein, FLIP, was also greater in aged plantaris and soleus muscles when compared to young adult muscles (Figure 3D). 
Caspase Enzymatic Activity. Caspase-8 and caspase-3 specific fluorogenic substrates were utilized to quantify the enzymatic activity in plantaris and soleus muscle homogenates. Caspase- 8 activity was $72 \%$ and $33 \%$ greater in aged plantaris and soleus muscles, respectively, when compared to young adult muscles (Figure 4A). Similarly, caspase- 3 activity was $27 \%$ and $20 \%$ greater in aged plantaris and soleus muscles, respectively, when compared to young adult muscles (Figure 4B).

Correlation Analyses. The changes in measures of apoptosis were examined for their correlation with the degree of plantaris and soleus muscle mass loses by calculating the Pearson correlation coefficient. The plantaris muscle weight was highly negatively correlated with the apoptotic index (Figure 5A), especially when muscle weight was normalized to the rodent bodyweight (Figure 5B). In contrast, only the normalized soleus weight was negatively correlated with the apoptotic index (Figure 5F). The changes in caspase activity of the plantaris muscle were also highly correlated with the apoptotic index (Figures 5C and 5D), especially the changes in caspase- 8 activity. In contrast, there were no significant correlations between the changes in caspase activity of the soleus muscle and the apoptotic index (Figures 5G and 5H).

\section{DISCUSSION}

Apoptotic signaling downstream of the type I TNFR (i.e., extrinsic apoptotic pathway) has been shown in a variety of tissues, but it has not been studied in detail in skeletal muscle. Based on the well-documented increase in circulating TNF- $\alpha$ levels with aging ${ }^{6-13}$ and increases in apoptosis of myonuclei in aged skeletal muscles ${ }^{18,22}$, we 
examined whether apoptotic signaling via the extrinsic pathway contributed to sarcopenia. Our data demonstrate that pro- and anti-apoptotic proteins in the extrinsic apoptotic pathway were altered in fast (plantaris) and slow (soleus) skeletal muscles from aged rats.

Muscles from aged rats were significantly smaller and exhibited a larger incidence in fragmented DNA, which would indicate a higher level of nuclear apoptosis in these muscles. In addition, muscles from aged rodents had higher TNFR and FADD mRNA content (measured by semi-quantitative RT-PCR) and protein contents for FADD, Bid, and FLIP, and enzymatic activities of caspase-8 and caspase-3, when compared to muscles from young adult rodents. Although we observed an increase in mRNA expression for the TNFR as measured by the semi-quantitative approach, the protein content for the TNFR was unchanged in this study. This may be explained by the fact that the TNFR antibody utilized in western immunoblots recognizes the soluble form of the receptor. Thus, the changes in the membrane bound form of the receptor, measured by PCR, and the amount of the soluble TNFR may not be equivalent.

It was surprising that the data obtained using semi-quantitative RT-PCR to measure apoptotic transcripts were not completely consistent with those obtained by the real-time method we utilized in this study. It is possible that the changes in mRNA expression may have been below the detectable limit of the real-time PCR method, based on the fact that the percent changes in mRNA obtained by semi-quantitative PCR were all less than 1-fold (40\%-95\%). Nevertheless, the changes in protein content as determined from western blots and changes in enzyme activity clearly show that extrinsic apoptotic signaling was activated in muscles from old rats. 
The pro-apoptotic changes observed in this study occurred in a similar fashion in both plantaris and soleus muscles, although strong relationships were observed between markers of apoptosis and muscle loss in the fast plantaris muscle that were not observed in the soleus. These data extend the previous demonstration that type II fibers are preferentially affected by aging and suggest that type II fiber containing skeletal muscles may be more susceptible to muscle mass loses via the extrinsic apoptotic pathway.

Effects of TNF- $\alpha$ in skeletal muscle. One potential mechanism contributing to the onset of sarcopenia may be the increase in circulating cytokines, some of which may activate the extrinsic apoptotic pathway. The circulating concentrations of specific cytokines have been shown to be elevated in the serum as a result of aging. In humans, serum levels of catabolic cytokines, such as TNF- $\alpha^{7,9,12}$ and IL-6 ${ }^{6,11,32}$, are increased in healthy elderly compared to young adults. Serum concentrations of TNF- $\alpha$ have been proposed as a prognostic marker of all cause-mortality in centenarians ${ }^{7}$ and with ageassociated pathology and mortality in 80 -year old adults ${ }^{9}$. Several studies have also drawn associations between the increases in circulating cytokines and the sarcopenic process ${ }^{11,13}$. Specifically, elevated circulating levels of TNF- $\alpha$ are associated with lower appendicular skeletal muscle mass ${ }^{11}$ and reduced knee extensor and grip strength ${ }^{13}$. Because we have found activation of the extrinsic apoptotic signaling pathway in muscles of old rats, we speculate that circulating TNF- $\alpha$ may be the initiator of this pathway in skeletal muscle. Nevertheless, we cannot rule out the possibility that other pathways that we did not examine may have been activated by circulating TNF- $\alpha$ in aging muscles. For example, TNF- $\alpha$ has been shown to directly promote protein degradation ${ }^{33}$ and 
$\operatorname{apoptosis}^{34}$ within skeletal muscle. Furthermore, intravenous injection of recombinant TNF- $\alpha$ increases protein degradation in rat skeletal muscles and this is associated with the increased activity of the ubiquitin-dependent proteolytic pathway ${ }^{35-38}$. In addition, elevated TNF- $\alpha$ concentrations in cell culture for $24-48 \mathrm{~h}$ increases apoptosis in skeletal myoblasts as determined by DNA fragmentation ${ }^{39,40}$. A reduction of procaspase- 8 occurs within 6 h of incubating myoblasts in vitro with recombinant TNF- $\alpha$, suggesting a TNF- $\alpha$ mediated cleavage and activation of this initiator caspase in myoblast cultures ${ }^{41}$.

The effects of TNF- $\alpha$ on apoptosis are not limited to in vitro conditions, because a systemic elevation of TNF- $\alpha$ in vivo increases DNA fragmentation within rodent skeletal muscle ${ }^{34}$. Based on the observation in the current study that TNF- $\alpha$ mRNA was not different between muscles from young adult and aged rats, it is reasonable to assume that muscle-derived TNF- $\alpha$ does not act in an autocrine manner to stimulate the pro-apoptotic signaling observed in this study. Thus, the well-documented systemic elevation of TNF$\alpha$ with age, may increase the likelihood of ligand binding to the TNFR and stimulate apoptotic signaling of the extrinsic pathway downstream of the TNFR and contribute to sarcopenia in skeletal muscle of old rats. Although this hypothesis was not directly examined in this study our data show that pro-apoptotic proteins associated with the extrinsic apoptotic pathway were increased in muscles of old animals as compared to muscles in young adult animals.

Apoptotic Changes in Aged Skeletal Muscle. Pro-apoptotic signaling is an active process in skeletal muscle during periods of reduced muscle activity (hindlimb suspension, denervation). Apoptosis is an early occurring event that can contribute to 
muscle atrophy at later time points ${ }^{22}$. Furthermore, nuclear apoptosis is a part of the normal aging process (reviewed in ${ }^{42-44}$ ) and is a contributing mechanism of muscle mass losses with aging. Dirks and Leeuwenburgh ${ }^{14}$ measured mono- and oligonucleosome fragmentation and reported that apoptosis was elevated 50\% in aged muscles compared to young adult. Hindlimb suspension (HS) in rodents has also been used to examine the effect of superimposing a muscle atrophic stimulus (i.e. - disuse) in aged skeletal muscle 15,17. A common finding is that apoptotic signaling differs when comparing muscles from aged rodents to muscles from young adult rodents following periods of HS. Increases in apoptotic nuclei, as well as in molecular markers of the intrinsic apoptotic pathway (Bax, Bcl-2, Apaf-1, AIF, caspase-9, and caspase-3) were evident in aged muscles, supporting the hypothesis that an environment exits in aged skeletal muscle that favors apoptosis. The current study extends these results by showing that apoptotic signaling via the extrinsic pathway is active in aged skeletal muscles but not in muscles from young adult animals.

Muscles from aged animals also up-regulate anti-apoptotic proteins. Data from our lab ${ }^{17}$ and others ${ }^{45}$ have consistently shown an increase in the protein content for Bcl-2 following disuse and in aged muscles, with further increases when disuse is superimposed with aging. This led to our hypothesis that aged muscles attempt to counteract pro-apoptotic stimuli by up-regulating anti-apoptotic proteins. The data from the current study is consistent with this hypothesis by showing that muscles from aged rodents up-regulate the anti-apoptotic protein, FLIP. FLIP protein can attenuate apoptotic signaling downstream of death receptors by inhibiting the cleavage of procaspase- $8^{46-49}$. However, despite these aging-related adaptations, the up-regulation of 
FLIP and Bcl-2 proteins appears to be ineffective in attenuating myonuclear loss in aged muscles.

Type II Muscle Fibers and Aging. Analyses from human muscle biopsy samples have consistently demonstrated that type II fibers are more susceptible to agingrelated atrophy when compared to type I fibers ${ }^{50}$. Doherty ${ }^{51}$ reported that the loss of type II fiber area was $20 \%-50 \%$, whereas type I area loss was much less (1\%-25\%). Part of the loss of type II fiber size and number has been attributed to denervation/reinnervation which is a contributing factor of sarcopenia ${ }^{51}$. An alternative mechanism as suggested by the current data is that type II fibers (i.e., the plantaris muscle) may be more susceptible to age-associated atrophy and nuclear loss as a result of pro-apoptotic signaling via the extrinsic pathway. Nevertheless, we cannot rule out the possibility that apoptotic signaling may be muscle and not fiber-type specific.

Our observations of potential muscle and/or fiber type specific differences in TNF- $\alpha$ associated apoptotic signaling differs from data reported by Phillips and Leeuwenburgh $^{25}$, who did not find differences in the expression of apoptotic markers between the soleus (primarily a type I fibered muscle) and the superficial vastus lateralis muscles (primarily a type II fibered muscle) of aged rats. These disparate findings may be due to the different strains and ages of rodents utilized in our study and the previous study $^{25}$. Despite these differences, the data from our study and that of Phillips and Leeuwenburgh ${ }^{25}$ suggest that the extrinsic apoptotic pathway is active in skeletal muscle of aged rodents and this may contribute to age-associated muscle loss via increases in apoptotic signaling. 
Skeletal muscle function is reduced and the extent of hypertrophy to loading is reduced with aging. However we do not know the extent to which nuclear apoptosis initiated through the extrinsic pathway, might contribute to a reduction in muscle force or an attenuation of hypertrophic adaptations in aging. Our laboratory has previously reported the reduced force production and prolonged contractile properties in muscles of aged animals ${ }^{52-54}$. Maximal tetanic muscle force is reduced by more than $30 \%$ between the ages of 9 and 26 months of age in Fischer 344 x Brown Norway rats as used in the present study ${ }^{54}$. Aging also attenuates the hypertrophic response of the plantaris muscle in these rats ${ }^{54,55}$. Recent evidence suggests that muscle function is impaired when circulating TNF- $\alpha$ levels are elevated. When extensor digitorum longus (EDL) muscles from guinea pigs were exposed to recombinant TNF- $\alpha\left(5\right.$ and $\left.10 \mathrm{ng}^{\cdot} \mathrm{ml}^{-1}\right)$, the forcefrequency relationship was shifted down and to the right indicating a reduced force output at specific frequencies of activation ${ }^{56}$. Furthermore, when coronary heart failure is induced in experimental animals, circulating TNF- $\alpha$ is elevated above control levels, and this is associated with reduced absolute force output as well as an increase in the incidence of apoptosis in the tibialis anterior muscle. These data demonstrate that not only is muscle function impaired with aging, but that TNF- $\alpha$ may also impair muscle function when circulating levels are elevated ${ }^{20}$.

Pro-Apoptotic Signaling Cross-Talk. Cross-talk between extrinsic and intrinsic apoptotic pathways was recently reviewed ${ }^{26}$. Cross-talk between these pathways is the result of the cleavage of the pro-apoptotic BCL-2 family member Bid. Cleaved and activated caspase- 8 cannot only serve to activate caspase 3 , which is the executioner 
caspase, but also cleave full-length Bid into a truncated version (tBid) ${ }^{57}$. tBid then interacts with pro-apoptotic Bax, to stimulate apoptotic signaling from the mitochondria ${ }^{58}$. As has been previously shown, apoptotic signaling from the mitochondria stimulates cleavage of procaspase-9, which then serves to activate caspase$3^{59}$. Thus, both the extrinsic and intrinsic apoptotic pathways converge on caspase-3, which then fully engages pro-apoptotic signaling.

Certain cell types seem to be more susceptible to pro-apoptotic signaling via the extrinsic pathway without involving the mitochondria. These cell types, termed type I cells, differ from type II cells based on the accumulation of DISC following ligand binding ${ }^{60}$. Upon ligand binding, type I cells accumulate a larger amount of DISC on the cytoplasmic side of the death receptor, and do not require additional pro-apoptotic signaling arising from the mitochondria, to fully activate apoptosis. In contrast, type II cells accumulate considerably less DISC and require mitochondrial signaling to fully activate an apoptotic program. Skeletal muscle cells may act as type II cells ${ }^{49}$, in that apoptotic signaling arising from the death receptor can include subsequent mitochondrial apoptotic signaling through Bid activation. Future studies should directly address the ability of truncated Bid to mediate messages from the death receptor to the mitochondria. Nevertheless, in the current study, skeletal muscles from aged rodents contained a greater protein expression of full-length Bid, which raises the possibility that cross talk between the extrinsic pathway and the intrinsic pathway may occur in aged skeletal muscles (Figure 6). 
Conclusions. The results of the current study demonstrate that pro-apoptotic signaling downstream of the type I TNFR resulting in caspase- 8 and caspase- 3 activation, is active in aged skeletal muscles and is a contributing mechanism of sarcopenia. Secondly, although no differences were observed in the pattern of expression of apoptotic markers between the plantaris and soleus muscles, the changes in these markers and muscle loss were highly correlated in the plantaris muscle only. Thus, type II fiber containing muscles may be more susceptible to apoptotic signaling via the extrinsic pathway. Third, aged skeletal muscles undergo an adaptation in which anti-apoptotic proteins such as FLIP and Bcl-2 are increased, possibly in an effort to counteract pro-apoptotic signaling. Lastly, because skeletal muscles from aged rodents contained a greater protein content of full-length Bid than muscles of young adult rats, it is possible that that cross talk between the extrinsic pathway and the intrinsic pathway may occur in aged skeletal muscles (Figure 6). Collectively, these data indicate that a pro-apoptotic intracellular environment may exist in aged skeletal muscles that can contribute to sarcopenia. 


\section{AKNOWLEDGEMENTS}

The study was supported by the National Institutes of Health, National Institute on Aging Grant RO1 AGO21530 and the American College of Sports Medicine Doctoral Student Research Grant FRG-14. The authors would like to thank Dr. Richard Dey, Dr. Tom Batchelor, and Dr. Dawn Hunter for their assistance with the real-time PCR experiments and data analysis. 


\section{References}

1. Ansved T, Larsson L. Effects of ageing on enzyme-histochemical, morphometrical and contractile properties of the soleus muscle in the rat. J.Neurol.Sci. 1989; 93: 105-124.

2. Larsson L, Grimby G, Karlsson J. Muscle strength and speed of movement in relation to age and muscle morphology. J.Appl.Physiol 1979; 46: 451-456.

3. Larsson L, Sjodin B, Karlsson J. Histochemical and biochemical changes in human skeletal muscle with age in sedentary males, age $22--65$ years. Acta Physiol Scand. 1978; 103: 31-39.

4. Tenover JL. Testosterone and the aging male. J.Androl 1997; 18: 103-106.

5. Tenover JS, Matsumoto AM, Plymate SR, Bremner WJ. The effects of aging in normal men on bioavailable testosterone and luteinizing hormone secretion: response to clomiphene citrate. J.Clin.Endocrinol.Metab 1987; 65: 1118-1126.

6. Bruunsgaard H. Effects of tumor necrosis factor-alpha and interleukin-6 in elderly populations. Eur.Cytokine Netw. 2002; 13: 389-391.

7. Bruunsgaard H, Andersen-Ranberg K, Hjelmborg JB, Pedersen BK, Jeune B. Elevated levels of tumor necrosis factor alpha and mortality in centenarians. Am.J.Med. 2003; 115: 278-283. 
8. Bruunsgaard H, Andersen-Ranberg K, Jeune B, Pedersen AN, Skinhoj P, Pedersen BK. A high plasma concentration of TNF-alpha is associated with dementia in centenarians. J.Gerontol.A Biol.Sci.Med.Sci. 1999; 54: M357-M364.

9. Bruunsgaard H, Ladelund S, Pedersen AN, Schroll M, Jorgensen T, Pedersen BK. Predicting death from tumour necrosis factor-alpha and interleukin-6 in 80-yearold people. Clin.Exp.Immunol. 2003; 132: 24-31.

10. Bruunsgaard H, Pedersen M, Pedersen BK. Aging and proinflammatory cytokines. Curr.Opin.Hematol. 2001; 8: 131-136.

11. Pedersen M, Bruunsgaard H, Weis $\mathrm{N}$ et al. Circulating levels of TNF-alpha and IL-6-relation to truncal fat mass and muscle mass in healthy elderly individuals and in patients with type-2 diabetes. Mech.Ageing Dev. 2003; 124: 495-502.

12. Sandmand M, Bruunsgaard H, Kemp K, Andersen-Ranberg K, Schroll M, Jeune B. High circulating levels of tumor necrosis factor-alpha in centenarians are not associated with increased production in T lymphocytes. Gerontology 2003; 49: $155-160$.

13. Visser M, Pahor M, Taaffe DR et al. Relationship of interleukin-6 and tumor necrosis factor-alpha with muscle mass and muscle strength in elderly men and women: the Health ABC Study. J.Gerontol.A Biol.Sci.Med.Sci. 2002; 57: M326M332.

14. Dirks A, Leeuwenburgh C. Apoptosis in skeletal muscle with aging. Am.J.Physiol Regul.Integr.Comp Physiol 2002; 282: R519-R527. 
15. Leeuwenburgh C, Gurley CM, Strotman BA, Dupont-Versteegden EE. Agerelated differences in apoptosis with disuse atrophy in soleus muscle. Am.J.Physiol Regul.Integr.Comp Physiol 2005; 288: R1288-R1296.

16. Siu PM, Alway SE. Mitochondria-associated apoptotic signalling in denervated rat skeletal muscle. J.Physiol 2005; 565: 309-323.

17. Siu PM, Pistilli EE, Alway SE. Apoptotic responses to hindlimb suspension in gastrocnemius muscles from young adult and aged rats. Am.J.Physiol Regul.Integr.Comp Physiol 2005; 289: \%1015-1026.

18. Siu PM, Pistilli EE, Butler DC, Alway SE. Aging influences cellular and molecular responses of apoptosis to skeletal muscle unloading. Am.J.Physiol Cell Physiol 2005; 288: C338-C349.

19. Pistilli EE, Siu PM, Alway SE. Molecular regulation of apoptosis in fast plantaris muscles of aged rats. J.Gerontol.A Biol.Sci.Med.Sci. 2006; 61: 245-255.

20. Dalla Libera L, Ravara B, Volterrani M et al. The beneficial effects of GH/IGF-I on skeletal muscle atrophy and experimental heart failure. Am.J.Physiol Cell Physiol 2004; 286: C138-C144.

21. Siu PM, Alway SE. Id2 and p53 participate in apoptosis during unloadinginduced muscle atrophy. Am.J.Physiol Cell Physiol 2005; 288: C1058-C1073. 
22. Allen DL, Linderman JK, Roy RR et al. Apoptosis: a mechanism contributing to remodeling of skeletal muscle in response to hindlimb unweighting. Am.J.Physiol 1997; 273: C579-C587.

23. Hikida RS, Van Nostran S, Murray JD, Staron RS, Gordon SE, Kraemer WJ. Myonuclear loss in atrophied soleus muscle fibers. Anat.Rec. 1997; 247: 350-354.

24. Adams V, Gielen S, Hambrecht R, Schuler G. Apoptosis in skeletal muscle. Front Biosci. 2001; 6: D1-D11.

25. Phillips T, Leeuwenburgh C. Muscle fiber specific apoptosis and TNF-alpha signaling in sarcopenia are attenuated by life-long calorie restriction. FASEB J. 2005; 19: 668-670.

26. Sprick MR, Walczak H. The interplay between the Bcl-2 family and death receptor-mediated apoptosis. Biochim.Biophys.Acta 2004; 1644: 125-132.

27. Winer J, Jung CK, Shackel I, Williams PM. Development and validation of realtime quantitative reverse transcriptase-polymerase chain reaction for monitoring gene expression in cardiac myocytes in vitro. Anal.Biochem. 1999; 270: 41-49.

28. Nieman DC, Davis JM, Henson DA et al. Carbohydrate ingestion influences skeletal muscle cytokine mRNA and plasma cytokine levels after a 3-h run. J.Appl.Physiol 2003; 94: 1917-1925. 
29. Nieman DC, Davis JM, Brown VA et al. Influence of carbohydrate ingestion on immune changes after 2 h of intensive resistance training. J.Appl.Physiol 2004; 96: $1292-1298$.

30. Rothermel B, Vega RB, Yang J, Wu H, Bassel-Duby R, Williams RS. A protein encoded within the Down syndrome critical region is enriched in striated muscles and inhibits calcineurin signaling. J.Biol.Chem. 2000; 275: 8719-8725.

31. Ng PW, Porter AG, Janicke RU. Molecular cloning and characterization of two novel pro-apoptotic isoforms of caspase-10. J.Biol.Chem. 1999; 274: 1030110308.

32. Forsey RJ, Thompson JM, Ernerudh J et al. Plasma cytokine profiles in elderly humans. Mech.Ageing Dev. 2003; 124: 487-493.

33. Llovera M, Lopez-Soriano FJ, Argiles JM. Effects of tumor necrosis factor-alpha on muscle-protein turnover in female Wistar rats. J.Natl.Cancer Inst. 1993; 85: 1334-1339.

34. Carbo N, Busquets S, van Royen M, Alvarez B, Lopez-Soriano FJ, Argiles JM. TNF-alpha is involved in activating DNA fragmentation in skeletal muscle. Br.J.Cancer 2002; 86: 1012-1016.

35. Garcia-Martinez C, Lopez-Soriano FJ, Argiles JM. Acute treatment with tumour necrosis factor-alpha induces changes in protein metabolism in rat skeletal muscle. Mol.Cell Biochem. 1993; 125: 11-18. 
36. Garcia-Martinez C, Llovera M, Agell N, Lopez-Soriano FJ, Argiles JM. Ubiquitin gene expression in skeletal muscle is increased during sepsis: involvement of TNF-alpha but not IL-1. Biochem.Biophys.Res Commun. 1995; 217: 839-844.

37. Llovera M, Garcia-Martinez C, Agell N, Marzabal M, Lopez-Soriano FJ, Argiles JM. Ubiquitin gene expression is increased in skeletal muscle of tumour-bearing rats. FEBS Lett. 1994; 338: 311-318.

38. Garcia-Martinez C, Agell N, Llovera M, Lopez-Soriano FJ, Argiles JM. Tumour necrosis factor-alpha increases the ubiquitinization of rat skeletal muscle proteins. FEBS Lett. 1993; 323: 211-214.

39. Foulstone EJ, Meadows KA, Holly JM, Stewart CE. Insulin-like growth factors (IGF-I and IGF-II) inhibit C2 skeletal myoblast differentiation and enhance TNF alpha-induced apoptosis. J.Cell Physiol 2001; 189: 207-215.

40. Meadows KA, Holly JM, Stewart CE. Tumor necrosis factor-alpha-induced apoptosis is associated with suppression of insulin-like growth factor binding protein-5 secretion in differentiating murine skeletal myoblasts. J.Cell Physiol 2000; 183: 330-337.

41. Stewart CE, Newcomb PV, Holly JM. Multifaceted roles of TNF-alpha in myoblast destruction: a multitude of signal transduction pathways. J.Cell Physiol 2004; 198: 237-247.

42. Dirks AJ, Leeuwenburgh C. The role of apoptosis in age-related skeletal muscle atrophy. Sports Med. 2005; 35: 473-483. 
43. Leeuwenburgh C. Role of apoptosis in sarcopenia. J.Gerontol.A Biol.Sci.Med.Sci. 2003; 58: 999-1001.

44. Dupont-Versteegden EE. Apoptosis in muscle atrophy: relevance to sarcopenia. Exp.Gerontol. 2005; 40: 473-481.

45. Hunter RB, Stevenson E, Koncarevic A, Mitchell-Felton H, Essig DA, Kandarian SC. Activation of an alternative NF-kappaB pathway in skeletal muscle during disuse atrophy. FASEB J. 2002; 16: 529-538.

46. Hashimoto M, Nakajima-Shimada J, Aoki T. Trypanosoma cruzi posttranscriptionally up-regulates and exploits cellular FLIP for inhibition of death-inducing signal. Mol.Biol.Cell 2005; 16: 3521-3528.

47. Suhara T, Mano T, Oliveira BE, Walsh K. Phosphatidylinositol 3-kinase/Akt signaling controls endothelial cell sensitivity to Fas-mediated apoptosis via regulation of FLICE-inhibitory protein (FLIP). Circ.Res. 2001; 89: 13-19.

48. Clarke P, Debiasi RL, Meintzer SM, Robinson BA, Tyler KL. Inhibition of NFkappa B activity and cFLIP expression contribute to viral-induced apoptosis. Apoptosis. 2005; 10: 513-524.

49. Nagaraju K, Casciola-Rosen L, Rosen A et al. The inhibition of apoptosis in myositis and normal muscle cells. J.Immunol. 2000; 164: 5459-5465.

50. Doherty TJ, Vandervoort AA, Brown WF. Effects of ageing on the motor unit: a brief review. Can.J.Appl.Physiol 1993; 18: 331-358. 
51. Doherty TJ. Invited review: Aging and sarcopenia. J.Appl.Physiol 2003; 95: 1717-1727.

52. Chen KD, Alway SE. Clenbuterol reduces soleus muscle fatigue during disuse in aged rats. Muscle Nerve 2001; 24: 211-222.

53. Chen KD, Alway SE. A physiological level of clenbuterol does not prevent atrophy or loss of force in skeletal muscle of old rats. J.Appl.Physiol 2000; 89: 606-612.

54. Degens H, Alway SE. Skeletal muscle function and hypertrophy are diminished in old age. Muscle Nerve 2003; 27: 339-347.

55. Alway SE, Lowe DA, Chen KD. The effects of age and hindlimb supension on the levels of expression of the myogenic regulatory factors MyoD and myogenin in rat fast and slow skeletal muscles. Exp.Physiol 2001; 86: 509-517.

56. Alloatti G, Penna C, Mariano F, Camussi G. Role of NO and PAF in the impairment of skeletal muscle contractility induced by TNF-alpha. Am.J.Physiol Regul.Integr.Comp Physiol 2000; 279: R2156-R2163.

57. Tang D, Lahti JM, Kidd VJ. Caspase-8 activation and bid cleavage contribute to MCF7 cellular execution in a caspase-3-dependent manner during staurosporinemediated apoptosis. J.Biol.Chem. 2000; 275: 9303-9307. 
58. Grinberg M, Schwarz M, Zaltsman Y et al. Mitochondrial carrier homolog 2 is a target of tBID in cells signaled to die by tumor necrosis factor alpha. Mol.Cell Biol. 2005; 25: 4579-4590.

59. Johnson CR, Jarvis WD. Caspase-9 regulation: an update. Apoptosis. 2004; 9: 423-427.

60. Scaffidi C, Fulda S, Srinivasan A et al. Two CD95 (APO-1/Fas) signaling pathways. EMBO J. 1998; 17: 1675-1687. 
Figure 1
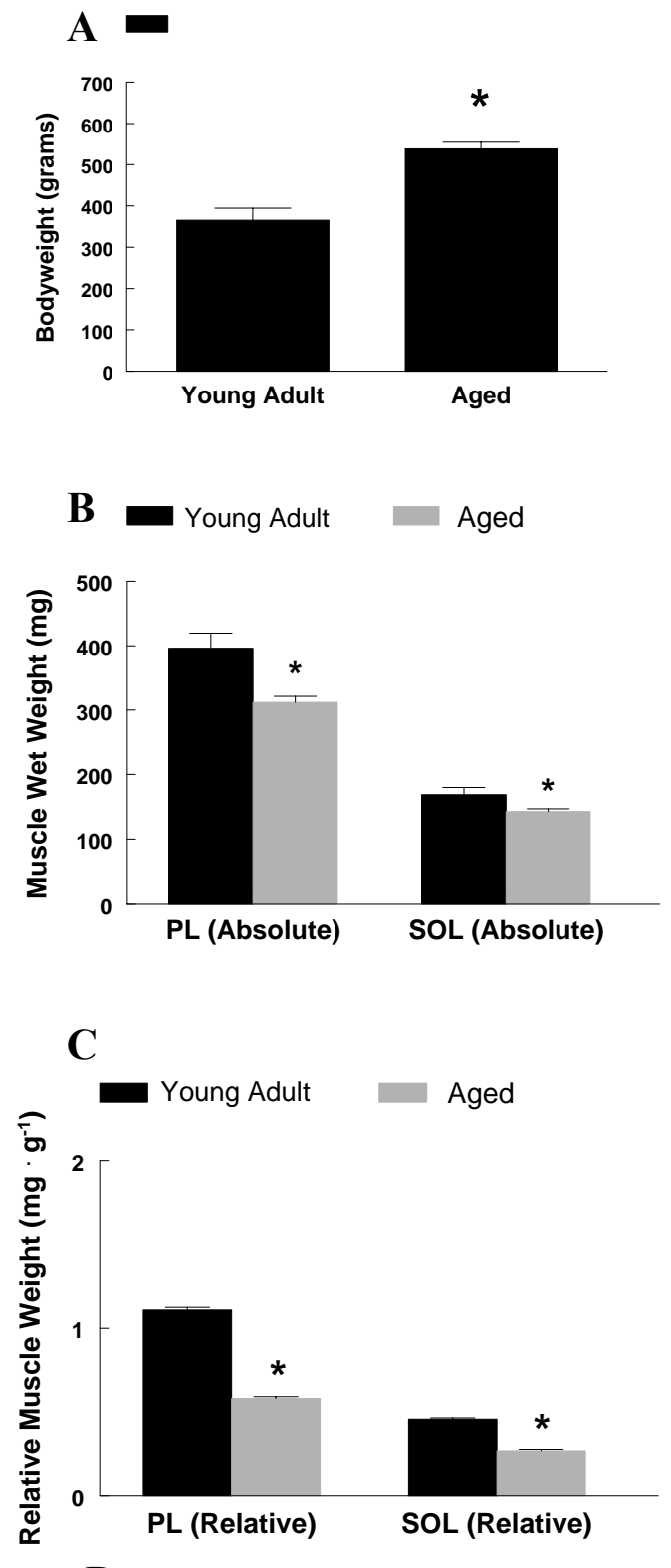

D

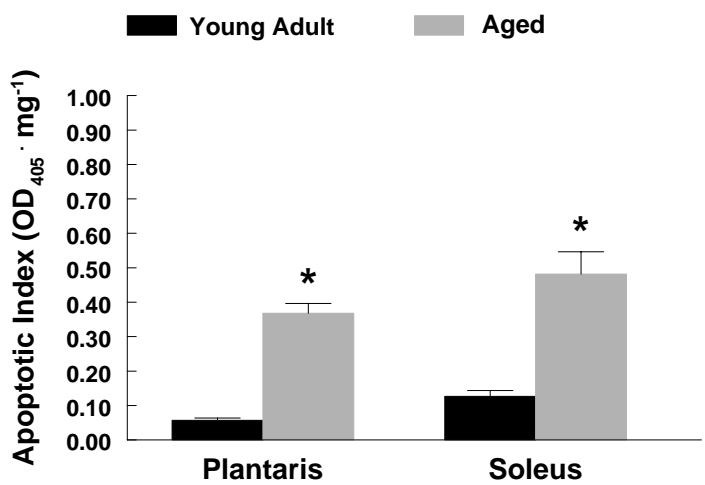




\section{Legend for Figure 1: Rodent and Skeletal Muscle Characteristics. Rodent}

bodyweight (A), as well as absolute $(\mathbf{B})$ and normalized $(\mathbf{C})$ muscles weights and incidence of apoptosis (D) was determined for plantaris and soleus muscles. Data presented as means \pm SE. ${ }^{*}$ Significant effect of age $(\mathrm{p}<0.05)$. PL-plantaris, SOL-soleus. 
Figure 2
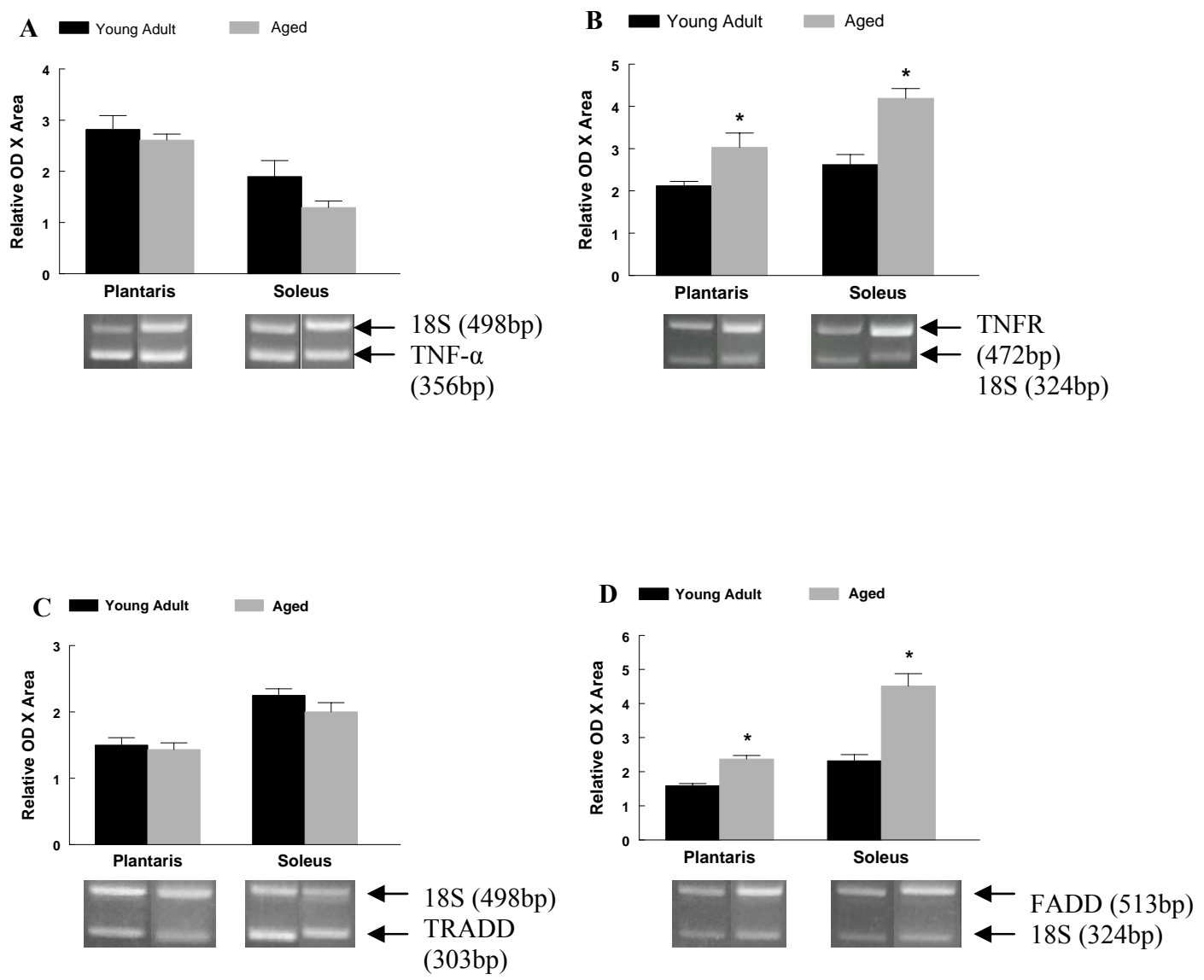

Legend for Figure 2: RT-PCR Analysis of Muscle mRNA. The mRNA content for TNF- $\alpha$ (A), TNFR (B), TRADD (C), and FADD (D) was determined by RT-PCR, with PCR products normalized to the $18 \mathrm{~S}$ gene. Representative agarose gel images following electrophoresis are displayed for each group. Data are presented as means $\pm \mathrm{SE}$. * Significant effect of age $(\mathrm{p}<0.05)$. 
Figure 3
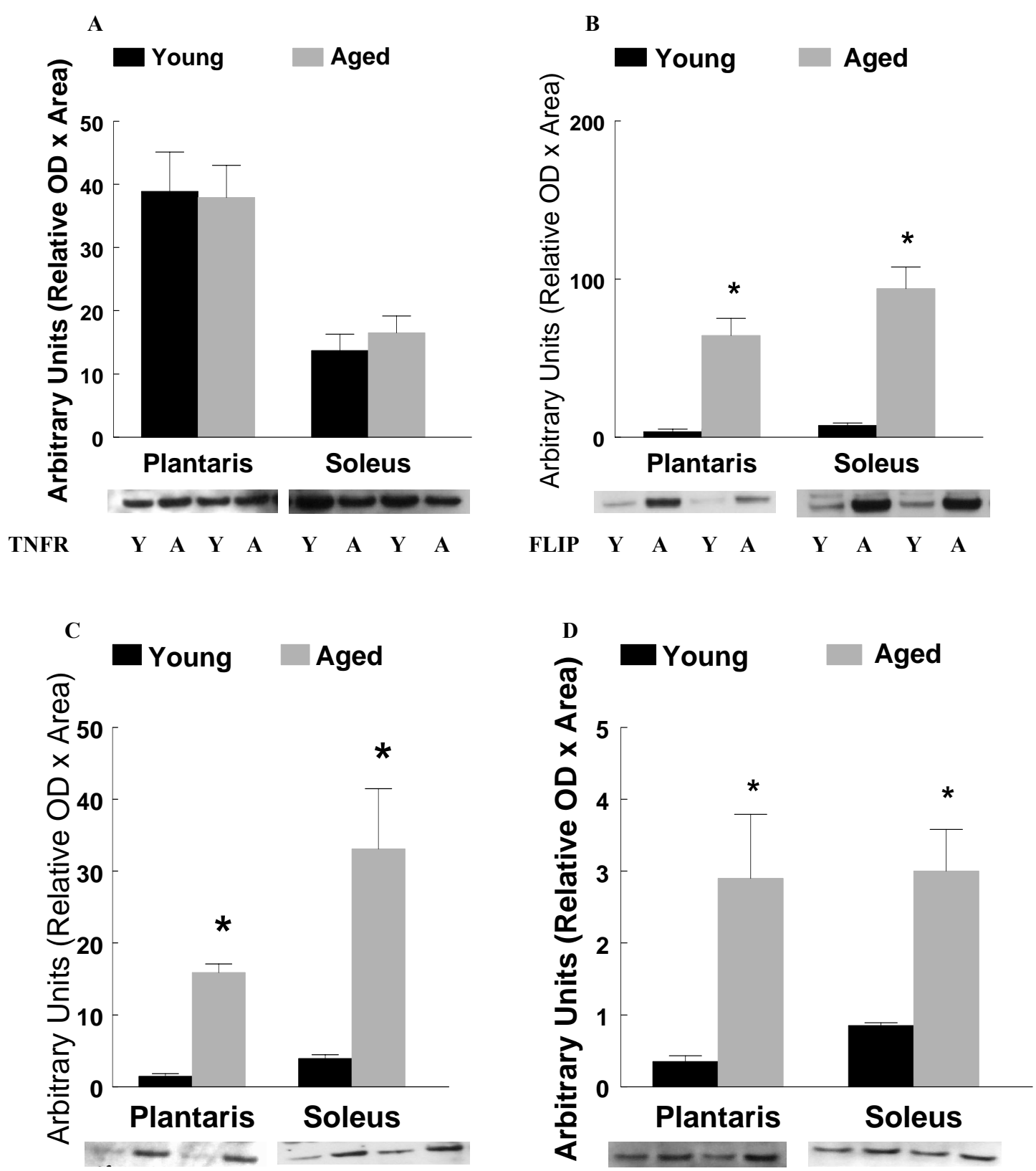

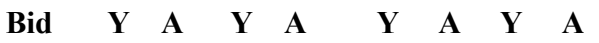

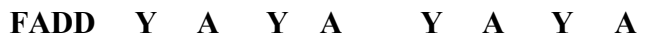


Legend for Figure 3: Western-Immunoblot Analyses. The protein content for the soluble TNFR (A), FLIP (B), Bid (C), and FADD (D) was determined by western immunoblot. Representative immunoblots for TNFR, FADD, BID, and FLIP are displayed for each graph. * Significant effect of age $(\mathrm{p}<0.05)$. PL-plantaris, SOL-soleus. 


\section{Figure 4}
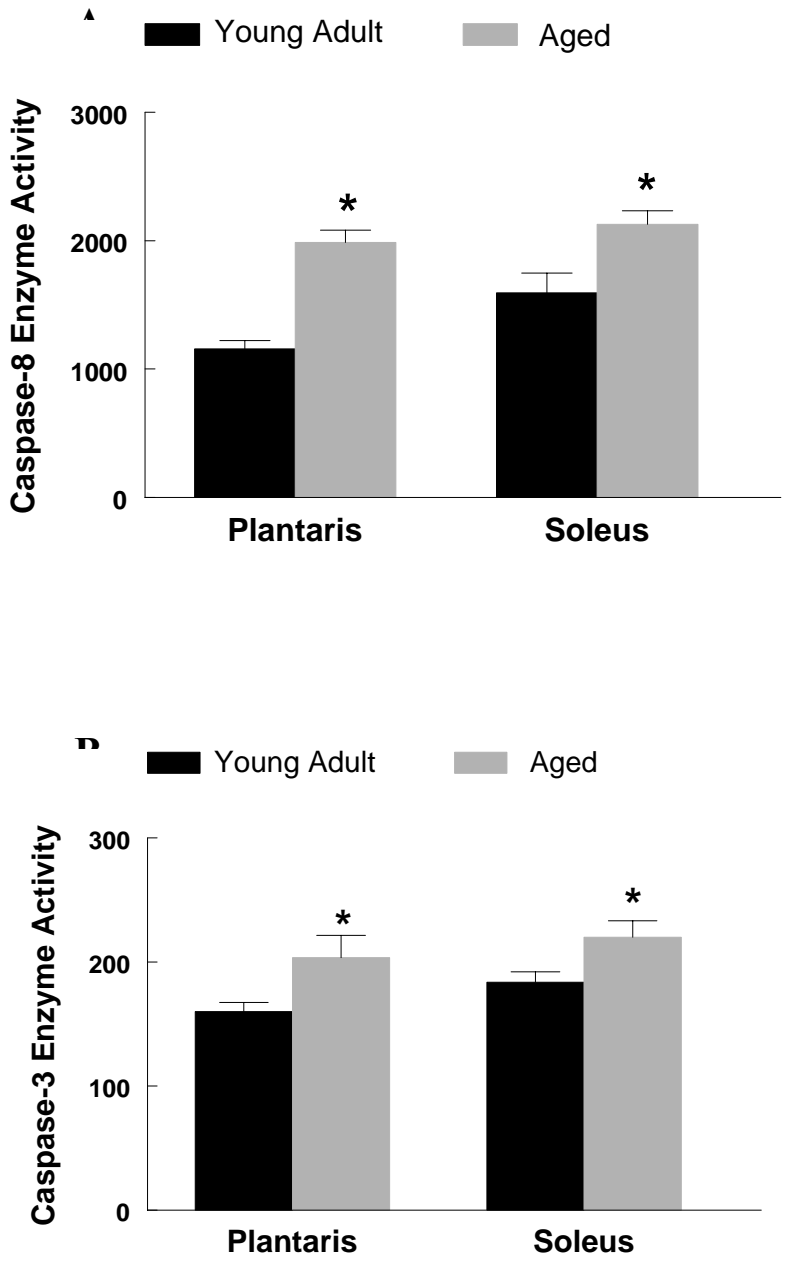

Legend for Figure 4: Caspase Enzymatic Activities. The caspase activity of caspase-8 (A) and caspase-3 (B) was measured using specific fluoremetric substrates. Caspase activity is expressed in fluoremetric units normalized to the protein concentration (caspase-8: 460nmmg protein ${ }^{-1}$; caspase-3: 400nmmg protein ${ }^{-1}$ ). Data are presented as means \pm SE. $*$ Significant effect of age $(\mathrm{p}<0.05)$ 
Figure 5
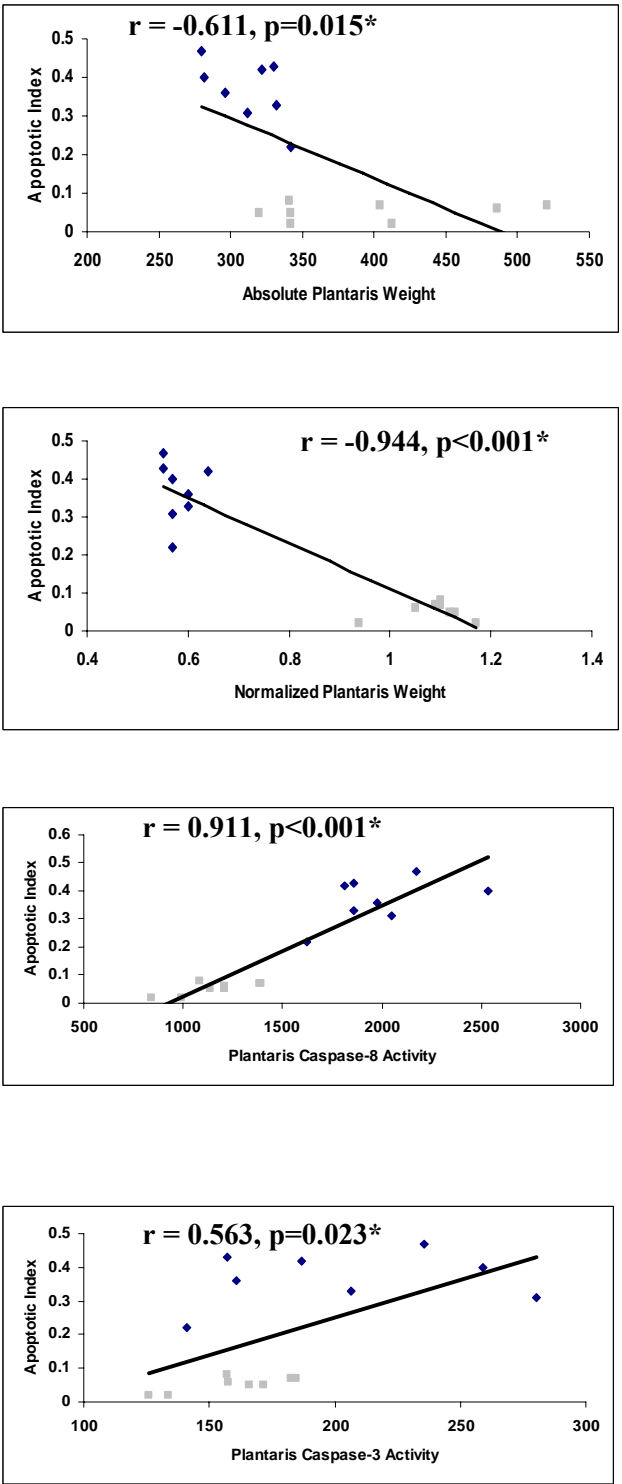
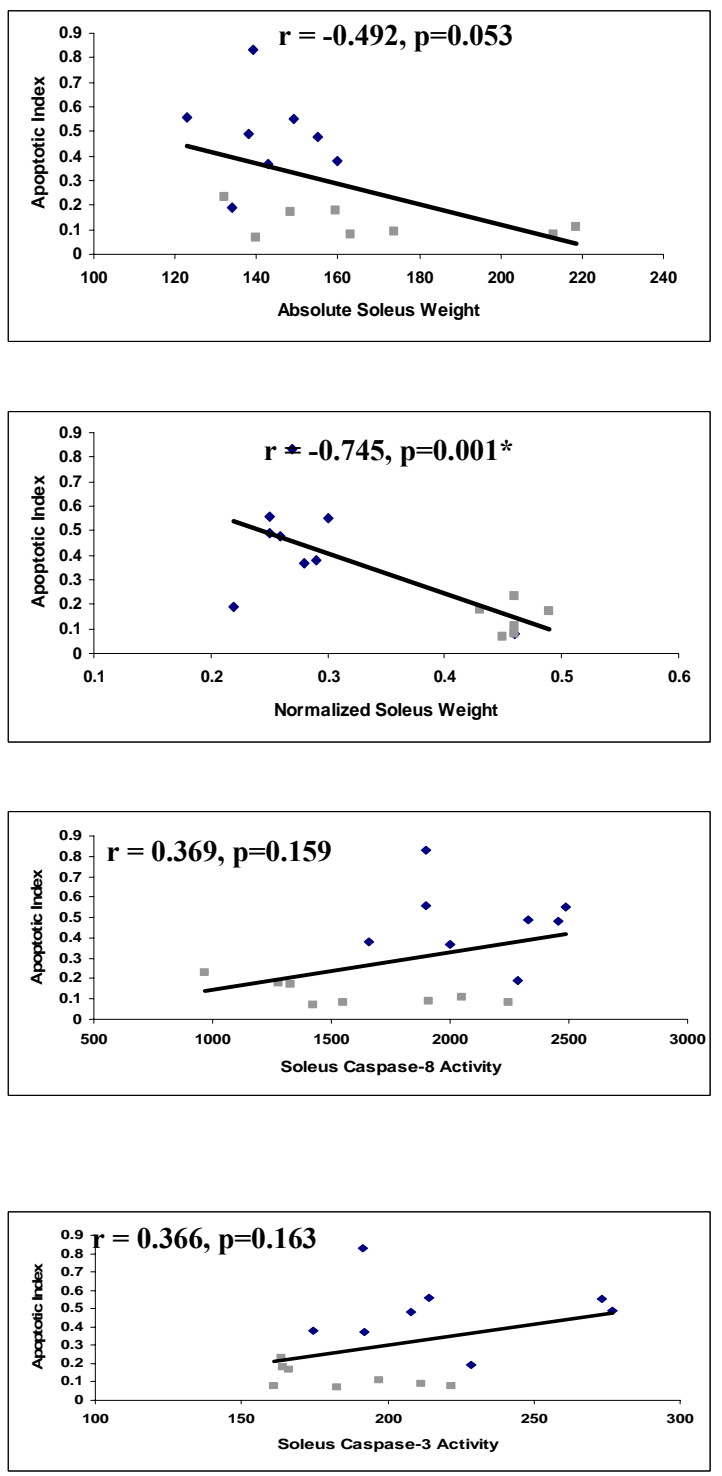


\section{Legend for Figure 5: Correlational analyses in plantaris and soleus muscles.} plantaris weight and the apoptotic index. The relationships between muscle phenotypes and apoptotic indicators were determined by calculating the Pearson correlation coefficient. The following relationships were analyzed: absolute plantaris weight and the apoptotic index $\left(\mathrm{OD}_{405} \mathrm{mg} \operatorname{protein}^{-1}\right)(\mathbf{A})$, normalized plantaris weight and the apoptotic index $\left(\mathrm{OD}_{405} \mathrm{mg}\right.$ protein $\left.^{-1}\right)(\mathbf{B})$, plantaris caspase- 8 activity and the apoptotic index $\left(\mathrm{OD}_{405} \mathrm{mg}\right.$ protein $\left.{ }^{-1}\right)(\mathbf{C})$, plantaris caspase-3 activity and the apoptotic index $\left(\mathrm{OD}_{405} \mathrm{mg}\right.$ protein $\left.^{-1}\right)(\mathbf{D})$, absolute soleus weight and the apoptotic index

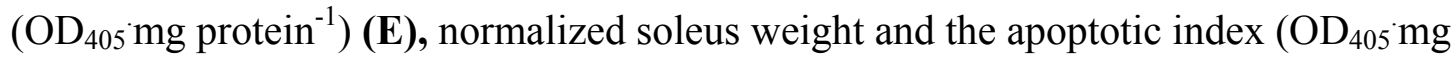
$\left.\operatorname{protein}^{-1}\right)(\mathbf{F})$, soleus caspase-8 activity and the apoptotic index $\left(\mathrm{OD}_{405} \cdot \mathrm{mg} \operatorname{protein}^{-1}\right)(\mathbf{G})$, soleus caspase-3 activity and the apoptotic index $\left(\mathrm{OD}_{405} \mathrm{mg} \operatorname{protein}^{-1}\right)(\mathbf{H}) . \square=$ young adult samples, $\bullet=$ aged samples. 
Figure 6

\section{Cross-Talk Apoptotic Pathways}

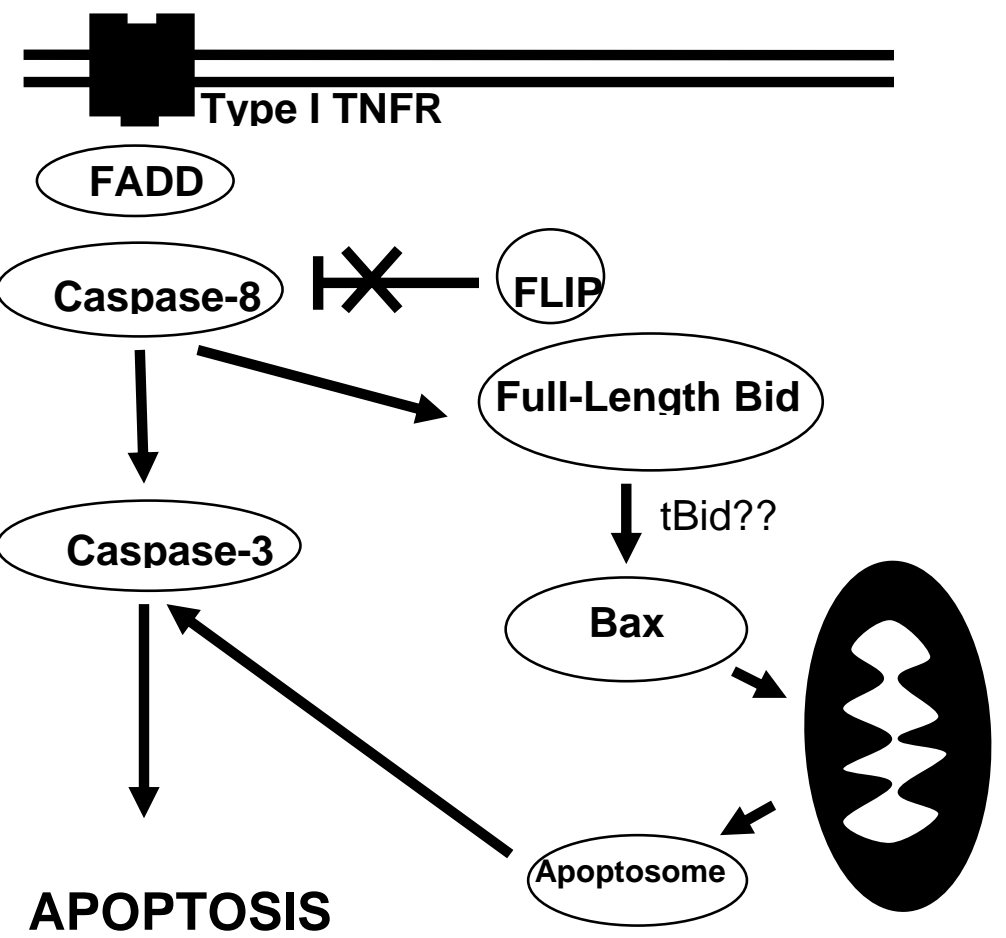

Legend for Figure 6: Cross-talk between apoptotic pathways. The extrinsic

apoptotic pathway, downstream of the type I TNFR, is active in aged skeletal muscle and consists of FADD, caspase-8, and caspase-3. Cleaved caspase-8 can activate BID, which can interact with Bax and promote further pro-apoptotic signaling arising from the mitochondria. 
Table 1. Primers used for Semi-Quantitative RT-PCR amplification of cDNA

\begin{tabular}{|c|c|c|c|c|c|c|c|}
\hline Product & $\begin{array}{l}\text { Accession } \\
\text { No. }\end{array}$ & Sequence & Position & $\mathrm{T}_{\mathrm{A}}{ }^{\circ} \mathrm{C}$ & $\begin{array}{l}\text { PCR } \\
\text { Length } \\
\text { (bp) }\end{array}$ & $\begin{array}{l}\text { Restriction } \\
\text { Enzyme }\end{array}$ & $\begin{array}{l}\text { Restriction } \\
\text { Products } \\
\text { (bp) }\end{array}$ \\
\hline TNF- $\alpha$ & NM_012675 & $\begin{array}{l}\text { F: 5'-CGGGGGCCACCACGCTCTTCTGT-3' } \\
\text { R: 5'-TCGGCTGACGGTGTGGGTGAGGA-3' }\end{array}$ & $\begin{array}{l}125-147 \\
458-480\end{array}$ & 62.0 & 356 & $\begin{array}{l}\text { XhoI } \\
\text { BglI }\end{array}$ & $\begin{array}{l}222,134 \\
222,134\end{array}$ \\
\hline TNFR & M63122 & $\begin{array}{l}\text { F: 5'-CCACCTGGTCCGATCGTCTTAC-3' } \\
\text { R: 5'-CACGGTGTCCATGTCAGCTTTG-3' }\end{array}$ & $\begin{array}{l}138-159 \\
588-609\end{array}$ & 58.5 & 472 & DraIII & 282,190 \\
\hline FADD & NM_152937 & $\begin{array}{l}\text { F: 5'-TGGCCTGGACCTGTTCTCG-3' } \\
\text { R: 5'-CGGGCTTGTCAGGGTGTTTC-3' }\end{array}$ & $\begin{array}{l}186-204 \\
679-698\end{array}$ & 59.5 & 513 & $\begin{array}{l}\text { BglII } \\
\text { PstI }\end{array}$ & $\begin{array}{l}350,163 \\
405,108\end{array}$ \\
\hline TRADD & AF517017 & $\begin{array}{l}\text { F: 5'-TGAGCTCTGCAAACTGACGTGT-3' } \\
\text { R: 5'-CCATCACGGCTCATACTCATAGG-3' }\end{array}$ & $\begin{array}{l}12-33 \\
292-314\end{array}$ & 59.1 & 303 & PstI & 237,66 \\
\hline
\end{tabular}

$\mathrm{T}_{\mathrm{A}}$, annealing temperature; bp, base pair; TNF- $\alpha$, tumor necrosis factor-alpha; TNFR, tumor necrosis factor receptor; FADD, Fas-associated death domain protein; TRADD, TNF receptor associated death domain protein 


\section{CHAPTER 3}

Pistilli EE, Siu PM, and Alway SE. Interleukin-15 responses to aging and unloading-induced skeletal muscle atrophy. American Journal Physiology: Cell Physiology, In Press, Dec 2006.

\section{ABSTRACT}

Interleukin-15 (IL-15) mRNA is constitutively expressed in skeletal muscle. Although IL-15 has proposed hypertrophic and anti-apoptotic roles in vitro, its role in skeletal muscle cells in vivo is less clear. The purpose of this study was to determine if skeletal muscle aging and unloading, two conditions known to promote muscle atrophy, would alter basal IL-15 expression in skeletal muscle. We hypothesized that IL-15 mRNA expression would increase as a result of both aging and muscle unloading and that muscle would express the mRNA for a functional trimeric IL-15 receptor (IL-15R). Two models of unloading were utilized in this study: hindlimb suspension (HS) in rats and wing unloading in quail. The absolute muscle wet weight of plantaris and soleus muscles from aged rats was significantly less when compared to muscles from young adult rats. Although 14 days of HS resulted in reduced muscle mass of plantaris and soleus muscles from young adult animals, this effect was not observed in muscles from aged animals. A significant aging times unloading interaction on IL-15 mRNA expression was observed in both the soleus and plantaris muscles. Patagalis (PAT) muscles from aged quail retained a significant $12 \%$ and $6 \%$ of stretch-induced hypertrophy after 7 and 14 days of unloading, respectively. PAT muscles from young quail retained $15 \%$ hypertrophy at 7 days of unloading but regressed to control levels following 14days of unloading. A main effect of age was observed on IL-15 mRNA expression in PAT muscles at the three time points examined (14 day overload, 7 day unload, 14 day unload). Skeletal muscle also expressed the mRNAs for a functional IL-15R, composed of IL$15 \mathrm{R} \alpha$, IL-2/15R- $\beta$, and $\gamma \mathrm{c}$. Based on these data, we speculate that increases in IL-15 mRNA in response to atrophic stimuli may be an attempt to counteract muscle mass loss in skeletal 
muscles of old animals. Additional research is warranted to determine the utility of manipulating the IL-15/IL-15R system to counter muscle wasting.

Key words: atrophy; interleukins; sarcopenia; gene signaling 


\section{INTRODUCTION}

Interleukin-15 (IL-15) is a recently discovered cytokine (20) that belongs to the four $\alpha$ helix bundle family of cytokines, that also include IL-2, IL-3, IL-4, IL-5, IL-6, IL-7, and IL-9. The roles of IL-15 within the immune system have been shown to include proliferation and survival of CD8+ T-cells (6), the activation of natural killer (NK) cells (11), and proliferation of B cells (5).

IL-15 mRNA is constitutively expressed in a wide variety of cell and tissue types including placenta, skeletal muscle, liver, epithelial cells, and activated macrophages (20). IL-15 and IL-2 have redundant roles as a result of similar receptor composition for these two cytokines. The IL-15 and IL-2 receptors (IL-15R, IL-2R, respectively) are trimeric structures composed of two identical chains, the IL-2R/IL-15R beta-chain (IL-2R $\beta$ ) and the common gamma $(\gamma \mathrm{c})$ chain, along with specific alpha-chains (18). The IL-15R alpha (IL-15R $\alpha$ ) exhibits a high affinity of binding for IL-15 protein, with a $\mathrm{K}_{\mathrm{d}}$ of $10 \mathrm{pM}$ (14). In addition to paracrine actions, IL-15 can be expressed in trans, in which the cytokine is either bound to cell surface IL-15R $\alpha$ or anchored to the cell membrane. In this manner, mature IL-15 can be presented to neighboring cells that express IL-2R $\beta$ and $\gamma c$ (7). Although both IL-15 (27) and IL-15R $\alpha$ (19) mRNA is expressed in skeletal muscle, it is not known if the mRNA for a functional trimeric IL-15R is also expressed in skeletal muscle, which would allow for trans presentation of IL-15 by muscle cells.

Within skeletal muscle, IL-15 can stimulate myosin heavy chain (MHC) protein expression in differentiated myotubes $(17 ; 34)$. Myotube cultures also exhibited a hypertrophic morphology when compared to control cultures that did not contain IL-15. Additionally, daily injections of IL-15 protein reduced DNA fragmentation of gastrocnemius muscles in a rodent model of cancer (15). These daily IL-15 protein injections also attenuated cancer associated skeletal muscle loss (cachexia) as well as reduced the gene expression of the type I TNF 
receptor. Although these results demonstrate a positive effect of exogenous IL-15 protein in myocytes, the response of endogenous intramuscular IL-15 has not been examined.

Furthermore, the response of IL-15 to muscle loss that results from conditions such as aging or muscle unloading is not known.

The purpose of this study was to determine the basal responses of IL-15 mRNA expression as a result of aging and to skeletal muscle unloading, two conditions known to promote muscular atrophy. A secondary aim of this study was to determine if skeletal muscle expresses the mRNAs for a functional trimeric IL-15R. We hypothesized that skeletal muscle would respond to unloading by increasing IL-15 mRNA, with further increases as a result of age in an attempt to counter muscle loss. We used two different models of unloading to test this hypothesis. In the first approach, we induced atrophy in soleus and plantaris muscles via hindlimb suspension (HS) in rats. This model reduces plantar flexor muscle mass below control levels. In the second approach, we first induced hypertrophy via wing weighting in quail and this was followed by wing unweighting. This approach reduces muscle mass from a hypertrophied state back to control levels, but not below control muscle mass levels. Our results demonstrate that aging results in significant increases in IL-15 mRNA with further increases as a result of muscle unloading, although this response may be fiber type and/or muscle specific. Additionally, skeletal muscle expresses mRNA for a functional trimeric IL-15R. These data demonstrate that the IL-15 gene is quite responsive to the two pro-atrophic stimuli utilized in this study, limb unloading and muscle aging. This response may represent a molecular (i.e. transcriptional) adaptation of aged skeletal muscle to counteract pro-atrophic stimuli. In addition, the expression of a trimeric IL-15R in skeletal muscle raises the possibility that muscle cells can respond to secreted IL-15 as well as present the cytokine in trans to neighboring cells, although this requires more direct experimentation. 


\section{METHODS}

All experimental procedures carried approval from the Institutional Animal Use and Care Committee from the West Virginia University School of Medicine. The animal care standards were followed by adhering to the recommendations for the care of laboratory animals as advocated by the American Association for Accreditation of Laboratory Animal Care (AAALAC) and following the policies and procedures detailed in the Guide for the Care and Use of Laboratory Animals as published by the U.S. Dept. of Health and Human Services and proclaimed in the Animals Welfare Act.

Rodent Hindlimb Suspension. Twenty young adult (5-7 mo) and eighteen senescent (33 mo) male Fischer $344 \times$ Brown Norway $(\mathrm{FBN})$ rats were obtained from the National Institute on Aging barrier-raised colony that is housed at Harlan Animal Colonies (Indianapolis, IN). The animals were housed at $20-22^{\circ} \mathrm{C}$ in barrier-controlled conditions under a $12: 12$-h light-dark cycle. They were provided rat chow and water ad libitum. The rats in each age group were randomly assigned to a HS group ( $n=10$ young adult; $n=10$ aged) or a control group $(n=10$ young adult; $\mathrm{n}=8$ aged). The HS animals were unloaded using methods described previously (26). Briefly, an adhesive (tincture of benzoin) was applied to the tail and allowed to dry. Orthopedic tape was applied along the proximal one-third of the tail, which distributed the load evenly and avoided excessive tension on a small area. The tape was placed through a wire harness that was attached to a fishlike swivel at the top of a specially designed hindlimb suspension cage. This provided the rats with $360^{\circ}$ of movement around the cage. Sterile gauze was wrapped around the orthopedic tape and was subsequently covered with a thermoplastic material, which formed a hardened cast (Vet-Lite, Veterinary Specialty Products, Boca Raton, FL). The exposed tip of the tail remained pink, indicating that HS did not interfere with blood flow to the tail. The 
suspension height was monitored daily and adjusted to prevent the hindlimbs from touching any supportive surface, with care taken to maintain a suspension angle of approximately $30^{\circ}$. The forelimbs maintained contact with a grid floor, which allowed the animals to move, groom themselves, and obtain food and water freely. Hindlimb suspension was maintained for a total of 14 days. Control rats maintained normal mobility and they moved unconstrained around their cages. Following 14 days of HS, rats were sacrificed with an overdose of xylazine and the soleus and plantaris muscles from the hindlimbs were excised.

Wing Loading/Unloading. In a second approach to study muscle loss, Japanese Coturnix quails were hatched and raised in pathogen-free conditions in the central animal care center at the West Virginia University School of Medicine. The birds were housed at a room temperature of $22^{\circ} \mathrm{C}$ with a 12:12-h light:dark cycle and were provided with food and water ad libitum. Twenty-four young adult birds ( $2 \mathrm{mo})$ and twenty-four aged birds $(24 \mathrm{mo})$ were examined in the present study. The lifespan of Japanese quails is $\sim 26-28$ mo and they are both physically and sexually mature by 1.5 mo of age $(25 ; 28)$. The patagialis (PAT) muscle is flexed with the wing on the birds back at rest, but it is stretched when the wing is extended. In our experimental stretchoverloading model, a tube containing $10-12 \%$ of the bird's body weight was placed over the left humeral-ulnar joint (4). This maintains the joint in extension throughout the period of stretch and induces stretch at the origin of the PAT muscle. Previous studies have shown this stretchoverloading protocol results in moderate hypertrophy of the PAT muscles (i.e., 14-day stretchloading induces $\sim 35 \%$ and $\sim 15 \%$ increases in muscle mass of young adult and aged birds, respectively (4). Following 14 days of stretch overload of the left wing, eight young and eight aged birds were sacrificed with an overdose of xylazine. Eight young and eight aged birds were maintained for a period of 7 days, in which the overloaded left wing was unloaded. The 
remaining young and aged animals were sacrificed 14 days after the weight removal. The unstretched right PAT muscle served as the intra-animal control muscle for each bird. PAT muscles were dissected from the surrounding connective tissue, removed, weighed, and frozen in isopentane cooled to the temperature of liquid nitrogen and then stored at $-80^{\circ} \mathrm{C}$ until used for analyses.

RT-PCR Estimates of mRNA. Semi-quantitative RT-PCR analysis was conducted as described in detail elsewhere (36). Frozen muscle samples ( $\sim 50 \mathrm{mg})$ were homogenized in $1 \mathrm{ml}$ of TriReagent (Molecular Research Center, Cincinnati, OH) with a mechanical homogenizer. Total RNA was isolated by centrifugation and washed in ethanol according to the manufacturer's instructions. RNA was solubilized in $20 \mu \mathrm{l}$ of RNase-free $\mathrm{H}_{2} \mathrm{O}$. RNA was treated with Dnase I (Ambion, Austin TX) and reverse transcribed (RT) with random primers (Invitrogen/Life Technologies, Bethesda MD). PCR primers were constructed from published sequences for the rat and chicken IL-15 genes (Table 1). Primer pairs for the gene of interest were co-amplified with $18 \mathrm{~S}$ primer pairs and competimers to the $18 \mathrm{~S}$ primers, as an internal control, according to the manufacture's protocols (Ambion, TX). The number of PCR cycles was determined for each gene to insure analyses were done in the linear range of amplification. The signal from the gene of interest was expressed as a ratio to the $18 \mathrm{~S}$ signal from the same PCR product in order to eliminate any loading errors. The cDNA from all muscle samples were amplified simultaneously for a given gene. Following amplification, $20 \mu 1$ of each reaction was electrophoresed on $1.5 \%$ agarose gels. Gels were stained with ethidium bromide. PCR signals were captured with a digital camera (Kodak 290) and the signals were quantified in arbitrary units as optical density $\mathrm{x}$ band area, using Kodak image analysis software (Eastman Kodak Company, Rochester, NY). As a positive control for IL-15 PCR, spleen and liver tissue were harvested from FBN rats and 
included in PCR analyses for IL-15 (Figure 1A) (13). Restriction digestion of IL-15 PCR products was performed for both rat and quail IL-15 to determine primer specificity (Figure 1B). The rat IL-15 product was cut with the AluI restriction enzyme producing bands of 466bp, and 128bp. The quail IL-15 PCR product was cut with the AluI restriction enzyme, producing bands of $321 \mathrm{bp}$ and $187 \mathrm{bp}$.

IL-15R $\alpha$ Sequencing. PCR amplification of the IL-15R $\alpha$ rattus sequence produced a PCR product approximately 100 base pairs larger than expected. The corresponding PCR products were gel purified using a commercially available gel extraction kit according to manufacture's instructions (QIAquick Gel Extraction Kit, Qiagen Sciences, MD), and sent for direct sequencing (SeqWright DNA Technology Services, Houston, TX). The newly acquired cDNA sequence information was then compared to the computer predicted sequence originally used for the design of PCR primers (XM_577598).

Statistical analysis. Statistical analyses were performed using the SPSS software package, version 10.0. Data were analyzed using a $2 \times 2$ ANOVA to examine the main effects of aging and unloading and the age $\mathrm{x}$ unload interaction. Data are presented as means $\pm \mathrm{SE}$ with significance set at $\mathrm{p}<0.05$. Relationships between given variables were examined by computing the Pearson correlation coefficient.

\section{RESULTS}

Body weight - Rodent HS. There were significant main effects of age $(F=91.7, p<0.001)$ and unloading $(\mathrm{F}=22.6, \mathrm{p}<0.001)$ on rodent bodyweight, although the aging $\mathrm{x}$ unloading interaction was not significant $(\mathrm{F}=0.006, \mathrm{p}=0.941)$. Fourteen days of HS significantly reduced body weights 
in both young adult (control: $374.7 \mathrm{~g} \pm 25.2 ; \mathrm{HS}: 295.2 \mathrm{~g} \pm 13.3 ;-80 \%$ ) and aged (control: $538.8 \mathrm{~g}$ \pm 15.9 ; aged: $456.7 \mathrm{~g} \pm 11.4 ;-15 \%$ ) rats. The bodyweight of the aged rats was $44 \%$ greater than the young adult rats (young adult: $374.7 \mathrm{~g} \pm 25.2$; aged: $538.8 \mathrm{~g} \pm 15.9$ ).

Muscle Characteristics - Rodent HS. Muscle wet weights have been reported previously (32) and absolute muscle wet weight and the muscle weight normalized to bodyweight are presented in Table 2. Following 14 days of HS, the soleus muscle wet weight was $43 \%$ less in young adult rats when compared to controls. In contrast, the wet weight of aged soleus was unchanged following HS. Control soleus wet weight was $17 \%$ less in aged vs. young rats. The aging $\mathrm{x}$ unloading interaction was significant in the soleus $(\mathrm{F}=15.0, \mathrm{p}<0.001)$. Following 14 days of HS, the plantaris wet weight was $20 \%$ less in young adult rats compared to controls. In contrast, the wet weight of the aged plantaris was unchanged following HS. Plantaris muscle wet weight was $22 \%$ less in aged as compared to control plantaris muscles.

PAT muscle - Quail wing unloading. The changes in PAT muscle mass following stretch overload and subsequent unloading have been reported previously (37). Fourteen days of stretch overload increased PAT wet weight approximately $35 \%$ in young quail and approximately $15 \%$ in aged quail. Young PAT muscles retained 15\% hypertrophy and aged PAT muscles retained $12 \%$ hypertrophy after 7 days of unloading, compared to intra-animal control muscles. Following 14 days of unloading, young PAT muscles returned to baseline. However, aged PAT muscles retained 6\% of stretch-induced hypertrophy after 14 days of unloading when compared to intra-animal control muscles. 
IL-15 Transcriptional Responses. Following 14 days of HS in rodents, a significant aging $\mathrm{x}$ unloading interaction was observed in both the soleus $(\mathrm{F}=8.2, \mathrm{p}=0.05)$ and plantaris $(\mathrm{F}=13.2$, $\mathrm{p}=0.011$ ) muscles. IL-15 mRNA was $81 \%$ greater in soleus muscles from young adult rodents relative to control muscles following HS. In contrast, IL-15 mRNA was unchanged in soleus muscles of aged rats following HS. IL-15 mRNA was $20 \%$ greater in the soleus of aged rats compared to young adult rats (Figure 2A). IL-15 mRNA was unchanged in young adult plantaris muscles following HS and when comparing control plantaris muscles from young adult and aged animals. In contrast, plantaris muscle IL-15 mRNA was $71 \%$ greater in aged rats following HS, relative to age-matched controls (Figure 2B).

A significant aging $\mathrm{x}$ loading/unloading interaction was not observed in the quail model at any analyzed time point, although there was a significant main effect of aging, with IL-15 mRNA an average of 53\% greater in aged PAT muscles, relative to muscles from young adult birds. This main effect of age on IL-15 expression was significant for all conditions: 14 day overload $(\mathrm{F}=5.8, \mathrm{p}=0.024), 7$ day unload $(\mathrm{F}=97.8, \mathrm{p}<0.001)$, and 14 day unload $(\mathrm{F}=61.9$, $\mathrm{p}<0.001)$. IL-15 mRNA was not affected by 14-days of stretch overload in either young or aged birds (Figure 3). In contrast, IL-15 mRNA was 25\% and 19\% greater in unloaded young and aged PAT muscles, respectively, relative to the intra-animal control muscles following 7-days of unloading (Figure 3). Following 14-days of unloading, IL-15 mRNA returned to baseline in PAT muscles of young and aged birds (Figure 3).

Sequencing of Rattus IL-15R $\boldsymbol{\alpha}$. A computer predicted mRNA sequence from GeneBank for the rattus IL-15R $\alpha$ chain was utilized to construct PCR primers (XM_577598). The PCR product had a predicted size of $325 \mathrm{bp}$ following amplification. However, following PCR amplification and subsequent gel electrophoresis, the PCR product was closer to $400 \mathrm{bp}$, with no multiple bands 
observed (Figure 4A). The PCR product was gel purified, sequenced, and compared to the computer predicted sequence from GeneBank. The newly sequenced cDNA was identical to the predicted sequence at the 5'- and 3'- ends, with a unique sequence of 103 bases contained in the middle (Figure 4B). Following verification by DNA sequencing and restriction digestion with HindIII (Figure 4A), the new sequence was submitted to GeneBank (Accession No: DQ157696).

IL-15R Expression in Skeletal Muscle. Primers specific for the three IL-15R chains $(\alpha, \beta, \gamma)$ as well as the IL-2R $\alpha$ chain were constructed to examine mRNA expression in rat skeletal muscle. Messenger RNA isolated from rodent spleen tissue was used as a positive control for each of these primers (Figure 5A). As shown in Figure 5B, rat skeletal muscle expresses mRNA for each of the IL-15R chains. Additionally, mRNA for the IL-2R specific alpha chain was detected in the spleen as well as in skeletal muscle.

\section{DISCUSSION}

The data from this study demonstrate that the IL-15 gene is responsive to skeletal muscle aging and unloading, two conditions known to promote muscle atrophy. IL-15 mRNA increased as a result of both unloading and aging in the predominantly slow-myosin containing soleus muscle, supporting previous microarray studies in skeletal muscle $(29 ; 38)$. In contrast, the fastmyosin containing plantaris muscle had increases in IL-15 mRNA only in the aged unloaded samples. The quail model of unloading utilized in this study differed from the HS model, in that wing unloading allowed regression of previously hypertrophied muscle, whereas during HS, the plantar flexor muscles atrophy relative to control muscles. The interaction of aging and loading/unloading on IL-15 mRNA expression was not significant in the quail model, indicating the age of the quail did not influence the adaptive response. Despite this difference, the main 
effect of age on IL-15 mRNA expression was evident in PAT muscles, as was the case in the soleus and plantaris muscles following HS. These data indicate that aging is a significant stimulus for increases in IL-15 mRNA in skeletal muscles, as IL-15 expression was greater in aged muscles of differing fiber type composition (i.e.- soleus vs. plantaris) and in the state of the muscle before unloading was initiated (i.e.- previously hypertrophied PAT vs. basal soleus and plantaris). The differences in IL-15 expression observed in this study support the observations from previous studies demonstrating that skeletal muscles from aged animals respond to atrophic conditions differently than muscles from young animals $(24 ; 32)$.

IL-15 and Skeletal Muscle. The first report on the effects of IL-15 in skeletal muscle demonstrated its ability to increase the myosin heavy chain protein content in differentiated mouse $\mathrm{C}_{2} \mathrm{C}_{12}$ myotubes in vitro (34). These results were subsequently supported by data in primary human skeletal muscle cell cultures (17). This effect of IL-15 was independent of the hypertrophic effects of IGF-1 (33), which may become important with aging when anabolic hormone levels typically decrease (40). In this study, IL-15 mRNA was greater in all aged skeletal muscles examined and, in general, increased as a result of unloading. We propose that this is an age-related adaptation of skeletal muscle to counter muscle loss in response to atrophic stimuli. Future studies should address the efficacy of IL-15 in sparing muscle mass in aged animals and in response to conditions that promote muscle atrophy.

The greatest effects of IL-15 may be seen under conditions of stress, such as that invoked by aging and disease. This is suggested in part, because the changes in IL-15 mRNA in the current study, were less dramatic in the muscles from young animals than in the aged. Furthermore, an increase in systemic IL-15 levels in vivo increases the force output of diaphragm muscles from $m d x$ mice (21), which, is a model for muscular dystrophy that has a high turnover 
of contractile protein as a result of degeneration/regeneration. In this same study, IL-15 promoted muscle regeneration within the first 6 days after a myotoxic injury as evidenced by an increase in fiber cross-sectional area (21). Elevated IL-15 also spares muscle mass and decreases the rate of protein degradation in young tumor-bearing rats (10). Collectively, these data suggest that IL-15 can act as an anabolic agent for skeletal muscle during periods of injury and/or periods of muscle wasting. This may explain, in part, why a significant interaction of aging and loading/unloading was not observed in the quail model utilized in this study. As noted, the quail model of unloading allows hypertrophied muscle to atrophy but muscle mass does not go below that of control contralateral muscles. The underlying mechanisms leading to atrophy of previously hypertrophied muscles to basal levels, compared to atrophy below control levels as observed in the HS model, may be less severe in nature. Our laboratory has previously demonstrated that previously hypertrophied PAT muscles from aged quail retain the loadinginduced increase of the anti-apoptotic molecule XIAP during periods of subsequent unloading (37). Additionally, other anti-apoptotic changes were noted in 14d unloaded PAT muscles of aged quails, such as increased Bcl-2 and decreased Bax protein levels (36). This is in contrast to the increased Bax mRNA expression and protein content our laboratory observed following $14 \mathrm{~d}$ of HS in the aged plantaris (32) and medial gastrocnemius muscles (35). We suggested that an anti-apoptotic adaptation of previously hypertrophied muscle may take place in aged quail during extended periods of unloading as muscle returned to basal levels. Similar adaptations may not take place during periods of HS-induced muscle atrophy where muscle mass can be considerably less when compared to muscles from control animals.

IL-15 and Apoptosis. A role for IL-15 in the attenuation of apoptosis is suggested by data showing that exogenous IL-15 protein inhibits death pathway associated apoptotic signaling. 
Multisystem apoptosis initiated in mice via treatment with an anti-Fas antibody was suppressed with injection of a long-lasting IL-15-IgG2b fusion protein (9). In addition, IL-15 transgenic (Tg) mice are resistant to a lethal dose of Escherichia coli (E. coli) (23). IL-15 administration into control mice also reduces the death rate from a lethal challenge of $E$. coli. The data further show that administration of IL-15 to isolated peritoneal cells in vitro, prevented TNF- $\alpha$ induced apoptosis (23).

The well-characterized cell death pathway initiated by the binding of TNF- $\alpha$ to the type I TNFR (i.e., extrinsic apoptotic pathway) can be altered with increases in IL-15 protein. For example, daily injections of IL-15 protein for 7-days in a rodent model of cancer, resulted in significant decreases in the gene expression of both the type I and type II TNFR (15). Furthermore, incubation of fibroblasts with IL-15 in vitro attenuates apoptosis induced by TNF$\alpha$ (8). The TNF- $\alpha$ apoptotic pathway was disrupted when the cytoplasmic signaling molecule TRAF2, which normally mediates the downstream apoptotic signal from the TNFR, was recruited to the cytoplasmic side of the IL-15R $\alpha$. Interestingly, this recruitment of TRAF2 to IL$15 \mathrm{R} \alpha$ was only observed when both TNF- $\alpha$ and IL-15 protein were present in the culture media (8). Thus, IL-15 seems to function, at least in part, to inhibit apoptosis by blocking the signaling downstream of the TNFR. This is relevant in aging muscle because the extrinsic apoptotic pathway is very active in aged skeletal muscle (31). We speculate that the changes in IL-15 mRNA observed in the current study may represent an attempt to counter the pro-apoptotic environment typically observed in aged skeletal muscle.

Another potential means for IL-15 to function in an anti-apoptotic role may be as a result of its association with the anti-apoptotic protein, $\mathrm{Bcl}-2(30 ; 41)$. There is a reduction in the percentage of $\mathrm{CD}^{+} \mathrm{T}$ cells in IL-15R $\alpha^{-/-}$mice and this is due in part to a reduction of $\mathrm{Bcl}-2$ expression (41). Exogenous IL-15 up-regulates Bcl-2 levels in these cells and contributes to a 
reduction in cell death upon activation (41). Additionally, HIV-specific $\mathrm{CD}^{+} \mathrm{T}^{\mathrm{T}}$ cells were shown to exhibit reduced levels of Bcl-2. When these cells were cultured with IL-15, Bcl-2 expression increased and this was associated with an attenuation of apoptosis of $\mathrm{CD} 8^{+} \mathrm{T}$ cell cultures (30). The mRNA expression and protein content of Bcl-2 has been shown to increase in aged skeletal muscles and in response to atrophic stimuli $(32 ; 35)$. Although these results do not show a direct Bcl-2 mediated anti-apoptotic role for IL-15, this possibility warrants further investigation.

Hindlimb Suspension in Rodents. The HS model of unloading has been widely utilized in rodents to study the effects of unloading on bone (22), and muscle $(2 ; 3 ; 16 ; 38)$. In the current study and others $(3 ; 24 ; 32)$, HS has been used to examine the interaction of aging and unloading. The aging associated loss of muscle mass and strength, (i.e. sarcopenia), is exacerbated with inactivity (39). Muscle mass declines by approximately $40 \%$ between the ages of 20 and 60, with strength declining by $20-40 \%$ [reviewed in (12)]. The current study is consistent with previous findings showing that aged skeletal_muscle responds differently to unloading when compared to young adult skeletal muscle $(24 ; 32 ; 35)$.

The results of this study differ from previous reports from our lab which, have shown greater muscle loss in aged FBN rats than in young adult rats after HS (3). Variability in animal responses to HS can occur, even in the same laboratory (16). For example, Fitts et al. (16) reported variability in soleus atrophy and peak isometric tetanic tension (Po) in response to 1and 2-weeks of HS. The authors speculated that variability in these data may be induced by diverse responses in animal movements or environmental disturbances that result in random muscular contractions. The HS technique results in limb unloading with muscular innervation left intact, which allows the hindlimbs to move freely in space. Initially, EMG activity 
decreases. but it returns to baseline levels as soon as 3 days after HS initiation (1). In our study, animals were checked twice daily after the induction of HS, and random hindlimb muscular contractions were observed, and this may have contributed to our current results.

Conclusions. IL-15 mRNA is constitutively expressed in skeletal muscle and it is responsive to both muscle aging and limb unloading. Our data indicate that aging is a significant stimulus for increased IL-15 mRNA expression, as main effects of age were observed in all muscles examined using two models of aging and in two different animal species. Additionally, skeletal muscle expresses mRNA for a functional trimeric IL-15R, which would allow for trans presentation of IL-15 by muscle cells. It is possible that skeletal muscle responds to atrophic stimuli by increasing IL-15 levels to be secreted as a traditional cytokine or by presenting IL-15 on the sarcolemma bound to the IL-15R. Future experiments should examine the direct effects of modulating IL-15/IL-15R system in response to atrophic stimuli as a means to spare muscle mass with aging and during periods of disuse or muscle injury/disease.

\section{ACKNOWLEDGEMENTS}

This study was supported by NIH: National Institute on Aging Grant R01 AG021530 and the American College of Sports Medicine Doctoral Student Research Grant (RFG-14). 
Reference List

1. Alford EK, Roy RR, Hodgson JA and Edgerton VR. Electromyography of rat soleus, medial gastrocnemius, and tibialis anterior during hind limb suspension. Exp Neurol 96: 635-649, 1987.

2. Allen DL, Linderman JK, Roy RR, Bigbee AJ, Grindeland RE, Mukku V and Edgerton VR. Apoptosis: a mechanism contributing to remodeling of skeletal muscle in response to hindlimb unweighting. Am J Physiol 273: C579-C587, 1997.

3. Alway SE, Lowe DA and Chen KD. The effects of age and hindlimb supension on the levels of expression of the myogenic regulatory factors MyoD and myogenin in rat fast and slow skeletal muscles. Exp Physiol 86: 509-517, 2001.

4. Alway SE, Winchester PK, Davis ME and Gonyea WJ. Regionalized adaptations and muscle fiber proliferation in stretch-induced enlargement. J Appl Physiol 66: 771-781, 1989.

5. Armitage RJ, Macduff BM, Eisenman J, Paxton R and Grabstein KH. IL-15 has stimulatory activity for the induction of B cell proliferation and differentiation. J Immunol 154: 483-490, 1995.

6. Berard M, Brandt K, Bulfone-Paus S and Tough DF. IL-15 promotes the survival of naive and memory phenotype CD8+ T cells. J Immunol 170: 5018-5026, 2003.

7. Bulfone-Paus S, Bulanova E, Budagian V and Paus R. The interleukin-15/interleukin-15 receptor system as a model for juxtacrine and reverse signaling. Bioessays 28: 362-377, 2006. 
8. Bulfone-Paus S, Bulanova E, Pohl T, Budagian V, Durkop H, Ruckert R, Kunzendorf U, Paus R and Krause H. Death deflected: IL-15 inhibits TNF-alpha-mediated apoptosis in fibroblasts by TRAF2 recruitment to the IL-15Ralpha chain. FASEB J 13: 1575-1585, 1999.

9. Bulfone-Paus S, Ungureanu D, Pohl T, Lindner G, Paus R, Ruckert R, Krause H and Kunzendorf U. Interleukin-15 protects from lethal apoptosis in vivo. Nat Med 3: 11241128, 1997.

10. Carbo N, Lopez-Soriano J, Costelli P, Busquets S, Alvarez B, Baccino FM, Quinn LS, Lopez-Soriano FJ and Argiles JM. Interleukin-15 antagonizes muscle protein waste in tumour-bearing rats. Br J Cancer 83: 526-531, 2000.

11. Carson WE, Giri JG, Lindemann MJ, Linett ML, Ahdieh M, Paxton R, Anderson D, Eisenmann J, Grabstein K and Caligiuri MA. Interleukin (IL) 15 is a novel cytokine that activates human natural killer cells via components of the IL-2 receptor. J Exp Med 180: 1395-1403, 1994.

12. Doherty TJ. Invited review: Aging and sarcopenia. J Appl Physiol 95: 1717-1727, 2003.

13. Doherty TM, Seder RA and Sher A. Induction and regulation of IL-15 expression in murine macrophages. J Immunol 156: 735-741, 1996.

14. Dubois S, Magrangeas F, Lehours P, Raher S, Bernard J, Boisteau O, Leroy S, Minvielle S, Godard A and Jacques Y. Natural splicing of exon 2 of human interleukin15 receptor alpha-chain mRNA results in a shortened form with a distinct pattern of expression. J Biol Chem 274: 26978-26984, 1999. 
15. Figueras M, Busquets S, Carbo N, Barreiro E, Almendro V, Argiles JM and LopezSoriano FJ. Interleukin-15 is able to suppress the increased DNA fragmentation associated with muscle wasting in tumour-bearing rats. FEBS Lett 569: 201-206, 2004.

16. Fitts RH, Metzger JM, Riley DA and Unsworth BR. Models of disuse: a comparison of hindlimb suspension and immobilization. J Appl Physiol 60: 1946-1953, 1986.

17. Furmanczyk PS and Quinn LS. Interleukin-15 increases myosin accretion in human skeletal myogenic cultures. Cell Biol Int 27: 845-851, 2003.

18. Giri JG, Ahdieh M, Eisenman J, Shanebeck K, Grabstein K, Kumaki S, Namen A, Park LS, Cosman D and Anderson D. Utilization of the beta and gamma chains of the IL-2 receptor by the novel cytokine IL-15. EMBO J 13: 2822-2830, 1994.

19. Giri JG, Kumaki S, Ahdieh M, Friend DJ, Loomis A, Shanebeck K, DuBose R, Cosman D, Park LS and Anderson DM. Identification and cloning of a novel IL-15 binding protein that is structurally related to the alpha chain of the IL-2 receptor. EMBO $J$ 14: 3654-3663, 1995.

20. Grabstein KH, Eisenman J, Shanebeck K, Rauch C, Srinivasan S, Fung V, Beers C, Richardson J, Schoenborn MA, Ahdieh M and . Cloning of a T cell growth factor that interacts with the beta chain of the interleukin-2 receptor. Science 264: 965-968, 1994.

21. Harcourt LJ, Holmes AG, Gregorevic P, Schertzer JD, Stupka N, Plant DR and Lynch GS. Interleukin-15 administration improves diaphragm muscle pathology and function in dystrophic mdx mice. Am J Pathol 166: 1131-1141, 2005.

22. Hefferan TE, Evans GL, Lotinun S, Zhang M, Morey-Holton E and Turner RT. Effect of gender on bone turnover in adult rats during simulated weightlessness. J Appl Physiol 95: 1775-1780, 2003. 
23. Hiromatsu T, Yajima T, Matsuguchi T, Nishimura H, Wajjwalku W, Arai T, Nimura Y and Yoshikai Y. Overexpression of interleukin-15 protects against Escherichia coliinduced shock accompanied by inhibition of tumor necrosis factor-alpha-induced apoptosis. J Infect Dis 187: 1442-1451, 2003.

24. Leeuwenburgh C, Gurley CM, Strotman BA and Dupont-Versteegden EE. Agerelated differences in apoptosis with disuse atrophy in soleus muscle. Am J Physiol Regul Integr Comp Physiol 288: R1288-R1296, 2005.

25. Marks HL. Long-term selection for body weight in Japanese quail under different environments. Poult Sci 75: 1198-1203, 1996.

26. Morey-Holton ER and Globus RK. Hindlimb unloading rodent model: technical aspects. J Appl Physiol 92: 1367-1377, 2002.

27. Nieman DC, Davis JM, Henson DA, Walberg-Rankin J, Shute M, Dumke CL, Utter AC, Vinci DM, Carson JA, Brown A, Lee WJ, McAnulty SR and McAnulty LS. Carbohydrate ingestion influences skeletal muscle cytokine mRNA and plasma cytokine levels after a 3-h run. J Appl Physiol 94: 1917-1925, 2003.

28. Ottinger MA. Quail and other short-lived birds. Exp Gerontol 36: 859-868, 2001.

29. Pattison JS, Folk LC, Madsen RW and Booth FW. Selected Contribution: Identification of differentially expressed genes between young and old rat soleus muscle during recovery from immobilization-induced atrophy. J Appl Physiol 95: 2171-2179, 2003.

30. Petrovas C, Mueller YM, Dimitriou ID, Bojczuk PM, Mounzer KC, Witek J, Altman JD and Katsikis PD. HIV-specific CD8+ T cells exhibit markedly reduced levels of Bcl-2 and Bcl-xL. J Immunol 172: 4444-4453, 2004. 
31. Pistilli EE, Jackson JR, and Alway S E. Death receptor associated pro-apoptotic signaling in aged skeletal muscle. Apoptosis. In Press. 2006.

32. Pistilli EE, Siu PM and Alway SE. Molecular regulation of apoptosis in fast plantaris muscles of aged rats. J Gerontol A Biol Sci Med Sci 61: 245-255, 2006.

33. Quinn LS, Haugk KL and Damon SE. Interleukin-15 stimulates C2 skeletal myoblast differentiation. Biochem Biophys Res Commun 239: 6-10, 1997.

34. Quinn LS, Haugk KL and Grabstein KH. Interleukin-15: a novel anabolic cytokine for skeletal muscle. Endocrinology 136: 3669-3672, 1995.

35. Siu PM, Pistilli EE and Alway SE. Apoptotic responses to hindlimb suspension in gastrocnemius muscles from young adult and aged rats. Am J Physiol Regul Integr Comp Physiol 289: R1015-1026, 2005.

36. Siu PM, Pistilli EE, Butler DC and Alway SE. Aging influences cellular and molecular responses of apoptosis to skeletal muscle unloading. Am J Physiol Cell Physiol 288: C338C349, 2005.

37. Siu PM, Pistilli EE, Ryan MJ and Alway SE. Aging sustains the hypertrophy-associated elevation of apoptotic suppressor X-linked inhibitor of apoptosis protein (XIAP) in skeletal muscle during unloading. J Gerontol A Biol Sci Med Sci 60: 976-983, 2005.

38. Stevenson EJ, Giresi PG, Koncarevic A and Kandarian SC. Global analysis of gene expression patterns during disuse atrophy in rat skeletal muscle. J Physiol 551: 33-48, 2003.

39. Stump CS, Tipton CM and Henriksen EJ. Muscle adaptations to hindlimb suspension in mature and old Fischer 344 rats. J Appl Physiol 82: 1875-1881, 1997. 
40. Tenover JL. Testosterone and the aging male. J Androl 18: 103-106, 1997.

41. Wu TS, Lee JM, Lai YG, Hsu JC, Tsai CY, Lee YH and Liao NS. Reduced expression of Bcl-2 in CD8+ T cells deficient in the IL-15 receptor alpha-chain. $J$ Immunol 168: 705$712,2002$. 


\section{Figure 1}

A
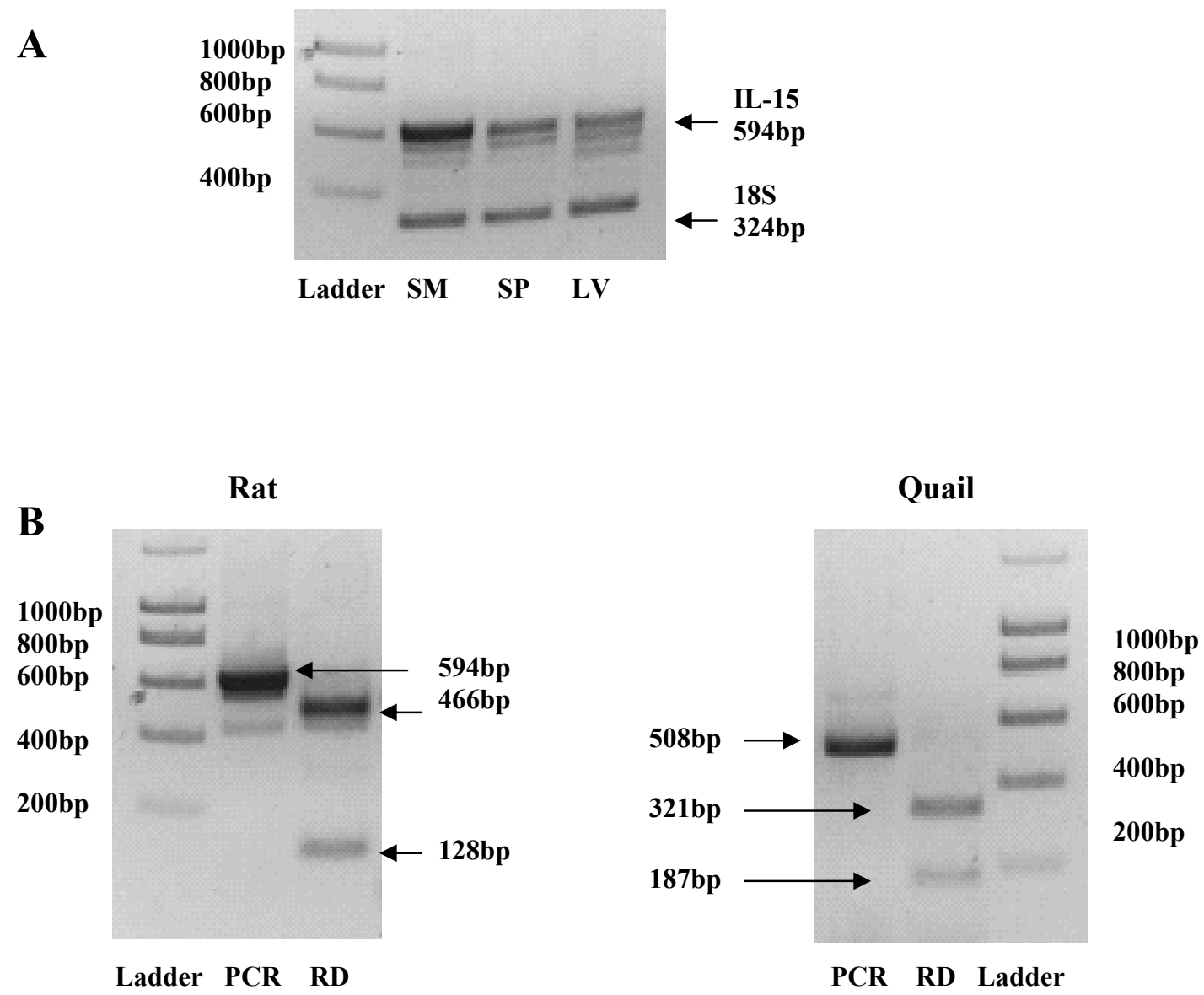
Legend for Figure 1. IL-15 primer specificity. A. RT-PCR was performed for IL-15 in cDNA from rat skeletal muscle (SM), with cDNA from rat spleen (SP) and liver (LV) tissue used as positive controls. Thirty four PCR cycles at a calculated $\mathrm{T}_{\mathrm{A}}$ of $56.6^{\circ} \mathrm{C}$ produced bands of 594bp in all three tissue types. B. Restriction digestion of IL-15 PCR products from rat and quail skeletal muscle with the AluI restriction enzyme. Incubation of PCR products at $37^{\circ} \mathrm{C}$ for $1 \mathrm{hr}$ produced the predicted fragments. $\mathrm{SM}-$ skeletal muscle, SP - spleen, LV - liver, PCR - full PCR product, RD - restriction enzyme digested PCR products. 


\section{Figure 2}

A

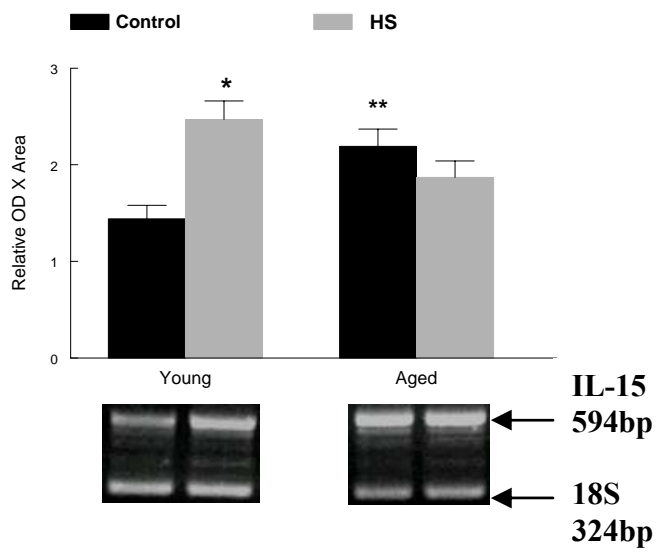

Soleus Muscle Age: $p=0.05$ *

HS: $p=0.005$ * Age $x$ HS: $p=0.007$ *
B

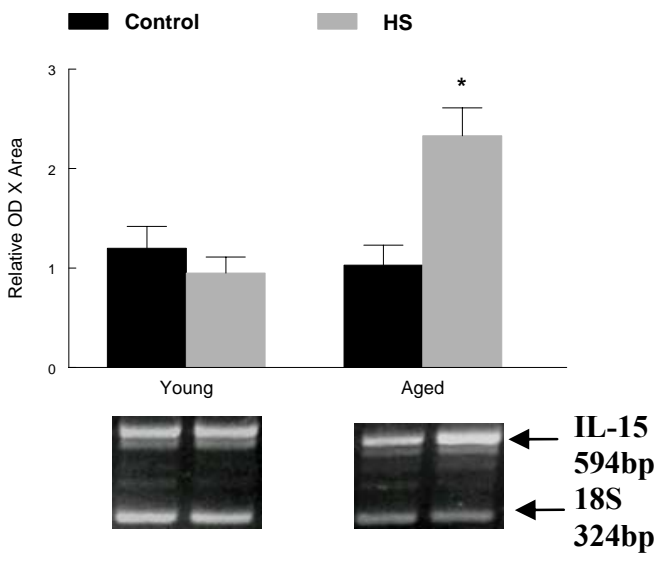

Plantaris Muscle Age: $p=0.011$ *

HS: $p=0.035$ * Age $x$ HS: $p=0.001$ * 
Legend for Figure 2. IL-15 Transcriptional Changes Following HS. A. IL-15 mRNA expression in soleus muscles following HS. B. IL-15 mRNA expression in plantaris muscles following HS. A significant aging x unloading interaction was observed in both skeletal muscles, indicating age influenced the response of IL-15 mRNA. Data are expressed as $\mathrm{MEAN} \pm \mathrm{SE}$ with significance set at $\mathrm{p}<0.05 ; *$, significant unloading effect; ** significant age effect. 


\section{Figure 3}

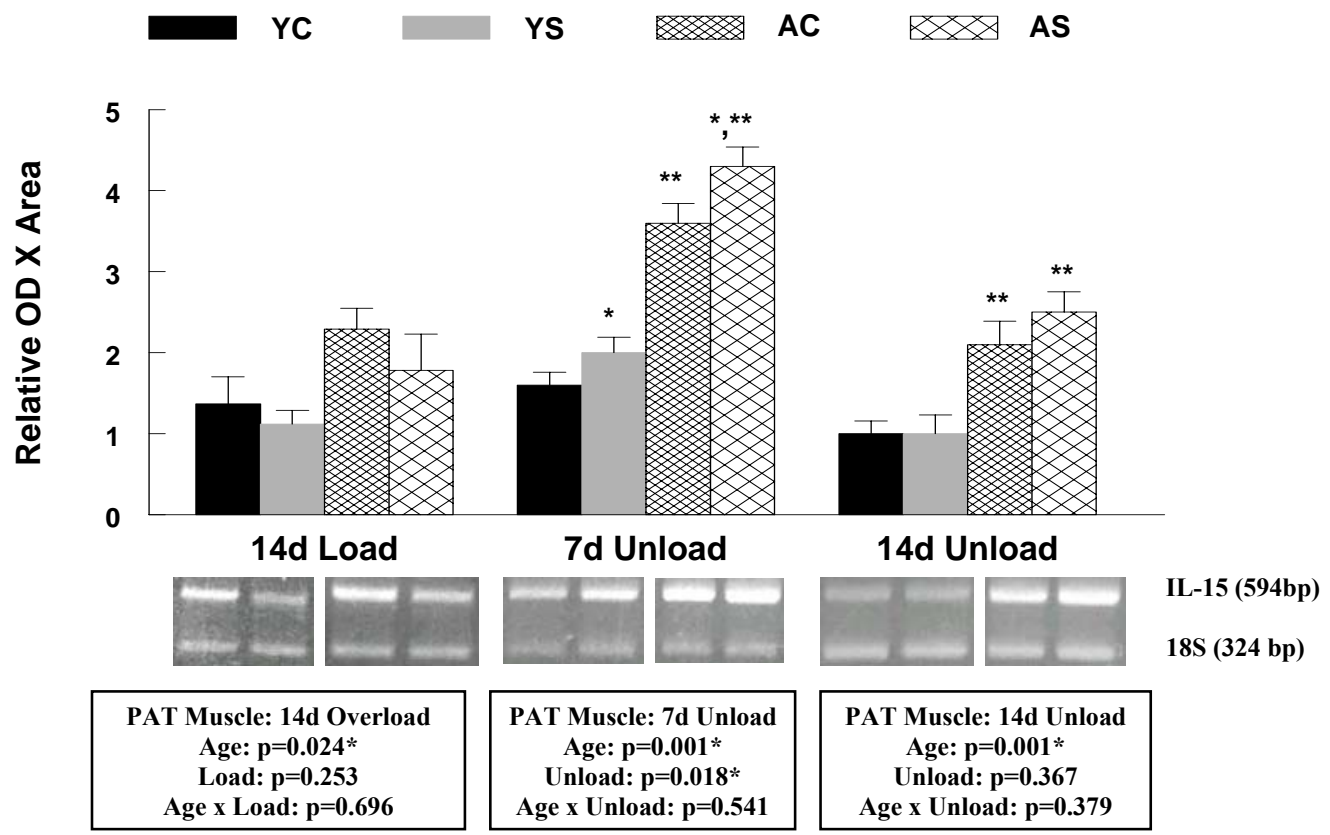




\section{Legend for Figure 3: IL-15 Transcriptional Changes in Response to Wing Overload and}

Subsequent Unloading. IL-15 mRNA expression in patagalis muscles following 14 days of stretch overload, 14 days of loading followed by 7 days of subsequent unloading, and 14 days of loading followed by 14 days of unloading. Data are expressed as MEAN $\pm \mathrm{SE}$ with significance set at $\mathrm{p}<0.05$. YC, young control; YS, young stretched; AC, aged control; AS, aged stretched. * significant unloading effect; **, significant age effect. 


\section{Figure 4}

A

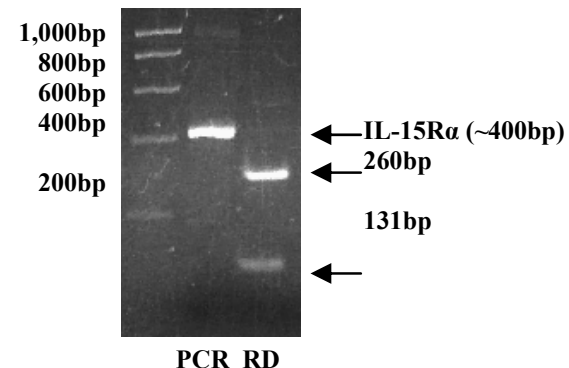

B

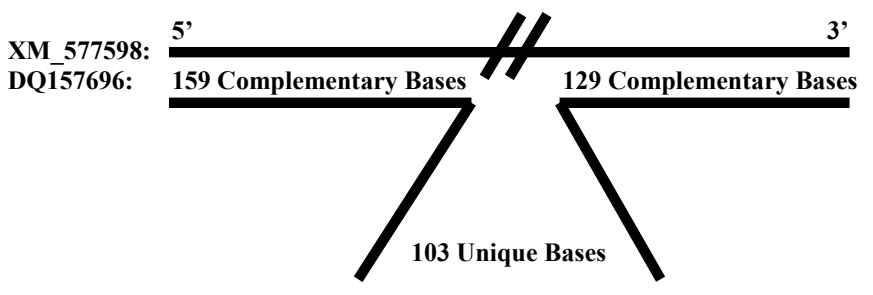

5' - GA GAC CCC TCC CTA GCT CAC TAC AGT CCA GTA CCA ACG GTA GTG ACG CCA AAG GTG ACC TCA CAA CCA GAG AGC CTC TCC CCT CCT GAA AAA GAG CCA GA AGC - 3'

HindIII 
Legend for Figure 4. Unique IL-15Ra Sequence in Rattus Skeletal Muscle. A.

Representative gel image of IL-15R $\alpha$ following PCR amplification and restriction digestion with HindIII. Incubation of PCR products at $37^{\circ} \mathrm{C}$ for $1 \mathrm{hr}$ produced the predicted fragments of $260 \mathrm{bp}$ and $131 \mathrm{bp}$. The HindIII restriction site was unique to the new IL-15R $\alpha$ sequence, DQ157696. B. Rattus IL-15R $\alpha$ sequence comparison following DNA sequencing. The new sequence information was compared to a computer predicted mRNA sequence (XM_577598). Both sequences were identical at the 5' and 3' ends, but the newly sequenced cDNA contained 103 unique bases. 


\section{Figure 5}

A

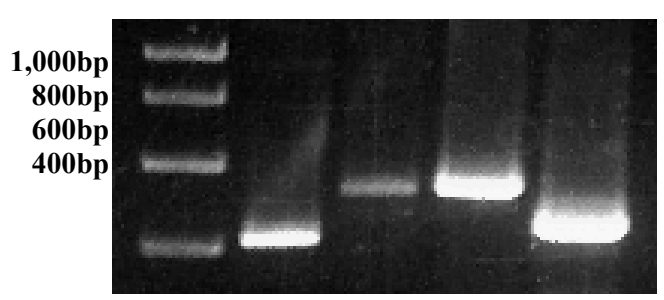

LAD IL-15R $\alpha$ IL-2R $\alpha$ IL-2Rß $\gamma c$
B

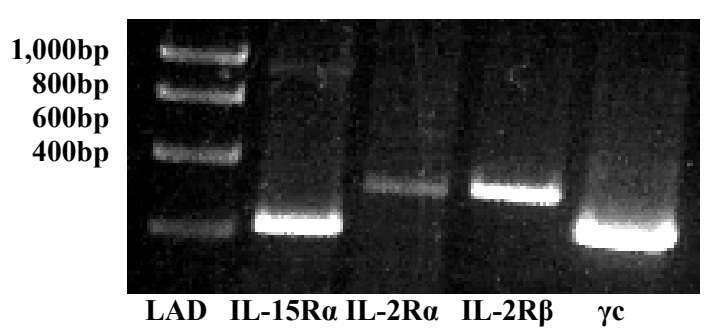

Legend for Figure 5. mRNA Expression of the Trimeric IL-15R in Skeletal Muscle. A. As a positive control, PCR amplification of the individual components of the IL-15R and IL$2 \mathrm{R}$ was performed in cDNA produced from spleen tissue and compared to PCR reactions performed in skeletal muscle cDNA. Both spleen tissue (A) and skeletal muscle tissue (B) contained mRNA for all components of the IL-15R and IL-2R. 
Table 1: PCR Primer Information

\begin{tabular}{|c|c|c|c|c|c|c|}
\hline Gene Name & Accession No. & Sequence & Position & $\mathrm{T}_{\mathrm{A}},{ }^{\circ} \mathrm{C}$ & Cycles & Product Length \\
\hline \multirow[t]{2}{*}{ IL-15 (rattus) } & NM_013129 & F: 5'-CGCCATAGCCCGCTCTTCTTCAAC & $494-517$ & 56.6 & 34 & $594 \mathrm{bp}$ \\
\hline & & R: 5'-TGGGCAGGCGGAGGTGTCTTAATAAC & $1062-1087$ & & & \\
\hline \multirow[t]{2}{*}{ Il-15 (gallus) } & AF139097 & F: 5’ -GCCGGAGAGTCAGAAAACACATGT & 176-199 & 53.0 & 36 & $508 \mathrm{bp}$ \\
\hline & & R: 5' -AGCGTATTTTTTGCATTCCCTCTG & $660-683$ & & & \\
\hline \multirow[t]{2}{*}{ IL-15R $\alpha$ (rattus) } & DQ157696 & F: 5' - TGCCCAACGCCCATATCTATT & $1-21$ & 57.3 & 35 & $391 \mathrm{bp}$ \\
\hline & & R: 5' - CTGGGGAGGACTTGTGTCT & $373-391$ & & & \\
\hline \multirow[t]{2}{*}{ IL-2R $\alpha$ (rattus) } & NM_013163 & F: 5' - CAGGGAGATGGAGCCACACTTG & $111-132$ & 57.8 & 40 & $526 \mathrm{bp}$ \\
\hline & & R: 5' - CGTCCACCTTATCTCCCCACACA & $614-636$ & & & \\
\hline \multirow[t]{2}{*}{ IL-2R $\beta$ (rattus) } & NM_013195 & F: 5' - CAGCTCTGCCTCTCGGATGTGAT & $91-113$ & 58.8 & 38 & $534 \mathrm{bp}$ \\
\hline & & R: 5' - ACGGGCCTCAAATTCCAAGTATG & $602-624$ & & & \\
\hline \multirow[t]{2}{*}{$\gamma \mathrm{c}$ (rattus) } & NM_080889 & F: 5' - GCCTCAGCCGACCAACCTCAC & $251-271$ & 56.7 & 36 & $440 \mathrm{bp}$ \\
\hline & & R: 5' - GGCTCCGAACCCGAAATGTGT & $670-690$ & & & \\
\hline
\end{tabular}

$\mathrm{T}_{\mathrm{A}}$ - annealing temperature, $\mathrm{bp}=$ base pair 
Table 2: Rodent Muscle Characteristics

\begin{tabular}{|c|c|c|c|c|c|c|c|}
\hline & \multicolumn{3}{|c|}{ Young adult animals } & \multicolumn{3}{|l|}{ Aged animals } & \\
\hline Muscle & $\begin{array}{l}\text { Young } \\
\text { Control } \\
(n=10)\end{array}$ & $\begin{array}{l}\text { Young HS } \\
(n=10)\end{array}$ & $\begin{array}{l}\text { \% Difference } \\
\text { HS vs. } \\
\text { Control }\end{array}$ & $\begin{array}{l}\text { Aged Control } \\
(n=8)\end{array}$ & $\begin{array}{l}\text { Aged HS } \\
(n=10)\end{array}$ & $\begin{array}{l}\text { \% Difference } \\
\text { HS vs. Control }\end{array}$ & $\begin{array}{l}\text { Age induced } \\
\text { difference in } \\
\text { control muscles } \\
\text { (Young vs. Aged) }\end{array}$ \\
\hline Soleus (mg) & $171.2 \pm 9.8$ & $97.9 \pm 6.0$ & $-43 \% *$ & $142.6 \pm 4.2$ & $127.5 \pm 7.6$ & $-11 \% \mathrm{~ns}$ & $17 \% *$ \\
\hline $\begin{array}{l}\text { Soleus/BM } \\
\left(\mathrm{mg} \cdot \mathrm{g}^{-1}\right)\end{array}$ & $0.46 \pm 0.006$ & $0.33 \pm 0.012$ & $-28 \% *$ & $0.27 \pm 0.009$ & $0.28 \pm 0.014$ & $+3 \% \mathrm{~ns}$ & $-41 \% *$ \\
\hline Plantaris (mg) & $400.8 \pm 22.2$ & $319.2 \pm 17.5$ & $-20 \% *$ & $312.0 \pm 9.6$ & $275.7 \pm 7.7$ & $-12 \% \mathrm{~ns}$ & $-22 \% *$ \\
\hline $\begin{array}{l}\text { Plantaris/BM } \\
\left(\mathrm{mg} \cdot \mathrm{g}^{-1}\right)\end{array}$ & $1.09 \pm 0.017$ & $1.08 \pm 0.014$ & $1 \% \mathrm{~ns}$ & $0.58 \pm 0.011$ & $0.60 \pm 0.014$ & $+3 \% \mathrm{~ns}$ & $-47 \% *$ \\
\hline
\end{tabular}

Characteristics of young 20 young adult $(5-7 \mathrm{mo})$ and 18 senescent $(33 \mathrm{mo})$ male Fischer $344 \times$ Brown Norway rats. Hindlimb suspension, HS; BM, Body mass; mg; milligrams, g, grams; ns, not significant, * , p $<0.05$ 


\section{CHAPTER 4}

Interleukin-15 does not attenuate TNF- $\alpha$ and/or aging induced pro-apoptotic signaling in skeletal muscles.

\section{ABSTRACT}

An anti-apoptotic role for interleukin-15 (IL-15) has been proposed from data in cell culture and whole animal experiments. In this study, we tested the hypothesis that apoptosis induced by tumor necrosis factor- $\alpha(\mathrm{TNF}-\alpha)$ in vitro and/or aging in vivo would be attenuated, specifically in skeletal muscles. As expected, treatment of $\mathrm{C}_{2} \mathrm{C}_{12}$ myoblasts with $20 \mathrm{ng}^{-1} \mathrm{ml}^{-1}$ of TNF- $\alpha$ decreased overall cell viability and reduced mitochondrial integrity. However, treatment with $20 \mathrm{ng}^{-1} \mathrm{ml}^{-1}$ of recombinant IL-15 (rIL15) did not attenuate the TNF- $\alpha$ induced decrease in cell viability and mitochondrial integrity in vitro. This indicates that IL-15 failed to protect against TNF- $\alpha$ induced apoptosis in myoblasts in vitro. To test the effects of IL-15 on muscle in vivo, rIL-15 $\left(100 \mu \mathrm{g} \mathrm{kg}^{-1}\right.$ per day) was administered via osmotic pumps, to young adult $(\mathrm{n}=6)$ and aged $(n=6)$ Fischer $344 \times$ Brown Norway rodents for 14d. Apoptosis, as measured by DNA fragmentation, was greater in plantaris, soleus, and medial gastrocnemius muscles from aged animals and in all muscles from IL-15 treated animals compared to muscles from control animals. DNA fragmentation was slightly greater in left ventricles from IL-15 treated aged rodents with no changes in young adult rodents. Signs of apoptosis in the liver were attenuated in all IL-15 treated animals compared to control, while no effects of age or IL-15 treatment were evident in the spleen. The data from these studies do not support our initial hypothesis and suggest that IL-15 does not prevent apoptotic signaling in skeletal myogenic cultures induced by TNF- $\alpha$ and in muscle tissue from aged rodents. 
The proposed anti-apoptotic property of IL-15 may be tissue specific; however, additional research is required to more clearly decipher this role.

KEYWORDS: apoptosis, IL-15, TNF- $\alpha$, aging, skeletal muscle 


\section{INTRODUCTION}

Interleukin-15 (IL-15) is a pleiotropic cytokine with numerous proposed roles in both lymphoid and non-lymphoid tissues (reviewed in $(13 ; 38)$ ). Cell and tissue types that have been shown to express IL-15 mRNA include placenta, skeletal muscle, liver, epithelial cells, activated macrophages $(10 ; 16)$, and muscle satellite cells (22). In addition to this widespread expression, IL-15 associated signaling can be initiated in a number of different ways (7). For example, secreted IL-15 protein can bind to its trimeric receptor, and to the individual IL-15R $\alpha$ chain at the cell surface. Additionally, IL-15 can be presented at the cell surface in a form bound to the IL-15R $\alpha$ chain (i.e. trans presentation) in which it can interact with cells expressing the IL-2/IL-15R $\beta$ and $\gamma$ chains as well as cause reverse signaling through soluble IL-15R $\alpha(6 ; 7)$. Furthermore, two isoforms of mature human IL-15 have been identified, based on alternative splicing in the 5 'region of the gene $(19 ; 24)$. The total amount of mature IL-15 protein is tightly regulated at the levels of translation and vesicle trafficking (1), possibly due to the widespread tissue expression of both IL-15 and IL-15R $\alpha$ transcripts as well as the diverse signaling pathways that can be initiated.

In an effort to decipher the specific roles of IL-15, cytokine concentrations have been experimentally modulated both in vitro and in vivo $(8 ; 9 ; 11 ; 14 ; 15 ; 17)$. One consistent finding is that IL-15 can act as an apoptosis-inhibitor in response to inflammatory conditions and/or pathological states in lymphoid cells such as CD8+ Tcells (2), non-lymphoid cells such as fibroblasts (8), and tissues such as skeletal muscle (14), spleen (9), and liver $(9 ; 36)$. This anti-apoptotic role seems to be protective against the pro-apoptotic property of another cytokine, TNF- $\alpha$, as well as FasL $(8 ; 18)$. These 
pro-apoptotic proteins initiate signaling upon ligation to their cell surface death receptors (i.e. - TNFR, Fas/CD95, respectively), resulting in activation of caspase-8 and caspase-3 (34).

Apoptotic nuclei have been previously demonstrated in skeletal muscle following muscle denervation $(30 ; 31)$, muscle unloading $(20 ; 27 ; 32 ; 33)$, and aging $(12)$, with signaling arising from the mitochondrial intrinsic apoptotic pathway. Recently, our laboratory has provided evidence that the extrinsic apoptotic pathway is also active in aged skeletal muscles (26). This may be in response to an age-related increase in circulating TNF- $\alpha$ concentrations (3-5). Specifically, skeletal muscles from aged animals exhibited greater mRNA and protein expression of FADD, greater protein content of proapoptotic Bid, and greater enzymatic activity of both caspase- 8 and caspase- 3 , when compared to muscles from young adult animals. Although systemic TNF- $\alpha$ concentrations were not measured in this study, the data suggest the pathway, downstream of the type I TNFR, is active in aged muscles. Interestingly, experiments have shown that IL-15 protein can attenuate this signaling pathway in vitro in a fibroblast cell line stimulated with TNF- $\alpha$ by disrupting the activation of caspase- 8 at the cytoplasmic portion of the type I TNFR(8). Similar observations have been made in vivo in tumor-bearing rodents (14).

Our laboratory has previously observed that IL-15 mRNA is elevated in skeletal muscles in response to aging and muscle unloading and we speculated that this is a molecular attempt to counter pro-atrophic and/or pro-apoptotic stimuli (manuscript in review). In the current experiments, we hypothesized that recombinant IL-15 (rIL-15) would have a similar anti-apoptotic property and attenuate apoptotic signaling in aged 
muscles. This hypothesis was tested in vitro using murine rIL-15 and rTNF- $\alpha$ in the mouse $\mathrm{C}_{2} \mathrm{C}_{12}$ myogenic cell line and in vivo by increasing the systemic levels of IL-15 in young adult and aged rodents. In addition to skeletal muscle, other tissues were analyzed from rodents to examine tissue specific effects of IL-15. The results of these experiments do not support the ability of IL-15 to attenuate pro-apoptotic signaling downstream of the type I TNFR within skeletal muscle. rIL-15 failed to attenuate pro-apoptotic signaling induced by rTNF- $\alpha$ in myoblasts in vitro. Although rIL-15 did not increase apoptosis in vitro, rIL-15 delivered to rodents systemically, increased DNA fragmentation in muscles from both young adult and aged animals. In contrast, in vivo administration of rIL-15 had an anti-apoptotic effect in liver, but it had minimal effects in the left ventricle and spleen of rodents. We speculate that the proposed anti-apoptotic property of IL-15 may be cell-type specific as well as specific to the degree of pathology present (i.e. - tumor burden vs. normal aging). Additional research is required to more precisely determine the roles of IL-15 in vivo.

\section{METHODS}

Experiment 1 - Myogenic Cell Culture. $\mathrm{C}_{2} \mathrm{C}_{12}$ mouse myoblasts were obtained from the American Type Culture Collection (Manassas, VA). Myoblasts were cultured in Dulbecco's modified Eagle's medium (DMEM, Gibco, Carlsbad, CA) supplemented with $10 \%$ fetal bovine serum (FBS) and antibiotic-antimycotic (Gibco, Carlsbad, CA) at $37^{\circ} \mathrm{C}$

and $5 \% \mathrm{CO} 2$. Myoblasts were plated in $10 \mathrm{~cm}^{2}$ cell culture dishes at a density of $2.5 \times 10^{5}$ cells and allowed to adhere to the bottom of the culture plate for a period of 4-6 hours. Following adherence, culture medium was changed to DMEM containing 2\% FBS with 
no antibiotic. Recombinant cytokines were added in the following groups: CON (no cytokines), TNF- $\alpha$ (20 ng'ml ${ }^{-1}$ recombinant mouse TNF- $\alpha$, R\&D Systems, Minneapolis, MN), IL-15 (20 ng $\mathrm{ml}^{-1}$ recombinant mouse IL-15, R\&D Systems, Minneapolis, MN), and COMBO (20 ng'ml ${ }^{-1}$ of TNF- $\alpha$ and IL-15). Myoblast cultures were maintained for $72 \mathrm{~h}$ with recombinant cytokines replaced every $24 \mathrm{~h}$. At $72 \mathrm{~h}$ of culture, myoblasts were harvested using trypsin and prepared for flow cytometric analyses. Preliminary experiments were performed to determine optimal concentrations of recombinant cytokines and duration of myoblast culture (data not shown). To verify the biological activity of recombinant IL-15, the CTLL-2 lymphocyte cell line was utilized in a proliferation experiment (data not shown) because previous data has shown IL-15 has the ability to stimulate proliferation of this IL-2 dependent cell line (35).

Flow Cytometric Analysis of Apoptosis. Following 72h of cytokine stimulation, both floating myoblasts and adherent myoblasts were harvested. Culture media was collected and centrifuged at 200rpm for 5-minutes to obtain the cell pellet. Adherent cells were washed twice with sterile PBS and incubated in $0.5 \%$ trypsin at $37^{\circ} \mathrm{C}$ for 5 -minutes. These myoblasts were collected, added to the cell pellet, and centrifuged at 2000rpm for 5-minutes. The combined cell pellet was washed once in PBS before being resuspended in $500 \mu 1$ of $1 \mathrm{X}$ PBS. A cell viability probe (Pharmingen, San Diego, CA, containing the DNA dye 7-amino-actinomycin D (7AAD), was used to assess overall cell survival and viability following treatments. As a secondary measure of cell apoptosis, a fluorescent dye that binds intact mitochondria (MitoTracker, Molecular Probes, Carlsbad, CA) was used following cytokine treatments. Ten microliters of Via-Probe and $10 \mu 1$ of 
MitoTracker was added to the cell suspension and incubated for 10 -minutes at $4{ }^{\circ} \mathrm{C}$ in the dark.

Statistics. Statistical analyses were performed using the SPSS software package, version 10.0. Data are presented as MEANS $\pm \mathrm{SE}$. Data were analyzed using a one-way analysis of variance (ANOVA) to examine the effects in the four treatment groups. The Scheffe post-hoc test was utilized to determine differences between groups, with significance set a $\mathrm{p}<0.05$.

Experiment 2 - In vivo Experiments in Rodents. All procedures followed the guidelines of the National Institutes of Health, and were approved by the Institutional Animal Care and Use Committee of the West Virginia University School of Medicine. Twelve young adult (3 mo.) and twelve senescent (30 mo.) male Fischer 344 XBrown Norway rats were obtained from the National Institute on Aging barrier-raised colony that is housed at Harlan Animal Colonies (Indianapolis, IN). The animals were housed at 20$22^{\circ} \mathrm{C}$ in barrier-controlled conditions under a 12:12-h light-dark cycle. They were provided rat chow and water ad libitum.

Experimental animals were randomly divided into four groups: young adult control (YC, n=6), young adult IL-15 (Y15, n=6), aged control (AC, n=6), and aged IL15 (A15, n=6). Mini-osmotic pumps (Model \#2002, Alzet, Cupertino, CA) were used to deliver rIL-15 systemically at a rate of $0.51 \mu \mathrm{l}^{1} \mathrm{hr}^{-1}$ over a $14 \mathrm{~d}$ period. Recombinant human IL-15 was generously provided by Amgen Corporation (Thousand Oaks, CA) at a stock concentration of $4.41 \mathrm{mg} \cdot \mathrm{ml}^{-1}$. The total amount of rIL-15 administered 
exogenously was based on the average bodyweight of young and aged animals, to

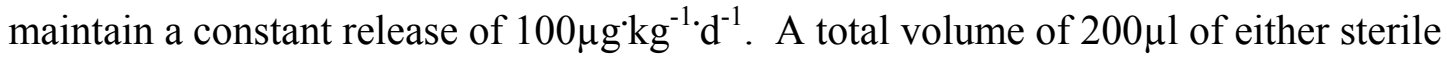
PBS or IL-15 was loaded into the mini-pumps and the pumps were subsequently incubated in sterile $\mathrm{PBS}$ at $37^{\circ} \mathrm{C}$ for $12 \mathrm{~h}$ to fully prime the pumps. Using sterile techniques, an incision was made along the mid-line of the dorsal surface of each animal and mini-pumps were implanted subcutaneously (sc). Incisions were closed using wound clips and animals were monitored daily for signs of infection and weighed at $7 \mathrm{~d}$ and $14 \mathrm{~d}$ of intervention.

The animals were deeply anesthetized with $5 \%$ isoflurane and the heart was exposed. Blood samples were obtained via cardiac puncture of the left ventricle. Blood was collected into EGTA containing collection tubes (Vacutainer, BD, Franklin Lakes, NJ) and allowed to sit at room temperature for 15-minutes. Samples were centrifuged for 5-minutes at $2000 \mathrm{rpm}$ and plasma was aliquoted and stored at $-80^{\circ} \mathrm{C}$ until assayed. Following blood collection, the animals were sacrificed by removing the heart. The heart was flushed in phosphate buffered saline to remove excess blood, weighed and flash frozen in liquid nitrogen. The entire spleen as well as a section of the liver were removed along with the plantarflexor and dorsiflexor skeletal muscles from both legs. The hamstring muscles were first removed to expose the plantar flexor muscles of the hindlimb. The entire gastrocnemius muscle was removed and subsequently separated into medial and lateral heads by visual inspection of muscle fiber orientation. The plantaris and soleus were then removed from each hindlimb and trimmed of visible connective tissue. The dorsiflexor muscles (tibialis anterior and extensor digitorum longus) were then removed, and trimmed of visible connective tissue. Immediately upon 
dissection, all tissue samples were flash frozen in isopentane cooled to the temperature of liquid nitrogen. All tissues were stored at $-80^{\circ} \mathrm{C}$ until biochemical analyses were performed.

Enzyme-Linked Immunosorbant Assay (ELISA). Plasma samples were used to verify a systemic elevation of human IL-15 using a sensitive ELISA kit (R\&D Systems, Minneapolis, MN) according to manufacture's instructions. A subset of tissue homogenates was also assayed with this kit to verify a tissue-specific elevation of human IL-15. Human IL-15 was detected in homogenates from the plantaris and soleus muscles as well as the left ventricle and spleen (data not shown). Systemic TNF- $\alpha$ levels were also assayed using a sensitive ELISA kit (R\&D Systems, Minneapolis, MN) according to manufacture's instructions.

Cytoplasmic protein extraction and quantification. Tissue samples, approximately $50-75 \mathrm{mg}$, were homogenized in $1 \mathrm{ml}$ of ice-cold lysis buffer $(10 \mathrm{mM} \mathrm{NaCl}, 1.5 \mathrm{mM}$ $\mathrm{MgCl}_{2}, 20 \mathrm{mM}$ HEPES at $\mathrm{pH} 7.4,20 \%$ glycerol, $0.1 \%$ Triton X-100, and 1mM dithioreitol) to obtain cytoplasmic protein extracts according to the methods of Rothermel et al (29). Homogenates were centrifuged at 3,000 rpm for 5-minutes at $4^{\circ} \mathrm{C}$. The supernatants were collected that contained the cytoplasmic protein fraction. The protein concentration of the total homogenate was assayed spectrophotometrically at $562 \mathrm{~nm}$ (BioRad, SmartSpec 3000) using a commercial bicinchoninic acid (BCA) method as recommended by the manufacturer (Pierce, Rockford, IL) with bovine serum albumin used as standards. To verify the BCA protein quantification method, samples were also 
assayed using a DC Protein Assay kit (BioRad, Hercules, CA), which is similar to the Lowry method (21). Briefly, this kit is a colometric assay that utilizes reducing agents and detergents for the determination of protein concentrations in tissue homogenates at a wavelength of $650-750 \mathrm{~nm}$.

Cell death ELISA and calculation of apoptotic index. Cytoplasmic protein extracts were used to quantify DNA fragmentation in all muscle samples using a commercially available ELISA kit (Cell Death Detection ELISA, Roche Diagnostics, Mannheim, Germany). Briefly, the wells of a 96-well plate were coated with a primary anti-histone mouse monoclonal antibody. Following the addition of $100 \mu 1$ of each sample, a secondary anti-DNA mouse monoclonal antibody coupled to peroxidase was added to each well. The substrate, 2,2'-azino-di-(3-ethylbenzthiazoline sulfonate) (ABST) was used to photometrically determine the amount of peroxidase retained in the immunocomplex. The color change of each well was determined at a wavelength of 405nm using a Dynex MRX plate reader and computer software (Revelation, Dynatech Laboratories, CA). The resulting optical density (OD) was normalized to the protein concentration of each sample and recorded as the apoptotic index $\left(\mathrm{OD}_{405} \mathrm{mg}\right.$ protein $\left.^{-1}\right)$.

Fluorometric Caspase-Activity Assay. Caspase-8 and caspase-3 activity were examined using commercially available fluoremetric substrates (caspase-8/10 AC-IETDAMC, caspase-3 AC-DEVD-AFC, Alexis Biochemical, San Diego, CA). Previous research has demonstrated that embryonic, but not adult skeletal muscle, contains detectable levels of caspase-10, thus allowing the assumption that the caspase-8/10 
substrate is specific to the activity of caspase- 8 in this study (23). To each well of a 96well fluorescent microplate (Nalgene Nunc Int., Rochester, NY) was added $50 \mu 1$ of caspase activity buffer, $50 \mu 1$ of cytoplasmic protein without protease inhibitor from each muscle, and $10 \mu \mathrm{l}$ of substrate $(1 \mathrm{mM})$. Samples were incubated at $37^{\circ} \mathrm{C}$ for 2 -hours with caspase activity accessed using a fluorescent microplate reader at the following wavelengths: caspase- 8 excitation 380nm and emission 460nm; caspase-3 excitation $400 \mathrm{~nm}$ and emission $505 \mathrm{~nm}$. Caspase activity was quantified by subtracting OD readings at time 2 -hour from the initial reading at time 0 -hour. The resulting optical density was normalized to the protein concentration of each muscle sample to provide a caspase activity index (OD'mg protein $\left.{ }^{-1}\right)$.

Statistics. Statistical analyses were performed using the SPSS software package, version 10.0. Data are presented as MEANS $\pm \mathrm{SE}$. Data were analyzed using a $2 \times 2$ ANOVA to examine the main effects of age and IL-15 treatment as well as the age $\mathrm{x}$ treatment interaction, with significance set a $\mathrm{p}<0.05$.

\section{RESULTS}

\section{EXPERIMENT 1}

Cell Viability Accessed by Flow Cytometry. A cell viability probe, containing 7AAD, which binds to DNA, was used to first examine overall cell death in response to rTNF- $\alpha$, rIL-15, and rTNF- $\alpha+$ rIL-15. This experiment was performed in duplicate, with representative results presented in Figure 1. Positive staining for 7AAD, indicative of an overall decrease of cell viability, was increased $28 \%$ following treatment with rTNF- $\alpha$, 
compared to unstimulated myoblasts, although this change did not reach significance $(p=0.487$; Figure 1B). Cell viability was unchanged when myoblasts were treated with rIL-15 alone ( $p=0.744$; Figure 1C). Positive 7AAD staining was increased $\sim 10 \%$ when myoblast cultures contained both rTNF- $\alpha$, rIL-15, although this change did not reach significance $(p=0.971$; Figure 1D). Visual inspection of myoblasts at day 3 of stimulation supported the changes in TNF- $\alpha$ containing cultures, as a significant number of myoblasts were unattached and floating in the culture media, while myoblasts remained healthy and attached in unstimulated cultures and in cultures containing rIL-15 only.

Mitochondrial Integrity Accessed by Flow Cytometry. As an additional marker of apoptosis, a fluorescent dye that specifically recognizes mitochondria was utilized. This experiment was performed in duplicated and repeated twice. The data are presented in Table 1, with representative graphs presented in Figure 2. When myoblasts were exposed to rTNF- $\alpha$, mitochondrial staining was reduced by $37 \%$ and $32 \%$. Incubation of myoblasts with rIL-15 did not change mitochondrial integrity from control values as assessed with this dye. However, when myoblast cultures contained both rTNF- $\alpha$ and rIL-15, mitochondrial staining was again reduced $33 \%$ and $30 \%$, indicating no protective role of IL-15 in these cultures.

\section{EXPERIMENT 2}

Systemic Elevation of Human IL-15. As a means to verify proper osmotic pump operation, plasma samples were used to measure human IL-15 in experimental animals. 
Human IL-15 was detected in the IL-15 treated experimental animals (Figure 4), although differences were observed when comparing values from Y15 and A15. Values for all control animals (YC and $\mathrm{AC}$ ) were below the lowest standard used in the microplate assay, indicating specificity for human IL-15 with this assay.

TNF- $\alpha$ ELISA. Plasma samples were used to assay systemic levels of TNF- $\alpha$ in an effort to support an age-related elevation of this cytokine. Surprisingly, TNF- $\alpha$ levels were below the detectable limit of the assay in all experimental animals (data not shown).

Bodyweight. The changes in bodyweight for all groups at $7 \mathrm{~d}$ and $14 \mathrm{~d}$ of intervention are presented in Table 2. The bodyweight of YC animals increased 12.3\% after the $14 \mathrm{~d}$ intervention, while the bodyweight of AC animals was unchanged. The bodyweight of YIL-15 animals increased 9.1\% after the $14 \mathrm{~d}$ intervention. In contrast, the bodyweight of AIL-15 animals decreased $4.1 \%$ following the $14 \mathrm{~d}$ intervention. When comparing groups, all aged animals were significantly heavier than all young animals.

Skeletal Muscle and Organ Weights. The individual muscle and organ weights for all experimental animals are presented in Table $\mathbf{3}$ and presented as absolute weights as well as weights normalized to the rodent bodyweight to account for the changes observed in all groups during the $14 \mathrm{~d}$ intervention. The pattern of change was similar for all 5 skeletal muscles analyzed. Specifically, normalized muscle weights from all aged animals were significantly less when compared to normalized muscle weights from young adult animals. Additionally, normalized muscle weights from animals receiving 
IL-15 were significantly less when compared to age-matched controls. The absolute weights of hearts from aged animals were greater than those from young adult animals, but were less when normalized to bodyweight. There was no effect of IL-15 treatment in hearts from experimental animals. The absolute weight of the spleen was greater in aged animals than in young adult and also greater in both groups with IL-15 treatment. Normalization of the spleen weight to the bodyweight abolished the effect of age in this tissue, but the effect of IL-15 treatment remained.

Cell-Death ELISA. Homogenates from three skeletal muscles (plantaris, soleus, medial gastrocnemius) as well as the left ventricle, liver, and spleen were used to measure any changes in apoptosis using a cell death ELISA kit to quantify fragmented DNA and calculate the apoptotic index. The presence of fragmented DNA followed a similar pattern of change in all skeletal muscles examined. Specifically, control muscles from aged rodents exhibited greater levels of DNA fragmentation compared to control muscles from young adult, while IL-15 treatment exacerbated the apoptotic index in muscles from young adult and aged rodents (Figures $\mathbf{4 A - C}$ ). In contrast, although aging itself had no effect on the apoptotic index in the left ventricle, the apoptotic index was slightly greater in muscles from IL-15 treated aged rodents (Figure 4D). Similarly, aging had no effect on the apoptotic index in liver homogenates, but systemic elevation of IL-15 had a positive effect on this parameter in both young adult and aged animals (Figure 4E). No differences in the presence of fragmented DNA were observed in the spleen homogenates (Figure 6F). 
Fluorometric Caspase Activity. The activity of caspase- 8 and caspase- 3 was assessed in tissue homogenates from three skeletal muscles (plantaris, soleus, medial gastrocnemius) as well as the left ventricle and spleen. Despite measurable changes in the presence of fragmented DNA, no changes were observed in the activity of either caspases in all tissues assayed (data not shown).

\section{DISCUSSION}

In this study, we sought to determine if IL-15 protein could attenuate proapoptotic signaling within skeletal muscle downstream of the type I TNFR (i.e. extrinsic apoptotic pathway), through both in vitro and in vivo experimentation. Previous work has shown IL-15 can disrupt the extrinsic apoptotic pathway in skeletal muscle in a rodent model of cancer as well as within other tissue types. Our laboratory has proposed that skeletal muscle increases IL-15 mRNA concentrations in response to pro-atrophic stimuli as a molecular attempt to counter muscle loss (manuscript in review) and previous work has shown IL-15 can inhibit apoptotic signaling via the extrinsic pathway. The results of the current studies, however, do not support a protective role of IL-15 in skeletal muscle in aged rodents or in myogenic cultures stimulated with rTNF- $\alpha$. In fact, when recombinant human IL-15 was elevated systemically for 14 days in experimental animals, muscles from young adult and aged rodents displayed increases in fragmented DNA.

The systemic elevation of IL-15 within experimental animals has been performed previously, either by daily subcutaneous (s.c.) bolus injections $(11 ; 14)$ or through similar osmotic mini-pumps as used in this study (17). Daily s.c. injections of $100 \mu \mathrm{gkg}^{-1}$ of rIL- 
15 over a 7 day period into young male tumor-bearing Wistar rats decreased the rate of protein degradation, while also inhibiting components of the ubiquitin-dependent proteolytic pathway (11). In a related study, daily IL-15 injections reduced the incidence of DNA fragmentation in skeletal muscles from tumor bearing rats and this was associated with an alteration of the mRNA expression of the type I and type II TNFRs (14). In vitro data also provided evidence that IL-15 had positive effects in myogenic cultures when IGF-I levels were experimentally reduced (28). Based on these data, we hypothesized that IL-15 would exert similar anti-apoptotic effects in aged animals where circulating TNF- $\alpha$ levels are also reported to be elevated (25) and anabolic hormone levels are typically reduced (37). However, despite measurable increases in systemic IL15 , especially in aged rodents, the incidence of DNA fragmentation was increased in all muscle types analyzed.

The overexpression of IL-15 has previously been shown to protect host animals against a lethal challenge. Specifically, IL-15 transgenic mice were resistant to a lethal dose of E. coli that killed $85 \%$ of non-transgenic mice within 12 hours of delivery. In this same study, wild-type mice that received a one time intraperitoneal injection of either $1 \mu \mathrm{g}$ or $10 \mu \mathrm{g}$ of recombinant IL-15 were also resistant to the same dose of E. coli. When peritoneal cells from IL-15 transgenic mice and IL-15 treated wild-type mice were isolated, these cells were resistant to apoptosis induced by TNF- $\alpha$ stimulation in vitro. Serum TNF- $\alpha$ levels, measured by ELISA, were greater than 600 pg.ml-1 following E. coli injection (18). Injection of $100 \mu \mathrm{g}$ of a mouse Fas monoclonal antibody induced massive hepatocyte apoptosis and death within a few hours. However, injection of a long-lasting IL-15 fusion protein prevented organ failure and death following Fas 
antibody injection. IL-15 also prevented apoptosis of human T- and B-cells induced by anti-Fas antibody, anti-CD3, dexamethasone, and anti-IgM in vitro (9). These data demonstrate that IL-15 has the ability to inhibit death resulting from large-scale apoptosis, induced by either TNF- $\alpha$ or anti-Fas antibody.

In the current study, we attempted to measure plasma TNF- $\alpha$ to support an agerelated increase of this cytokine. An increase in systemic TNF- $\alpha$ would have supported the assumption that this cytokine could initiate the extrinsic apoptotic pathway in our rodent model. However, TNF- $\alpha$ was not detectable in the plasma collected from either young adult or aged animals. It is possible that the age of the rodents utilized in this study (i.e. 30 mo.) was not old enough to elicit an increase in TNF- $\alpha$ levels.

Additionally, the aging stimulus may not have as dramatic an effect as a cancer stimulus for eliciting elevations in this cytokine.

In summary, our data suggest that IL-15 does not attenuate apoptotic signaling induced by TNF- $\alpha$ in myogenic cultures or in the skeletal muscles of aged animals. These data conflict with other data showing a protective effect of IL-15. However, this protective effect may take place in response to acute and dramatic increases in apoptosis, as observed following E. coli or anti-Fas injections, and not during the chronic stimulus of aging. Additionally, variability in the delivery methods of IL-15 and/or the type of IL15 utilized may contribute to our conflicting data, as well as ages and strains of experimental animals. Future studies should address the efficacy of IL-15 treatment to spare muscle mass in response to muscle wasting disorders and in very old animals, as IL-15 has shown promise as an apoptotic inhibitor in conditions with more extreme stresses than imposed in this study. 


\section{Reference List}

1. Bamford RN, DeFilippis AP, Azimi N, Kurys G and Waldmann TA. The 5' untranslated region, signal peptide, and the coding sequence of the carboxyl terminus of IL-15 participate in its multifaceted translational control. $J$ Immunol 160: 4418-4426, 1998.

2. Berard M, Brandt K, Bulfone-Paus S and Tough DF. IL-15 promotes the survival of naive and memory phenotype CD8+ T cells. J Immunol 170: 5018-5026, 2003.

3. Bruunsgaard H. Effects of tumor necrosis factor-alpha and interleukin-6 in elderly populations. Eur Cytokine Netw 13: 389-391, 2002.

4. Bruunsgaard H, Andersen-Ranberg K, Hjelmborg JB, Pedersen BK and Jeune B. Elevated levels of tumor necrosis factor alpha and mortality in centenarians. Am J Med 115: 278-283, 2003.

\section{Bruunsgaard H, Ladelund S, Pedersen AN, Schroll M, Jorgensen T and} Pedersen BK. Predicting death from tumour necrosis factor-alpha and interleukin-6 in 80-year-old people. Clin Exp Immunol 132: 24-31, 2003. 
6. Budagian V, Bulanova E, Paus R and Bulfone-Paus S. IL-15/IL-15 receptor biology: A guided tour through an expanding universe. Cytokine Growth Factor Rev 17: 259-280, 2006.

7. Bulfone-Paus S, Bulanova E, Budagian $\mathbf{V}$ and Paus R. The interleukin15/interleukin-15 receptor system as a model for juxtacrine and reverse signaling. Bioessays 28: 362-377, 2006.

8. Bulfone-Paus S, Bulanova E, Pohl T, Budagian V, Durkop H, Ruckert R, Kunzendorf U, Paus R and Krause H. Death deflected: IL-15 inhibits TNF-alphamediated apoptosis in fibroblasts by TRAF2 recruitment to the IL-15Ralpha chain. FASEB J 13: 1575-1585, 1999.

9. Bulfone-Paus S, Ungureanu D, Pohl T, Lindner G, Paus R, Ruckert R, Krause H and Kunzendorf U. Interleukin-15 protects from lethal apoptosis in vivo. Nat Med 3: 1124-1128, 1997.

10. Burton JD, Bamford RN, Peters C, Grant AJ, Kurys G, Goldman CK, Brennan J, Roessler E and Waldmann TA. A lymphokine, provisionally designated interleukin $\mathrm{T}$ and produced by a human adult $\mathrm{T}$-cell leukemia line, stimulates T-cell proliferation and the induction of lymphokine-activated killer cells. Proc Natl Acad Sci U S A 91: 4935-4939, 1994. 


\section{Carbo N, Lopez-Soriano J, Costelli P, Busquets S, Alvarez B, Baccino FM,} Quinn LS, Lopez-Soriano FJ and Argiles JM. Interleukin-15 antagonizes muscle protein waste in tumour-bearing rats. Br J Cancer 83: 526-531, 2000.

12. Dirks A and Leeuwenburgh C. Apoptosis in skeletal muscle with aging. Am $J$ Physiol Regul Integr Comp Physiol 282: R519-R527, 2002.

13. Fehniger TA and Caligiuri MA. Interleukin 15: biology and relevance to human disease. Blood 97: 14-32, 2001.

14. Figueras M, Busquets S, Carbo N, Barreiro E, Almendro V, Argiles JM and Lopez-Soriano FJ. Interleukin-15 is able to suppress the increased DNA fragmentation associated with muscle wasting in tumour-bearing rats. FEBS Lett 569: 201-206, 2004.

15. Furmanczyk PS and Quinn LS. Interleukin-15 increases myosin accretion in human skeletal myogenic cultures. Cell Biol Int 27: 845-851, 2003.

16. Grabstein KH, Eisenman J, Shanebeck K, Rauch C, Srinivasan S, Fung V, Beers C, Richardson J, Schoenborn MA, Ahdieh M and . Cloning of a T cell growth factor that interacts with the beta chain of the interleukin-2 receptor. Science 264: 965-968, 1994. 
17. Harcourt LJ, Holmes AG, Gregorevic P, Schertzer JD, Stupka N, Plant DR and Lynch GS. Interleukin-15 administration improves diaphragm muscle pathology and function in dystrophic mdx mice. Am J Pathol 166: 1131-1141, 2005.

18. Hiromatsu T, Yajima T, Matsuguchi T, Nishimura H, Wajjwalku W, Arai T, Nimura Y and Yoshikai Y. Overexpression of interleukin-15 protects against Escherichia coli-induced shock accompanied by inhibition of tumor necrosis factoralpha-induced apoptosis. J Infect Dis 187: 1442-1451, 2003.

19. Kurys G, Tagaya Y, Bamford R, Hanover JA and Waldmann TA. The long signal peptide isoform and its alternative processing direct the intracellular trafficking of interleukin-15. J Biol Chem 275: 30653-30659, 2000.

20. Leeuwenburgh C, Gurley CM, Strotman BA and Dupont-Versteegden EE. Age-related differences in apoptosis with disuse atrophy in soleus muscle. Am J Physiol Regul Integr Comp Physiol 288: R1288-R1296, 2005.

21. Lowry OH, Rosebrough NJ, Farr AL and Randall RJ. Protein measurement with the Folin phenol reagent. J Biol Chem 193: 265-275, 1951.

22. Michal J, Xiang Z, Davenport G, Hayek M, Dodson MV and Byrne KM. Isolation and characterization of canine satellite cells. In Vitro Cell Dev Biol Anim 38: 467-480, 2002. 
23. Ng PW, Porter AG and Janicke RU. Molecular cloning and characterization of two novel pro-apoptotic isoforms of caspase-10. J Biol Chem 274: 10301-10308, 1999.

24. Onu A, Pohl T, Krause H and Bulfone-Paus S. Regulation of IL-15 secretion via the leader peptide of two IL-15 isoforms. J Immunol 158: 255-262, 1997.

25. Phillips T and Leeuwenburgh C. Muscle fiber specific apoptosis and TNF-alpha signaling in sarcopenia are attenuated by life-long calorie restriction. FASEB J 19: 668-670, 2005.

26. Pistilli EE, Jackson JR, and Alway SE. Death receptor associated pro-apoptotic signaling in aged skeletal muscle. Apoptosis. In Press. 2006.

27. Pistilli EE, Siu PM and Alway SE. Molecular regulation of apoptosis in fast plantaris muscles of aged rats. J Gerontol A Biol Sci Med Sci 61: 245-255, 2006.

28. Quinn LS, Haugk KL and Damon SE. Interleukin-15 stimulates C2 skeletal myoblast differentiation. Biochem Biophys Res Commun 239: 6-10, 1997.

29. Rothermel B, Vega RB, Yang J, Wu H, Bassel-Duby $R$ and Williams RS. A protein encoded within the Down syndrome critical region is enriched in striated muscles and inhibits calcineurin signaling. J Biol Chem 275: 8719-8725, 2000. 
30. Siu PM and Alway SE. Mitochondria-associated apoptotic signalling in denervated rat skeletal muscle. J Physiol 565: 309-323, 2005.

31. Siu PM and Alway SE. Deficiency of the Bax gene attenuates denervation-induced apoptosis. Apoptosis 11: 967-981, 2006.

32. Siu PM, Pistilli EE and Alway SE. Apoptotic responses to hindlimb suspension in gastrocnemius muscles from young adult and aged rats. Am J Physiol Regul Integr Comp Physiol 289: R1015-26, 2005.

33. Siu PM, Pistilli EE, Butler DC and Alway SE. Aging influences cellular and molecular responses of apoptosis to skeletal muscle unloading. Am J Physiol Cell Physiol 288: C338-C349, 2005.

34. Sprick MR and Walczak H. The interplay between the Bcl-2 family and death receptor-mediated apoptosis. Biochim Biophys Acta 1644: 125-132, 2004.

35. Sugiura T, Harigai M, Kawaguchi Y, Takagi K, Fukasawa C, Ohsako-Higami S, Ohta S, Tanaka M, Hara M and Kamatani N. Increased IL-15 production of muscle cells in polymyositis and dermatomyositis. Int Immunol 14: 917-924, 2002.

36. Suzuki A, McCall S, Choi SS, Sicklick JK, Huang J, Qi Y, Zdanowicz M, Camp T, Li YX and Diehl AM. Interleukin-15 increases hepatic regenerative activity. J Hepatol 45: 410-418, 2006. 
37. Tenover JL. Testosterone and the aging male. J Androl 18: 103-106, 1997.

38. Waldmann TA and Tagaya Y. The multifaceted regulation of interleukin-15 expression and the role of this cytokine in NK cell differentiation and host response to intracellular pathogens. Annu Rev Immunol 17: 19-49, 1999. 


\section{Figure 1}
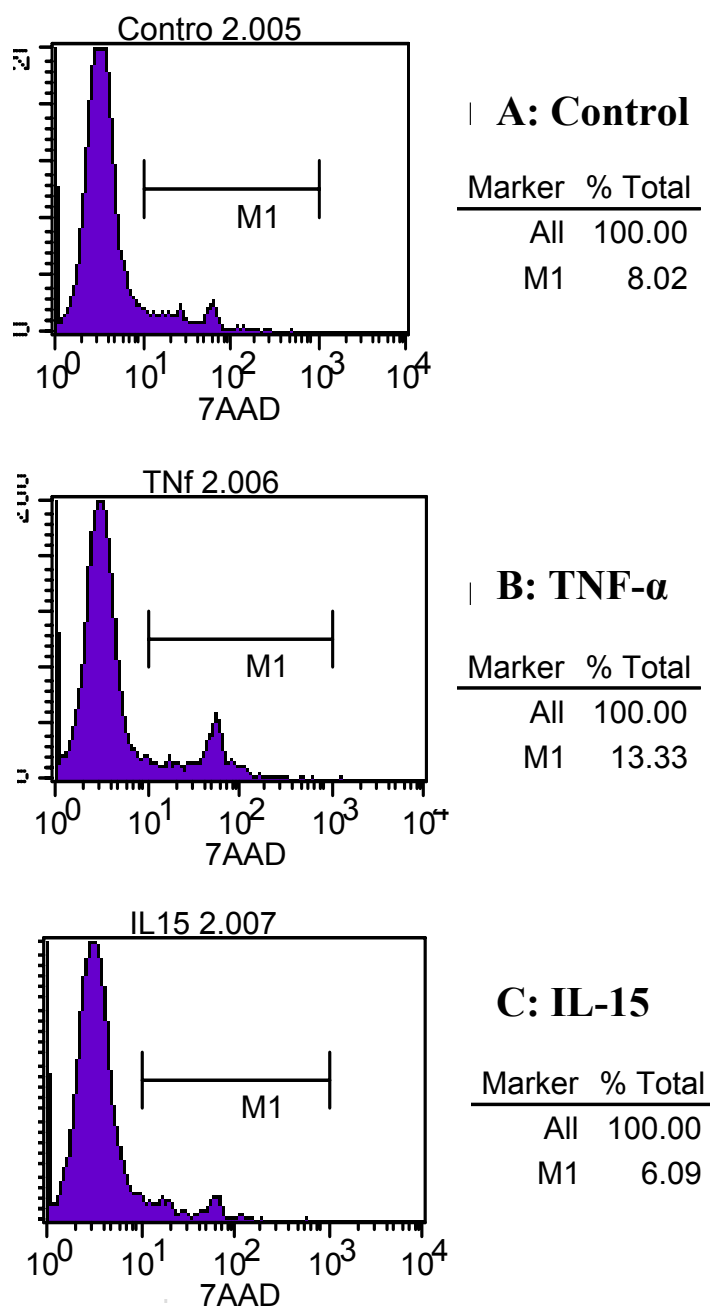

\section{C: IL-15}

$\begin{array}{r}\text { Marker } \% \text { Total } \\ \hline \text { All } 100.00\end{array}$

M1 6.09

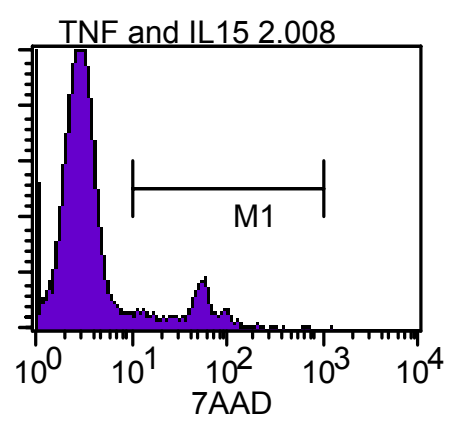

\section{D: TNF- $\alpha+$ IL-15}

$\begin{array}{r}\text { Marker } \% \text { Total } \\ \hline \text { All } 100.00\end{array}$

M1 10.59 


\section{Legend for Figure 1: Flow cytometric analysis of cell viability using 7AAD.}

Myoblasts cultures were maintained for $72 \mathrm{~h}$ with the following treatment

conditions: A, control cultures with no cytokines; B, 20ng $\mathrm{ml}^{-1}$ of TNF- $\alpha$; $\mathbf{C}$, 20ng $\mathrm{ml}^{-1}$ of IL-15; and D, 20ng $\mathrm{ml}^{-1}$ of TNF- $\alpha+$ IL-15. Cytokines were replenished every $24 \mathrm{~h}$. Both adherent and non-adherent cells were harvested after $72 \mathrm{~h}$ and analyzed for cell viability using the DNA marker, 7AAD. This experiment was performed in duplicate, with the graphs representing one set of data. 
Figure 2
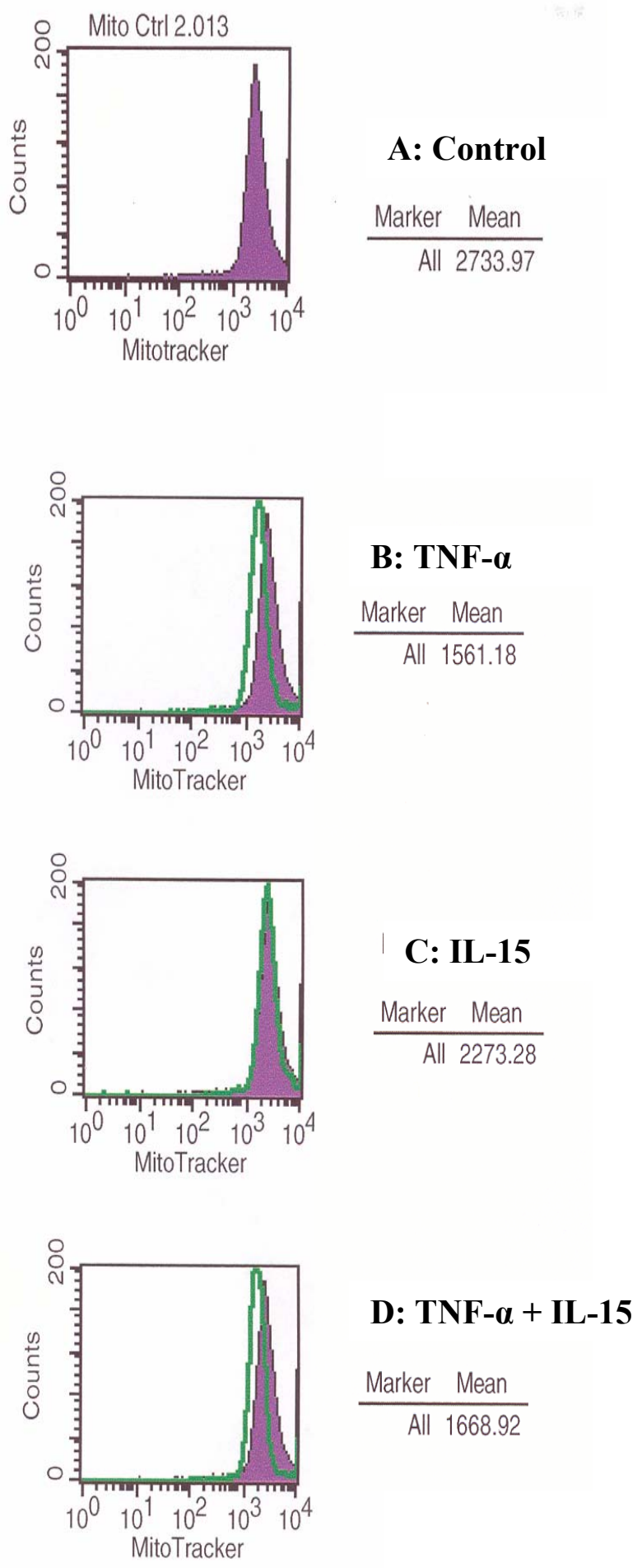


\section{Legend for Figure 2: Flow cytometric analysis of mitochondrial integrity using}

MitoTracker. Myoblasts cultures were maintained for $72 \mathrm{~h}$ with the following treatment conditions: $\mathbf{A}$, control cultures with no cytokines; $\mathbf{B}, 20 \mathrm{ng} \mathrm{m}^{-1}$ of TNF- $\alpha$; C, 20ng $\mathrm{ml}^{-1}$ of IL-15; and D, 20ng ml ${ }^{-1}$ of TNF- $\alpha+$ IL-15. Cytokines were replenished every $24 \mathrm{~h}$. Both adherent and non-adherent cells were harvested after $72 \mathrm{~h}$ and analyzed for mitochondrial integrity using the Mito Tracker. This experiment was performed in duplicate and repeated twice, with the graphs representing one set of data. The green line in $\mathrm{B}, \mathrm{C}$, and $\mathrm{D}$ represents control data from A. 
Figure 3

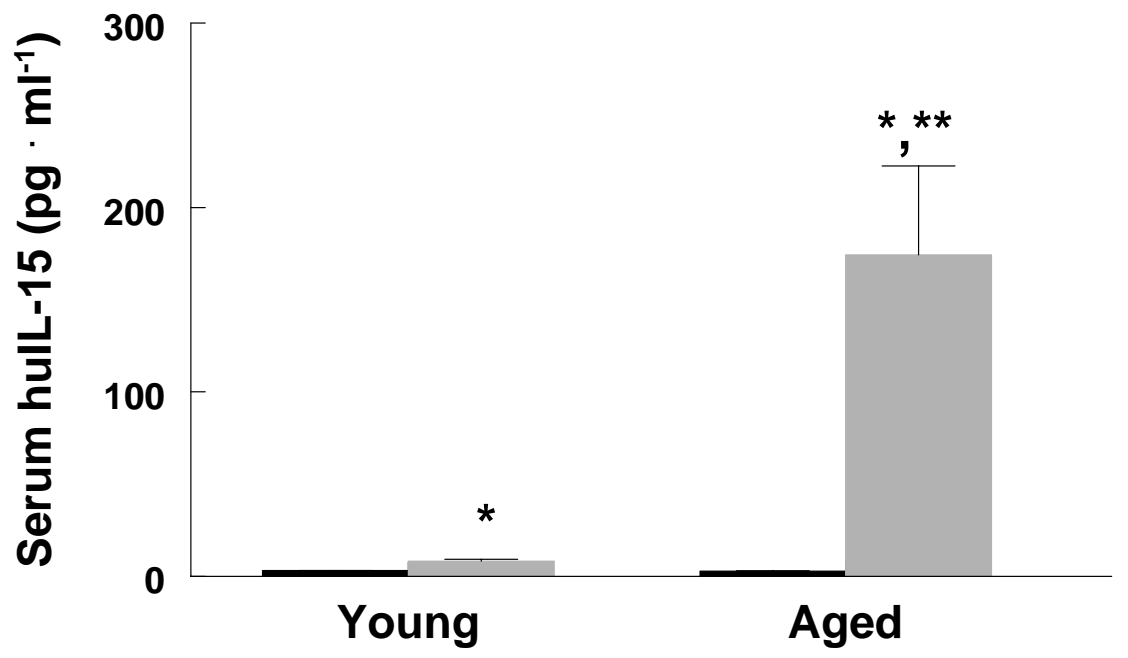

Figure 3: Verification of systemic elevation of human IL-15. An ELISA assay was utilized to verify a systemic elevation of human IL-15 via mini-osmotic pumps. Data are presented as $\mathrm{MEANS} \pm \mathrm{SE}$ with significance set at $\mathrm{p}<0.05 .{ }^{*}$, significant effect of IL-15 treatment; **, significant effect of aging. 


\section{Figure 4}
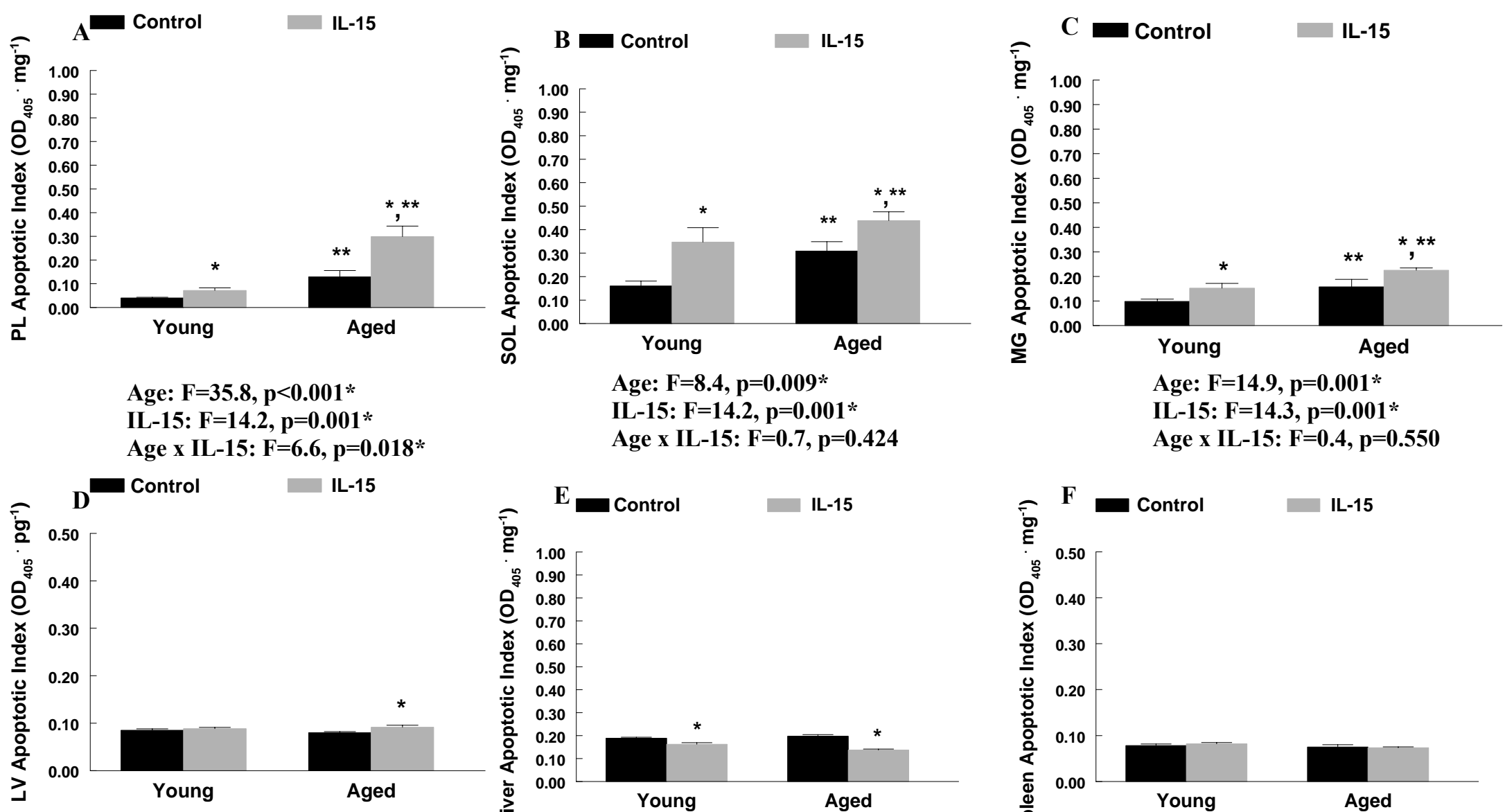

Age: $F=1.1, p=0.316$

Age: $F=8.4, p=0.009 *$

IL-15: $F=14.2, p=0.001$ *

IL-15: $\mathrm{F}=14,2, \mathrm{p}=0.001$ \%

Age $x$ IL-15: $F=0.7, p=0.424$

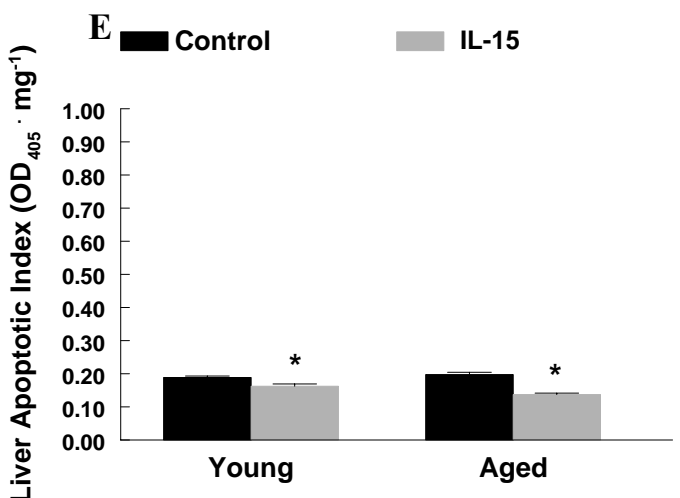

IL-15: $F=8.2, p=0.010$

Age: $\mathrm{F}=\mathbf{2 . 1}, \mathrm{p}=\mathbf{0 . 1 6 6}$

IL-15: $\mathrm{F}=55.9, \mathrm{p}<0.001$ *

Age $x$ IL-15: $F=0.1, p=0.735$

Age $x$ IL-15: $F=8.3, p=0.009$ *

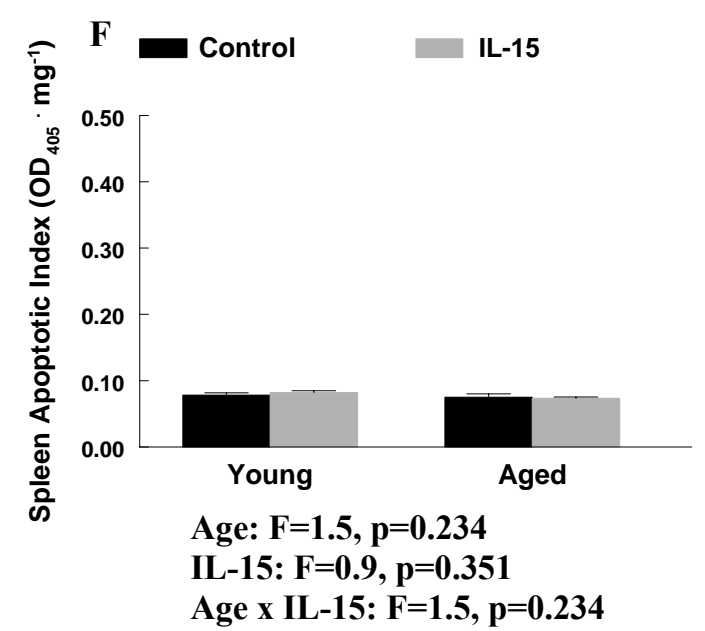


Legend for Figure 4: Incidence of apoptosis assessed by DNA fragmentation. An ELISA assay was utilized to examine the incidence of DNA fragmentation in tissue homogenates from: A, plantaris muscle (PL); B, soleus muscle (SOL); C, medial gastrocnemius muscle (MG); D, left ventricle (LV); E, liver; and F, spleen. Data are presented as MEANS \pm SE with significance set at $\mathrm{p}<0.05$. *, significant effect of IL-15 treatment; **, significant effect of aging. 
Table 1: Analysis of Mitochondrial Integrity in Myoblast Cultures

\section{Experiment 1 (Performed in Duplicate)}

\begin{tabular}{|c|c|c|c|c|c|}
\hline Group & $\begin{array}{c}\text { Repetition } \\
\mathbf{1}\end{array}$ & $\begin{array}{c}\text { Repetition } \\
\mathbf{2}\end{array}$ & Mean \pm SD & \%Change & p-Value \\
\hline Control & 1186.8 & 1052.8 & $1119.8 \pm$ & --- & \\
\hline rTNF- $\alpha$ & 792.0 & 617.7 & $704.9 \pm$ & $-37 \%^{*}$ & 0.005 \\
\hline rIL-15 & 1285.5 & 1188.4 & $1236.9 \pm$ & --- & 0.311 \\
\hline $\begin{array}{c}\text { rTNF- } \alpha+ \\
\text { rIL-15 }\end{array}$ & 689.8 & 820.3 & $755.1 \pm$ & $-33 \% *$ & 0.004 \\
\hline
\end{tabular}

\section{Experiment 2 (Performed in Duplicate)}

\begin{tabular}{|c|c|c|c|c|c|}
\hline Group & $\begin{array}{c}\text { Repetition } \\
\mathbf{1}\end{array}$ & $\begin{array}{c}\text { Repetition } \\
\mathbf{2}\end{array}$ & Mean \pm SD & \%Change & p-Value \\
\hline Control & 2391.2 & 2733.9 & $2562.6 \pm$ & --- & \\
\hline rTNF- $\alpha$ & 1909.8 & 1561.2 & $1735.5 \pm$ & $-32 \% *^{*}$ & 0.036 \\
\hline rIL-15 & 2443.7 & 2273.3 & $2358.5 \pm$ & --- & 0.848 \\
\hline $\begin{array}{c}\text { rTNF- } \alpha+ \\
\text { rIL-15 }\end{array}$ & 1896.8 & 1668.9 & $1782.9 \pm$ & $-30 \% *$ & 0.029 \\
\hline
\end{tabular}


Table 2: Bodyweight Changes During 14d IL-15 Intervention

\begin{tabular}{|c|c|c|c|c|c|}
\hline & Initial & 7d & \%Change & 14d & \%Change \\
\hline YC & $293.8 \pm 9.5$ & $305.9 \pm 9.3$ & $+4.1 \%$ & $329.4 \pm 9.3$ & $+12.1 \% *, * *$ \\
\hline Y15 & $289.2 \pm 9.7$ & $300.7 \pm 11.6$ & $+4.0 \%$ & $315.0 \pm 9.7$ & $+8.9 \% *, * *$ \\
\hline AC & $607.6 \pm 20.0$ & $603.5 \pm 19.8$ & $-0.7 \%$ & $598.0 \pm 20.2$ & $-1.6 \%$ \\
\hline $\mathbf{A 1 5}$ & $620.8 \pm 10.6$ & $619.6 \pm 9.6$ & $-0.2 \%$ & $595.4 \pm 8.6$ & $-4.1 \% *$ \\
\hline
\end{tabular}

Legend: YC - young control rodents, Y15 - young IL-15 treated rodents, AC - aged control rodents, A15 - aged IL-15 treated rodents, $*$ - significant change from baseline $(\mathrm{p}<0.05), * *$ - significant change with aging $(\mathrm{p}<0.05)$ 
Table 3: Organ and Skeletal Muscle Weights From Experimental Rodents

\begin{tabular}{|c|c|c|c|c|c|c|c|c|}
\hline Tissue & $\begin{array}{l}\text { Young } \\
\text { Con }\end{array}$ & $\begin{array}{l}\text { Young } \\
\text { IL15 }\end{array}$ & $\begin{array}{l}\text { \% Change } \\
\text { Con vs. IL15 } \\
\end{array}$ & $\begin{array}{l}\text { Aged } \\
\text { Con }\end{array}$ & $\begin{array}{l}\text { Aged } \\
\text { IL15 }\end{array}$ & $\begin{array}{l}\% \text { Change } \\
\text { Con vs. IL15 } \\
\end{array}$ & $\begin{array}{c}\% \text { Change } \\
\text { Aged vs. Young Con }\end{array}$ & $\begin{array}{c}\% \text { Change } \\
\text { Aged vs. Young IL15 }\end{array}$ \\
\hline Heart & 914.0 & 866.6 & $-5.2 \% \mathrm{~ns}$ & 1333.3 & 1414.3 & $+6.1 \% \mathrm{~ns}$ & $+45.9 \% * *$ & $+63.2 \% * *$ \\
\hline Norm Heart & 2.8 & 2.8 & 0 & 2.3 & 2.4 & 0 & $-21.7 * *$ & $-14.3 \% * *$ \\
\hline Spleen (SPL) & 629.1 & 871.7 & $+38.6^{*}$ & 1066.7 & 1243.9 & $+17.6 \% *$ & $+69.6 \% * *$ & $+42.7 \% * *$ \\
\hline Norm SPL & 1.94 & 2.78 & $+43.3 \% *$ & 1.78 & 2.09 & $+17.4 \% *$ & $-8.2 \% \mathrm{~ns}$ & $-24.8 \%$ \\
\hline Plantaris (PL) & 336.8 & 304.8 & $-9.5 \% *$ & 375 & 341.3 & $-9.0 \% *$ & $+11.3 \% * *$ & $+12 \% * *$ \\
\hline Norm PL & 1.02 & .97 & $-5 \%$ & .63 & .57 & $-9.5 \%$ & $-38.2 \% * *$ & $-41.2 \% * *$ \\
\hline Soleus (SOL) & 140.4 & 123.1 & $-12.3 \% *$ & 171.7 & 156.3 & $-9 \% *$ & $+22.3 \% * *$ & $+27 \% * *$ \\
\hline Norm SOL & .43 & .39 & $-9.3 \% *$ & .29 & .26 & $-10.3 \% *$ & $-32.6 \% * *$ & $-33.3 \% * *$ \\
\hline $\begin{array}{l}\text { Med Gastroc } \\
(\mathrm{MG})\end{array}$ & 785.5 & 703.2 & $-10.5 \% *$ & 787.5 & 731 & $-7.2 \% *$ & $+0.3 \% \mathrm{~ns}$ & $+4 \% \mathrm{~ns}$ \\
\hline Norm MG & 2.39 & 2.24 & $-6.3 \% *$ & 1.32 & 1.23 & $-6.8 \% *$ & $-44.8 \% * *$ & $-45.1 \% * *$ \\
\hline Lat Gastroc (LG) & 1029.1 & 994.1 & $-3.4 \% \mathrm{~ns}$ & 964.2 & 962.5 & $-0.2 \% \mathrm{~ns}$ & $-6.3 \% \mathrm{~ns}$ & $-3.2 \% \mathrm{~ns}$ \\
\hline
\end{tabular}




\begin{tabular}{|c|c|c|c|c|c|c|c|c|}
\hline Norm LG & 3.13 & 3.16 & $-1.0 \% \mathrm{~ns}$ & 1.62 & 1.62 & Ons & $-48.2 \% * *$ & $-48.7 \% * *$ \\
\hline $\begin{array}{l}\text { Gastrocnemius } \\
\text { (Gastr) }\end{array}$ & 1814.6 & 1697.3 & $-6.5 \% \mathrm{~ns}$ & 1751.7 & 1693.5 & $-3.3 \% \mathrm{~ns}$ & $-3.5 \% \mathrm{~ns}$ & $-0.2 \% \mathrm{~ns}$ \\
\hline Norm Gastr & 5.5 & 5.4 & $-1.8 \% \mathrm{~ns}$ & 2.9 & 2.8 & $-3 / 4 \%$ ns & $-47.3 \% * *$ & $-48.1 \% * *$ \\
\hline $\begin{array}{l}\text { Tibialis Anterior } \\
\text { (TA) }\end{array}$ & 624.6 & 573.4 & $-8.2 \% *$ & 701.7 & 646.6 & $-7.9 \% *$ & $+12.3 \% * *$ & $+12.8 \% * *$ \\
\hline Norm TA & 1.90 & 1.82 & $-4.2 \% *$ & 1.18 & 1.09 & $-7.6 \% *$ & $-37.9 \% * *$ & $-40.1 \% * *$ \\
\hline $\begin{array}{l}\text { Extensor } \\
\text { Digitorum } \\
\text { Longus (EDL) }\end{array}$ & 157.0 & 144.2 & $-8.2 \% *$ & 175.8 & 164.5 & $-6.4 \% *$ & $+12.0 \% * *$ & $+14.1 \% * *$ \\
\hline Norm EDL & .48 & .46 & $-4.2 \% \mathrm{~ns}$ & .29 & .28 & $-3.4 \% \mathrm{~ns}$ & $-39.6 \% * *$ & $-39.1 \% * *$ \\
\hline
\end{tabular}




\section{General Discussion}

Aging is characterized by a gradual loss of skeletal muscle mass and strength, which has been termed sarcopenia (reviewed in (36)). There are multiple contributing mechanisms leading to the onset of sarcopenia, including: denervation and reinnervation of motor units, especially within skeletal muscles composed of a high degree of type II muscle fibers $(1 ; 45)$; an alteration in the hormonal milieu in which anabolic hormone concentrations progressively decline (43; 44); elevated concentrations of inflammatory mediators that are not only associated with disease states, but also occur in healthy older adults $(4-8 ; 32 ; 37 ; 46)$; and muscle nuclei and fiber loss through apoptotic mechanisms $(16 ; 30 ; 38-40)$. Regardless of which of these factors predominates, the result is the same. Muscle strength declines an average of $20-40 \%$ in healthy men and women during the seventh and eighth decades of life, and muscle mass, determined by cross sectional area (CSA), is reduced an average of $40 \%$ between the ages of 20 and 60 (17). Sarcopenia represents an important public health issue, effecting the independence and ability of the elderly to perform activities of daily living $(28 ; 35)$. Thus, determining the signaling pathways that contribute to the onset of sarcopenia will greatly aid in developing treatment options that can offset and/or delay the loss of muscle mass and strength.

\section{Pro-Inflammatory Factors are Elevated Systemically with Aging}

A well-characterized increase in the circulating concentrations of inflammatory factors has been observed with advanced age. Specifically, increases in the concentrations of circulating cytokines occur as a result of the aging process $(8 ; 27)$. Systemic levels of tumor necrosis factor-alpha (TNF- $\alpha)(5 ; 7 ; 37)$ and interleukin-6 (IL-6, 
$(4 ; 20 ; 32)$ increase when comparing young adult, and elderly healthy adults. Elevated circulating levels of TNF- $\alpha$ are associated with lower appendicular skeletal muscle mass as measured by dual-energy x-ray absorptiometry (DEXA) (32). Additionally, elevated levels of TNF- $\alpha$ and IL-6 in aged humans have been associated with smaller muscle area, less appendicular skeletal muscle mass, and lower knee extensor and grip strength (46). Circulating TNF- $\alpha$ levels are also a predictor of all cause mortality in centenarians. Thus, one potential mechanism contributing to the onset of sarcopenia may be the increase in circulating pro- and anti-inflammatory cytokines.

Animal studies have demonstrated negative effects of TNF- $\alpha$ and IL-6 on muscle protein synthesis, muscle mass, and incidence of apoptosis. Injection of recombinant TNF- $\alpha$ and IL-6 into rats increased muscle proteolysis and decreased the rate of protein synthesis in rodent skeletal muscles $(15 ; 22 ; 23)$. Additionally, Garcia-Martinez et al (21) showed increased ubiquitinization of skeletal muscle proteins and Carbo et al (13) reported increased DNA fragmentation, characteristic of apoptosis, in gastrocnemius muscles in animals injected with recombinant TNF- $\alpha$. These studies suggest that increases in TNF- $\alpha$ and IL-6 can not only increase protein degradation through ubiquitin directed proteolysis, but also may initiate a program of apoptosis within skeletal muscle. Treatments aimed at negating the effects of these cytokines may help to spare muscle mass in the elderly.

\section{The Extrinsic Apoptotic Pathway is an Active Process in Aged Skeletal Muscle}

The increased incidence of apoptosis in skeletal muscles from aged animals has provided convincing evidence that apoptotic signaling contributes to the loss of myonuclei with age. Most reports have focused on the pro-apoptotic signaling that arises from the mitochondria and its impact on myonuclear loss. The contribution of the 
extrinsic apoptotic pathway to skeletal muscle mass losses, especially during aging, has been less studied (34). The increase in circulating concentrations of TNF- $\alpha$ may initiate pro-apoptotic signaling upon binding to the type I TNF receptor. Upon binding, a death inducing signaling complex (DISC) is formed at the cytoplasmic portion of the TNFR, composed of adaptor proteins such as Fas associated death domain protein (FADD), TNFR associated death domain protein (TRADD) and procaspase-8 (reviewed in (41)). Formation of the DISC stimulates cleavage of procaspase- 8 into the functional initiator caspase-8. Once cleaved, caspase-8 stimulates cleavage and activation of the executioner caspase-3, which is directly linked to pro-apoptotic changes. Thus, an extrinsic pathway of apoptosis is activated by binding of a ligand (TNF- $\alpha$ ) to a cell surface death receptor (type-I TNFR).

A novel finding of this dissertation is that the extrinsic apoptotic pathway, downstream of the type I TNFR, is an active process within aged skeletal muscles and may contribute to the onset of sarcopenia. Plantaris and soleus muscles from aged rodents were smaller than muscles from young adult rodents, whether expressed in absolute terms or relative to the rodent bodyweight, while also having a greater apoptotic index. When analyzing the components of the signaling pathway and comparing aged plantaris and soleus muscles to young adult muscles, a greater mRNA expression for the type I TNFR, greater mRNA expression and protein content for the adaptor protein FADD, greater protein content of pro-apoptotic Bid, and greater caspase activities of caspase- 8 and caspase- 3 was observed. The changes in these signaling molecules are consistent with an activation of this apoptotic pathway in aged muscles and were associated with the phenotypic changes in the skeletal muscles, especially the plantaris. 
Analyses from human muscle biopsy samples have consistently demonstrated that type II fibers are more susceptible to aging-related atrophy when compared to type I fibers (18; 29). Type II fibers (i.e., the plantaris muscle) may be more susceptible to age associated atrophy and nuclear loss as a result of pro-apoptotic signaling via the extrinsic pathway. Nevertheless, the possibility that apoptotic signaling may be muscle and not fiber-type specific cannot be rules out.

Another novel finding of this dissertation is the greater protein content of the fulllength pro-apoptotic molecule, Bid, in aged skeletal muscles. Bid has been previously shown to mediate cross-talk between the extrinsic apoptotic pathway and the intrinsic apoptotic pathway. Specifically, cleaved caspase- 8 can cleave full-length Bid, producing truncated or tBid, which can interact with another pro-apoptotic protein, Bax, and initiate cytochrome-c release from the mitochondria. In addition, myoblasts stimulated with rTNF- $\alpha$, in vitro displayed decreases in mitochondrial content, further suggesting crosstalk between the extrinsic and intrinsic apoptotic pathways. The current study as well as data from Nagaraju et al. (31) reveal that skeletal muscle cells may act as type II cells, in that apoptotic signaling arising from the death receptor can include subsequent mitochondrial apoptotic signaling through Bid activation. Type II cells accumulate considerably less DISC following ligand binding to the death receptor and, therefore, require mitochondrial signaling to fully activate an apoptotic program. Future studies should directly address the ability of tBid to mediate messages from the death receptor to the mitochondria and contribute to apoptosis in aged skeletal muscles. Nevertheless, skeletal muscles from aged rodents contained a greater protein expression of full-length Bid, and TNF- $\alpha$ can decrease mitochondrial integrity in myoblast cultures, which raises 
the possibility that cross talk between the extrinsic pathway and the intrinsic pathway may occur in aged skeletal muscles.

\section{The IL-15/IL-15R System in Skeletal Muscle}

Interleukin-15 (IL-15) is a recently discovered cytokine $(12 ; 24)$ that belongs to

the four $\alpha$-helix bundle family of cytokines, that also include IL-2, IL-3, IL-4, IL-5, IL-6, IL-7, and IL-9 (for in-depth reviews on IL-15, see(9; 10; 19; 47). The roles of IL-15 within the immune system have been shown to include proliferation and survival of CD8+ T-cells (3), the activation of natural killer (NK) cells(14), and proliferation of B cells(2). Both IL-15 and its high affinity receptor, IL-15R $\alpha$, are expressed in skeletal muscle. Furthermore, roles for IL-15 in stimulating myosin heavy chain protein content in myogenic cultures and in attenuating muscle wasting and apoptosis during disease states have been demonstrated. Based on these data, I wanted to determine if muscle unloading and aging, two conditions that promote muscle atrophy, would alter the basal expression of IL-15.

The IL-15 gene is responsive to skeletal muscle aging and unloading, two conditions known to promote muscle atrophy. The responses of IL-15 mRNA may however, be fiber type and/or muscle specific. This response of IL-15 was observed in two different models of unloading using young and aged experimental animals; the hindlimb suspension model in rodents and the wing unloading following stretch overload model in quail. These two models differ in that the HS model causes muscle atophy of the plantar flexor muscles below control levels, while the wing unloading model allows regression of previously hypertrophied muscle to control levels but not below control. Despite the differences in the models and the different species of experimental animals utilized, the response of IL-15 was 
consistent. In addition, skeletal muscles express the mRNA for the functional trimeric IL15R. Thus, skeletal muscle cells may not only respond to secreted IL-15, but also respond to and present IL-15 in trans, bound to the sarcolemma. Future studies should address how skeletal muscles functionally respond to IL-15, as this cytokine has promise as a muscle sparing agent during muscle wasting conditions.

\section{Overexpression of IL-15 Does Not Attenuate Apoptotic Signaling in Skeletal Muscle}

Based on the changes in IL-15 expression in skeletal muscles following periods of unloading and especially during aging, the efficacy of increasing IL-15 levels to spare muscle mass and attenuate apoptotic signaling was tested using cell culture experiments to specifically examine the effects of IL-15 on TNF- $\alpha$-induced apoptosis in myoblasts, as well as in vivo to examine the effects of IL-5 in aged rodents. The following hypotheses were tested: murine rIL-15 would attenuate rTNF- $\alpha$-induced apoptosis in the mouse $\mathrm{C}_{2} \mathrm{C}_{12}$ myogenic cell line, and the incidence of apoptosis in muscles from aged rodents would be reduced with systemic elevation of IL-15. In addition to skeletal muscle, other tissues were analyzed from rodents to examine tissue specific effects of IL- 15 .

The results of these studies, however, do not support a protective role of IL-15 in skeletal muscle in aged rodents or in myogenic cultures stimulated with rTNF- $\alpha$. In fact, when recombinant human IL-15 was elevated systemically for 14 days in experimental animals, muscles from young adult and aged rodents displayed increases in the presence of fragmented DNA. Based on these data, I rejected my working hypotheses, with the following caveats: 1) it is possible that the age of the rodents utilized in this study (i.e. 30 mo.) was not old enough to elicit an increase in systemic TNF- $\alpha$ levels; and 2) the chronic aging stimulus may not have as dramatic an effect as an acute cancer stimulus for 
eliciting elevations in this cytokine; and 3) the anti-apoptotic effects of IL-15 may be tissue specific. In these experiments, I specifically hypothsized that IL-15 would exert positive effects in aged animals where circulating TNF- $\alpha$ levels were reported to be elevated (34) and anabolic hormone levels are typically reduced (43). However, despite measurable increases in systemic human IL-15, especially in aged rodents, the incidence of DNA fragmentation was increased in all muscle types analyzed.

The overexpression of IL-15 has previously been shown to protect host animals against a lethal challenge. Specifically, IL-15 transgenic mice were resistant to a lethal dose of Escherichia coli (E. coli) that killed 85\% of non-transgenic mice within 12 hours of delivery. In this same study, non-transgenic mice that received a one time intraperitoneal injection of either $1 \mu \mathrm{g}$ or $10 \mu \mathrm{g}$ of recombinant IL-15 were also resistant to the same dose of E. coli. When peritoneal cells from IL-15 transgenic mice and IL-15 treated non-transgenic mice were isolated, these cells were resistant to apoptosis induced by TNF- $\alpha$ stimulation in vitro. Serum TNF- $\alpha$ levels, measured by ELISA, were greater than $600 \mathrm{pg} \mathrm{ml}^{-1}$ following E. coli injection (26). Injection of $100 \mu \mathrm{g}$ of a mouse Fas monoclonal antibody induced massive hepatocyte apoptosis and death within a few hours. However, injection of a long-lasting IL-15 fusion protein prevented organ failure and death following Fas antibody injection. IL-15 also prevented apoptosis of human Tand B-cells induced by anti-Fas antibody, anti-CD3, dexamethasone, and anti-IgM in vitro (11). These data demonstrate that IL-15 has the ability to inhibit death resulting from large-scale apoptosis, induced by either TNF- $\alpha$ or anti-Fas antibody. In the current study, I attempted to measure and quantify plasma TNF- $\alpha$ to support an age-related increase of this cytokine. An increase in systemic TNF- $\alpha$ would have allowed the 
assumption that this cytokine could initiate the extrinsic apoptotic pathway in our rodent model. However, TNF- $\alpha$ was not detectable in the plasma collected from either young adult or aged animals. It is possible that the age of the rodents utilized in this study (i.e. 30 mo.) was not old enough to elicit an increase in TNF- $\alpha$ levels. Additionally, the aging stimulus may not have as dramatic an effect as a cancer stimulus for eliciting elevations in this cytokine.

A possible limitation of this study was the delivery method of rIL-15 (i.e.osmotic mini-pumps). As noted previously (33), results can often conflict when comparing data from among studies utilizing different methods. For example, direct injections of rTNF has been shown to promote signs of apoptosis within skeletal muscles(13). However, in a recent study that utilized mini-osmotic pumps to deliver rTNF, apoptosis was not increased in skeletal muscles, contradicting the previous study interpretations (33). Although this study was not the first to utilize mini-pumps to deliver rIL-15 (25), it was the first to use them in aged rodents. The circulating levels of rIL-15 in aged rodents in this study were more than 20 -fold higher than in young adult rodents. It cannot be ruled out that this supra-physiological level of IL-15 may have negatively affected the aged rodents more so than the young adult rodents. In addition, recent evidence suggests that the biological activity of IL-15 is enhanced when bound in a complex with the IL-15R $\alpha$ (i.e.-trans presentation, (42)). This study suggested that the soluble levels of IL-15R $\alpha$ may be limiting and the total effects of IL-15 may not be observed by increasing systemic levels of IL-15 protein alone.

In summary, IL-15 does not appear to attenuate apoptotic signaling induced by TNF- $\alpha$ in myogenic cultures or in the skeletal muscles of aged animals. These data 
conflict with other data showing a protective effect of IL-15. However, this protective effect may take place in response to acute and dramatic increases in apoptosis, as observed following E. coli or anti-Fas injections, and not during the chronic stimulus of aging. Additionally, variability in the delivery methods of IL-15 and/or the type of IL-15 utilized may contribute to our conflicting data, as well as ages and strains of experimental animals utilized in these studies. Future studies should address the efficacy of IL-15 treatment to spare muscle mass in response to muscle wasting disorders, as IL-15 has shown promise as an apoptotic inhibitor. 


\section{Reference List}

1. Ansved T and Larsson L. Effects of ageing on enzyme-histochemical, morphometrical and contractile properties of the soleus muscle in the rat. $J$ Neurol Sci 93: 105-124, 1989.

2. Armitage RJ, Macduff BM, Eisenman J, Paxton R and Grabstein KH. IL-15 has stimulatory activity for the induction of B cell proliferation and differentiation. J Immunol 154: 483-490, 1995.

3. Berard M, Brandt K, Bulfone-Paus S and Tough DF. IL-15 promotes the survival of naive and memory phenotype CD8+ T cells. J Immunol 170: 5018-5026, 2003.

4. Bruunsgaard H. Effects of tumor necrosis factor-alpha and interleukin-6 in elderly populations. Eur Cytokine Netw 13: 389-391, 2002.

\section{Bruunsgaard H, Andersen-Ranberg K, Hjelmborg JB, Pedersen BK and Jeune} B. Elevated levels of tumor necrosis factor alpha and mortality in centenarians. Am J Med 115: 278-283, 2003.

6. Bruunsgaard H, Andersen-Ranberg K, Jeune B, Pedersen AN, Skinhoj P and Pedersen BK. A high plasma concentration of TNF-alpha is associated with dementia in centenarians. J Gerontol A Biol Sci Med Sci 54: M357-M364, 1999.

\section{Bruunsgaard H, Ladelund S, Pedersen AN, Schroll M, Jorgensen $\mathbf{T}$ and} Pedersen BK. Predicting death from tumour necrosis factor-alpha and interleukin-6 in 80-year-old people. Clin Exp Immunol 132: 24-31, 2003. 
8. Bruunsgaard $\mathbf{H}$, Pedersen $\mathbf{M}$ and Pedersen BK. Aging and proinflammatory cytokines. Curr Opin Hematol 8: 131-136, 2001.

9. Budagian V, Bulanova E, Paus R and Bulfone-Paus S. IL-15/IL-15 receptor biology: A guided tour through an expanding universe. Cytokine Growth Factor Rev 17: 259-280, 2006.

10. Bulfone-Paus S, Bulanova E, Budagian V and Paus R. The interleukin15/interleukin-15 receptor system as a model for juxtacrine and reverse signaling. Bioessays 28: 362-377, 2006.

11. Bulfone-Paus S, Ungureanu D, Pohl T, Lindner G, Paus R, Ruckert R, Krause $\mathbf{H}$ and Kunzendorf $\mathbf{U}$. Interleukin-15 protects from lethal apoptosis in vivo. Nat Med 3: 1124-1128, 1997.

12. Burton JD, Bamford RN, Peters C, Grant AJ, Kurys G, Goldman CK, Brennan J, Roessler E and Waldmann TA. A lymphokine, provisionally designated interleukin $\mathrm{T}$ and produced by a human adult $\mathrm{T}$-cell leukemia line, stimulates T-cell proliferation and the induction of lymphokine-activated killer cells. Proc Natl Acad Sci U S A 91: 4935-4939, 1994.

13. Carbo N, Busquets S, van Royen M, Alvarez B, Lopez-Soriano FJ and Argiles JM. TNF-alpha is involved in activating DNA fragmentation in skeletal muscle. $\mathrm{Br}$ J Cancer 86: 1012-1016, 2002.

14. Carson WE, Giri JG, Lindemann MJ, Linett ML, Ahdieh M, Paxton R, Anderson D, Eisenmann J, Grabstein K and Caligiuri MA. Interleukin (IL) 15 is a novel cytokine that activates human natural killer cells via components of the IL-2 receptor. J Exp Med 180: 1395-1403, 1994. 
15. Charters $\mathbf{Y}$ and Grimble RF. Effect of recombinant human tumour necrosis factor alpha on protein synthesis in liver, skeletal muscle and skin of rats. Biochem J 258: 493-497, 1989.

16. Dirks A and Leeuwenburgh C. Apoptosis in skeletal muscle with aging. Am $J$ Physiol Regul Integr Comp Physiol 282: R519-R527, 2002.

17. Doherty TJ. Invited review: Aging and sarcopenia. J Appl Physiol 95: 1717-1727, 2003.

18. Doherty TJ, Vandervoort AA and Brown WF. Effects of ageing on the motor unit: a brief review. Can J Appl Physiol 18: 331-358, 1993.

19. Fehniger TA and Caligiuri MA. Interleukin 15: biology and relevance to human disease. Blood 97: 14-32, 2001.

20. Forsey RJ, Thompson JM, Ernerudh J, Hurst TL, Strindhall J, Johansson B, Nilsson BO and Wikby A. Plasma cytokine profiles in elderly humans. Mech Ageing Dev 124: 487-493, 2003.

21. Garcia-Martinez C, Lopez-Soriano FJ and Argiles JM. Acute treatment with tumour necrosis factor-alpha induces changes in protein metabolism in rat skeletal muscle. Mol Cell Biochem 125: 11-18, 1993.

22. Goodman MN. Tumor necrosis factor induces skeletal muscle protein breakdown in rats. Am J Physiol 260: E727-E730, 1991.

23. Goodman MN. Interleukin-6 induces skeletal muscle protein breakdown in rats. Proc Soc Exp Biol Med 205: 182-185, 1994. 


\section{Grabstein KH, Eisenman J, Shanebeck K, Rauch C, Srinivasan S, Fung V,} Beers C, Richardson J, Schoenborn MA, Ahdieh M and . Cloning of a T cell growth factor that interacts with the beta chain of the interleukin-2 receptor. Science 264: 965-968, 1994.

25. Harcourt LJ, Holmes AG, Gregorevic P, Schertzer JD, Stupka N, Plant DR and Lynch GS. Interleukin-15 administration improves diaphragm muscle pathology and function in dystrophic mdx mice. Am J Pathol 166: 1131-1141, 2005.

26. Hiromatsu T, Yajima T, Matsuguchi T, Nishimura H, Wajjwalku W, Arai T, Nimura Y and Yoshikai Y. Overexpression of interleukin-15 protects against Escherichia coli-induced shock accompanied by inhibition of tumor necrosis factoralpha-induced apoptosis. J Infect Dis 187: 1442-1451, 2003.

27. Huang H, Patel DD and Manton KG. The immune system in aging: roles of cytokines, T cells and NK cells. Front Biosci 10: 192-215, 2005.

28. Janssen I, Shepard DS, Katzmarzyk PT and Roubenoff R. The healthcare costs of sarcopenia in the United States. J Am Geriatr Soc 52: 80-85, 2004.

29. Larsson L, Sjodin B and Karlsson J. Histochemical and biochemical changes in human skeletal muscle with age in sedentary males, age 22--65 years. Acta Physiol Scand 103: 31-39, 1978.

\section{Leeuwenburgh C, Gurley CM, Strotman BA and Dupont-Versteegden EE.} Age-related differences in apoptosis with disuse atrophy in soleus muscle. Am J Physiol Regul Integr Comp Physiol 288: R1288-R1296, 2005. 
31. Nagaraju K, Casciola-Rosen L, Rosen A, Thompson C, Loeffler L, Parker T, Danning C, Rochon PJ, Gillespie J and Plotz P. The inhibition of apoptosis in myositis and in normal muscle cells. J Immunol 164: 5459-5465, 2000.

32. Pedersen M, Bruunsgaard H, Weis N, Hendel HW, Andreassen BU, Eldrup E, Dela F and Pedersen BK. Circulating levels of TNF-alpha and IL-6-relation to truncal fat mass and muscle mass in healthy elderly individuals and in patients with type-2 diabetes. Mech Ageing Dev 124: 495-502, 2003.

33. Peterson JM, Feeback KD, Baas JH and Pizza FX. Tumor necrosis factor-alpha promotes the accumulation of neutrophils and macrophages in skeletal muscle. $J$ Appl Physiol 101: 1394-1399, 2006.

34. Phillips T and Leeuwenburgh C. Muscle fiber specific apoptosis and TNF-alpha signaling in sarcopenia are attenuated by life-long calorie restriction. FASEB J 19: 668-670, 2005.

35. Roubenoff R. Sarcopenia: a major modifiable cause of frailty in the elderly. J Nutr Health Aging 4: 140-142, 2000.

36. Roubenoff R. Origins and clinical relevance of sarcopenia. Can J Appl Physiol 26: 78-89, 2001.

37. Sandmand M, Bruunsgaard H, Kemp K, Andersen-Ranberg K, Schroll M and Jeune B. High circulating levels of tumor necrosis factor-alpha in centenarians are not associated with increased production in T lymphocytes. Gerontology 49: 155160, 2003.

38. Siu PM and Alway SE. Mitochondria-associated apoptotic signalling in denervated rat skeletal muscle. J Physiol 565: 309-323, 2005. 
39. Siu PM, Pistilli EE and Alway SE. Apoptotic responses to hindlimb suspension in gastrocnemius muscles from young adult and aged rats. Am J Physiol Regul Integr Comp Physiol 289: R1015-1026, 2005.

40. Siu PM, Pistilli EE, Butler DC and Alway SE. Aging influences cellular and molecular responses of apoptosis to skeletal muscle unloading. Am J Physiol Cell Physiol 288: C338-C349, 2005.

41. Sprick MR and Walczak $\mathbf{H}$. The interplay between the Bcl-2 family and death receptor-mediated apoptosis. Biochim Biophys Acta 1644: 125-132, 2004.

42. Stoklasek TA, Schluns KS and Lefrancois L. Combined IL-15/IL-15Ralpha immunotherapy maximizes IL-15 activity in vivo. J Immunol 177: 6072-6080, 2006.

43. Tenover JL. Testosterone and the aging male. J Androl 18: 103-106, 1997.

44. Tenover JS, Matsumoto AM, Plymate SR and Bremner WJ. The effects of aging in normal men on bioavailable testosterone and luteinizing hormone secretion: response to clomiphene citrate. J Clin Endocrinol Metab 65: 1118-1126, 1987.

45. Timothy J.Doherty, Anthony A.Vandervoort, Albert W.Taylor, and William F.Brown. Effects of motor unit losses on strength in older men and women. 74(2), 868-874. 1993.

Ref Type: Generic

46. Visser M, Pahor M, Taaffe DR, Goodpaster BH, Simonsick EM, Newman AB, Nevitt $\mathbf{M}$ and Harris TB. Relationship of interleukin-6 and tumor necrosis factor- 
alpha with muscle mass and muscle strength in elderly men and women: the Health ABC Study. J Gerontol A Biol Sci Med Sci 57: M326-M332, 2002.

47. Waldmann TA and Tagaya $\mathbf{Y}$. The multifaceted regulation of interleukin-15 expression and the role of this cytokine in NK cell differentiation and host response to intracellular pathogens. Annu Rev Immunol 17: 19-49, 1999. 